\title{
Formulação Dual do Método dos Elementos de Contorno Anisotrópico
}

\author{
LUIZ HENRIQUE DA SILVA FERNÁNDEZ
}

\author{
DISSERTAÇÃO APRESENTADA \\ $\mathrm{AO}$ \\ DEPARTAMENTO DE ENGENHARIA DE ESTRUTURAS \\ DA \\ UnIVERSIDADE DE SÃO PAUlO \\ PARA \\ OBTENÇÃO DO TÍTULO \\ DE \\ Mestre em Engenharia CiviL
}

Programa: Engenharia de Estruturas

Orientador: Prof. Tit. Wilson Sergio Venturini

Orientador designado: Prof. Dr. João Batista de Paiva

Durante o desenvolvimento deste trabalho o autor recebeu auxílio financeiro da CAPES

São Carlos, Julho de 2012 
AUTORIZO A REPRODUÇÃO TOTAL OU PARCIAL DESTE TRABALHO, POR QUALQUER MEIO CONVENCIONAL OU ELETRÔNICO, PARA FINS DE ESTUDO E PESQUISA, DESDE QUE CITADA A FONTE.

Ficha catalográfica preparada pela Seção de Atendimentos ao Usuário do Serviço de Biblioteca - EESC/USP.

F363f Fernández, Luiz Henrique da Silva

Formulação dual do método dos elementos de contorno anisotrópico. / Luiz Henrique da Silva Fernández; orientador João Batista de Paiva. São Carlos, 2012.

Dissertação (Mestrado) - Programa de Pós-Graduação em Engenharia de Estruturas -- Escola de Engenharia de São Carlos da Universidade de São Paulo, 2012.

1. Método dos elementos de contorno dual. 2. Anisotropia. 3. Regularização de integrais impróprias. 4. Processamento em paralelo. I. Título. 


\title{
Formulação Dual do Método dos Elementos de Contorno Anisotrópico
}

\author{
Esta dissertação contém as correções e alterações \\ sugeridas pela Comissão Julgadora durante a defesa \\ realizada por Luiz Henrique da Silva Fernández em 27/07/2012. \\ O original encontra-se disponível no Departamento de \\ Engenharia de Estruturas da Universidade de São Paulo.
}

Comissão Julgadora:

- Prof. Dr. João Batista Paiva - SET-USP

- Prof. Dr. Edson Denner Leonel - SET-USP

- Prof. Dr. José Sergio Komatsu - UFSCar 


\section{FOLHA DE JULGAMENTO}

\section{Candidata: Engenheiro LUIZ HENRIQUE DA SILVA FERNANDEZ.}

Título da dissertação: "Formulação dual do método dos elementos de contorno anisotrópico".

Data da defesa: 26/07/2012

\section{Comissão Julgadora:}

Prof. Associado João Batista de Paiva (Orientador)

(Escola de Engenharia de São Carlos/EESC)

Prof. Dr. Edson Denner Leonel

(Escola de Engenharia de São Carlos/EESC)

Prof. Dr. José Sergio Komatsu

(Universidade Federal de São Carlos/UFSCar)
Resultado:

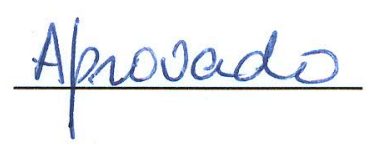

APPOUADO

APROVADO

Coordenador do Programa de Pós-Graduação em Engenharia Civil (Engenharia de Estruturas):

Profa. Associada Ana Lucia Homce de Cresce El Debs

Presidente da Comissão de Pós-Graduação:

Prof. Titular Denis Vinicius Coury 

À memória de um grande engenheiro: Prof. Wilson Sergio Venturini 



\section{Agradecimentos}

À minha querida Letícia por todo o apoio e carinho. $\infty$

Aos meus pais, à minha tia Tereza Cristina Lopez Fernández e em especial à minha avó Áurea Lopez Fernández cujo o amor pela engenharia me fascina.

Aos meus amigos Mateus Nogueira, Markus Rebmann, Humberto Boratto e Gabriel Senarezi pelo apoio.

Aos meus orientadores, Prof. Wilson Venturini e Prof. João Paiva, por terem me acolhido.

Aos professores, e amigos, da Universidade Federal de Minas Gerais, em especial ao Prof. Estevão Bicalho, Prof. Armando Lavall, Prof. Ricardo Fakury e Prof. Roque Pitangueira. Acredito que cada um deles saiba de que forma ímpar contribuíram pra este momento.

Aos professores da Universidade de São Paulo, em especial aos professores Wilson Venturini, Humberto Coda e Samuel Giongo que tornaram esta experiência ainda mais interessante.

Aos colegas de mestrado, em especial ao Aref Kzam, a Socorro Sampaio e a Eunice Santos pela companhia.

A todos os funcionários do Departamento de Estruturas da USP que, direta ou indiretamente, contribuíram para a realização deste trabalho.

À CAPES pelo auxílio financeiro concedido. 


\section{Resumo}

Este texto trata do Método dos Elementos de Contorno Dual empregando a solução fundamental anisotrópica. As integrais impróprias que surgem nesta formulação são regularizadas pela técnica da subtração de singularidade. Aplica-se a transformação de coordenadas auto-adaptativa de Telles para a avaliação das integrais quase-singulares. Apresenta-se o programa computacional desenvolvido utilizando os paradigmas da programação orientada a objetos e processamento em paralelo. Foram analisados diversos problemas e os resultados obtidos comparados àqueles da solução analítica. Os resultados alcançados mostraram-se satisfatórios validando a formulação proposta.

Palavras-chave: Método dos Elementos de Contorno Dual, Anisotropia, Regularização de Integrais Impróprias, Processamento em Paralelo. 


\section{Abstract}

This text deals with the Dual Boundary Element Formulation Method using the fundamental solution for anisotropic body. The improper integrals that arise in this formulation are regularized using the singularity subtraction technique. The self-adaptive coordinate transformation developed by Telles is used to evaluate the near-singular integrals. The computer program developed using the paradigms of object-oriented programming and parallel processing is presented. Several problems were analyzed and its results compared with those proposed by analytical solution. The results achieved were satisfactory therefore validating the proposed formulation.

Keywords: Dual Boundary Element Method, Anisotropy, Regularization of Improper Integrals, Parallel Processing. 


\section{Sumário}

Lista de Símbolos $\quad$ xi

Lista de Figuras $\quad$ xiii

Lista de Tabelas $\quad$ xv

1 Introdução $\quad 1$

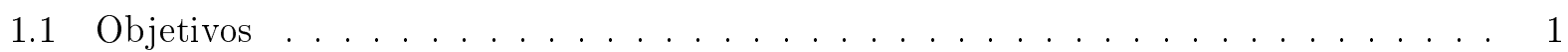

1.2 Contribuições . . . . . . . . . . . . . . . . . . . . 2

1.3 Organização do Trabalho . . . . . . . . . . . . . . . . . . 2

2 Revisão Bibliográfica $\quad 5$

3 Teoria da Elasticidade $\quad 9$

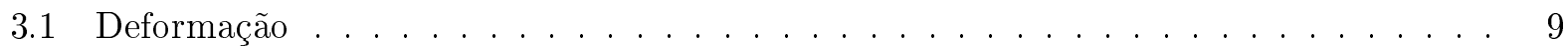

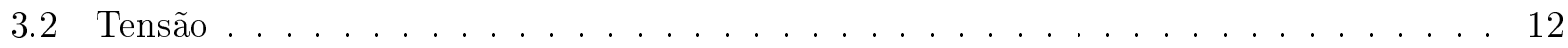

3.3 Equações de Equilíbrio . . . . . . . . . . . . . . . . . . . . . . . . 13

3.4 Equações de Compatibilidade . . . . . . . . . . . . . . . . 16

3.5 Lei de Hooke Generalizada . . . . . . . . . . . . . . . . . . . . . . . . . . 17

3.6 Estado Plano de Deformação . . . . . . . . . . . . . . . . . 20

3.7 Estado Plano de Tensão . . . . . . . . . . . . . . . . . . . . . . . . . . 21

3.8 Solução Fundamental . . . . . . . . . . . . . . . . . . . . . . . . 22

4 Equações Integrais de Contorno $\quad 27$

4.1 Método dos Resíduos Ponderados . . . . . . . . . . . . . . . . . . . . . 27

4.2 Equações Integrais de Contorno . . . . . . . . . . . . . . . . . . . . 28

5 Método dos Elementos de Contorno Dual 33

5.1 Elementos Isoparamétricos de Contorno . . . . . . . . . . . . . . . . . . . . 34

5.2 Método da Subtração de Singularidade . . . . . . . . . . . . . . . . . . . . 37

5.2 .1 Singularidades do Tipo $\ln |r| \ldots \ldots \ldots \ldots \ldots \ldots$

5.2 .2 Singularidades do Tipo $|r|^{-1} \ldots \ldots \ldots \ldots \ldots \ldots$

5.2 .3 Singularidades do Tipo $|r|^{-2} \ldots \ldots \ldots \ldots \ldots \ldots \ldots \ldots$

5.3 Integração Numérica . . . . . . . . . . . . . . . . . . . . . . . 43

5.4 Sistema de Equações Algébricas . . . . . . . . . . . . . . . . . . . . 46 
6 Implementação Computacional $\quad 49$

6.1 Programação Orientada a Objetos . . . . . . . . . . . . . . . . . . . 49

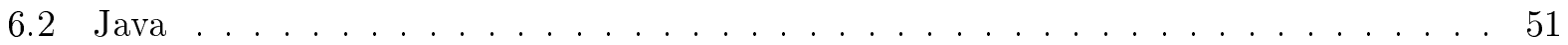

6.3 Implementação . . . . . . . . . . . . . . . . . . . . . 51

6.3 .1 Model . . . . . . . . . . . . . . . . . . . . . 52

6.3 .2 Assembler . . . . . . . . . . . . . . . . . 53

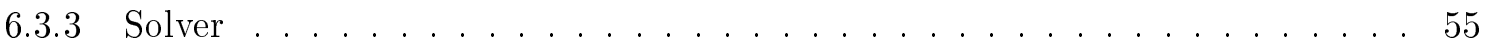

$\begin{array}{lll}7 & \text { Exemplos } & 57\end{array}$

7.1 Chapa sob Tensão Uniforme . . . . . . . . . . . . . . . . . . . 57

7.2 Chapa sob Cisalhamento Puro . . . . . . . . . . . . . . . . . . . 59

7.3 Viga sob Flexão Pura . . . . . . . . . . . . . . . . . . . . . 60

7.4 Viga Engastada sob Carregamento Uniforme . . . . . . . . . . . . . . . . . 63

7.5 Furo Elíptico em Meio Infinito . . . . . . . . . . . . . . . . . . . . . . 66

7.6 Fratura em Meio Infinito . . . . . . . . . . . . . . . . . . . . . . . . 69

8 Conclusões $\quad 77$

8.1 Considerações Finais . . . . . . . . . . . . . . . . . . . . 77

8.2 Sugestões para Pesquisas Futuras . . . . . . . . . . . . . . . . 78

$\begin{array}{ll}\text { A Delta de Dirac } & 79\end{array}$

$\begin{array}{ll}\text { B Subtração de Singularidade para Elemento Linear } & 81\end{array}$

$\begin{array}{ll}\text { C Tensões Sobre o Contorno } & 85\end{array}$

D Erro Absoluto e Relativo $\quad 89$

$\begin{array}{lll}\text { E Dados do Tempo de Processamento } & 91\end{array}$

$\begin{array}{ll}\text { Referências Bibliográficas } & 93\end{array}$ 


\section{Lista de Símbolos}

c Matriz de coeficientes elásticos de flexibilidade

$n \quad$ Vetor normal

$t$ Força de superfície

$u$ Deslocamento

$z \quad$ Coordenada complexa do ponto campo

$z^{\prime}$ Coordenada complexa do ponto fonte

C Matriz de coeficientes elásticos de rigidez

E Módulo de deformação longitudinal

$G$ Módulo de deformação transversal

$J$ Jacobiano

$\delta \quad$ Delta de Dirac

$\varepsilon \quad$ Deformação

$\eta \quad$ Coeficientes de influência mútua de primeiro e segundo tipo

$\mu \quad$ Raiz da equação característica

$\nu$ Coeficiente de Poisson

$\xi$ Coordenada adimensional

$\rho$ Coeficiente de Chentsov

$\sigma$ Tensão

$\phi$ Função de forma 


\section{Lista de Figuras}

3.1 Vetor deslocamento. . . . . . . . . . . . . . . . . . . . . 10

3.2 Deformação de um elemento infinitesimal. . . . . . . . . . . . . . . . . 10

3.3 Força de superfície. . . . . . . . . . . . . . . . . . . . . . . 12

3.4 Componentes de tensão. . . . . . . . . . . . . . . . . . . . . . 13

3.5 Equilíbrio de um elemento de volume. . . . . . . . . . . . . . . . . . 14

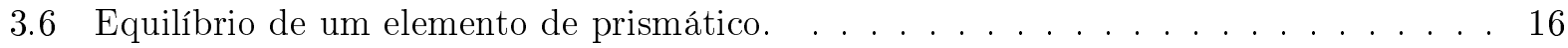

3.7 Diagrama tensão-deformação típica do aço. . . . . . . . . . . . . . 18

3.8 Estado plano de deformação. . . . . . . . . . . . . . . . . . . . 21

3.9 Estado plano de tensão. . . . . . . . . . . . . . . . . . . . . . . 22

3.10 Mapeamento no plano complexo. . . . . . . . . . . . . . . . . . . . 23

3.11 Solução fundamental. . . . . . . . . . . . . . . . . . . . . . . . . . . . . 24

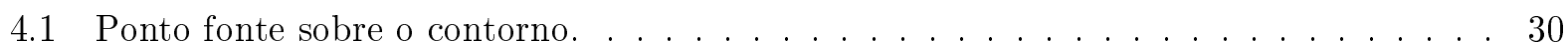

5.1 Método dos elementos de contorno dual. . . . . . . . . . . . . . . . . . . 33

5.2 Discretização do contorno. . . . . . . . . . . . . . . . . . . . . 34

5.3 Parametrização da geometria de um elemento. . . . . . . . . . . . . . . . . 34

5.4 Efeito Runge. . . . . . . . . . . . . . . . . . . . . . . . . . 35

5.5 Jacobiano da transformação de coordenadas. . . . . . . . . . . . . . . . . . . 36

5.6 Regularização do integrando singular. . . . . . . . . . . . . . . . . . . . . 43

5.7 Transformação cúbica de coordenadas. . . . . . . . . . . . . . . . . . 44

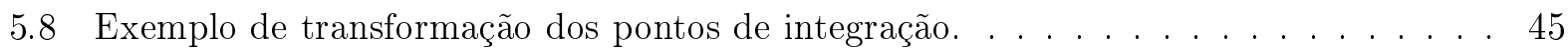

5.9 Geração das matrizes de influência. . . . . . . . . . . . . . . . . . . . . . 46

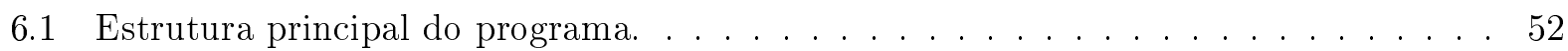

6.2 Estrutura do Model. . . . . . . . . . . . . . . . . . . . . . . . . 52

6.3 Estrutura do Assembler. . . . . . . . . . . . . . . . . . . . . . . . . 54

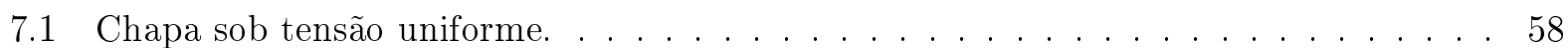

7.2 Discretização do problema chapa sob tensão uniforme. . . . . . . . . . . . . . . 58

7.3 Configuração deformada do problema chapa sob tensão uniforme. . . . . . . . . . . . 59

7.4 Chapa sob cisalhamento puro. . . . . . . . . . . . . . . . . . . . 59

7.5 Configuração deformada do problema chapa sob cisalhamento puro. . . . . . . . . . . 60

7.6 Viga sob flexão pura. . . . . . . . . . . . . . . . . . . . 61

7.7 Discretização do problema viga sob flexão pura . . . . . . . . . . . . . . . 61

7.8 Configuração deformada do problema viga sob flexão pura. . . . . . . . . . . . . . . 62 
7.9 Tempo de processamento. . . . . . . . . . . . . . . . . . 62

7.10 Viga engastada sob carregamento uniforme. . . . . . . . . . . . . . 63

7.11 Discretização do problema viga engastada sob carregamento uniforme. . . . . . . . . 64

7.12 Configuração deformada do problema viga engastada sob carregamento uniforme. . . 64

7.13 Distribuição de tensões para o problema viga engastada sob carregamento uniforme. 65

7.14 Erro relativo das tensões $\sigma_{12}$ para viga engastada sob carregamento uniforme. . . . . 66

7.15 Furo elíptico em meio infinito. . . . . . . . . . . . . . . . . . . . 66

7.16 Discretização do problema furo elíptico em meio infinito. . . . . . . . . . . . . 67

7.17 Configuração deformada do problema furo elíptico em meio infinito. . . . . . . . . . 68

7.18 Erro relativo para os deslocamentos do problema furo elíptico em meio infinito. . . . 68

7.19 Distribuição de tensões para o problema furo elíptico em meio infinito. . . . . . . . . 69

7.20 Discretização do problema fratura em meio infinito. . . . . . . . . . . . . 70

7.21 Configuração deformada do problema fratura em meio infinito. . . . . . . . . . . . 70

7.22 Distribuição de tensões para o problema fratura em meio infinito. . . . . . . . . . 71

7.23 Tensões exatas e aproximadas de $\sigma_{11}$ e $\sigma_{22}$ para a seção A-A' do problema fratura em meio infinito. . . . . . . . . . . . . . . . . . 72

7.24 Erros absolutos e relativos das tensões $\sigma_{11}$ e $\sigma_{22}$ para a seção A-A' do problema fratura em meio infinito. . . . . . . . . . . . . . . . . 73

7.25 Tensões exatas e aproximadas de $\sigma_{11}$ e $\sigma_{22}$ para a seção B-B' do problema fratura em meio infinito. . . . . . . . . . . . . . . . . . . . 74

7.26 Erros absolutos e relativos das tensões $\sigma_{11}$ e $\sigma_{22}$ para a seção B-B' do problema fratura em meio infinito. . . . . . . . . . . . . . . . 75

A.1 Delta de Dirac. . . . . . . . . . . . . . . . . . . . 79

B.1 Parametrização elemento linear. . . . . . . . . . . . . . . . . . . . 81

C.1 Elemento com grandezas referentes ao sistema de coordenadas global. . . . . . . . . 86

C.2 Elemento com grandezas referentes ao sistema de coordenadas local. . . . . . . . . 86 


\section{Lista de Tabelas}

7.1 Deslocamentos nodais do problema chapa sob tensão uniforme $\left(10^{-05} \mathrm{~m}\right) \ldots \ldots 9$

7.2 Deslocamentos nodais do problema chapa sob cisalhamento puro $\left(10^{-05} \mathrm{~m}\right) \ldots$. . . 60

7.3 Deslocamentos nodais do problema viga sob flexão pura $\left(10^{-05} \mathrm{~m}\right) \ldots \ldots$. . . . . . 62

7.4 Tensões $\sigma_{12}$ do problema viga engastada sob carregamento uniforme (MPa) $\ldots$. . . 66

E.1 Tempo de processamento para formulação em deslocamento $(\mathrm{ms}) \ldots \ldots$. . . . . . . 91

E.2 Tempo de processamento para formulação em força de superfície $(\mathrm{ms})$. . . . . . . 91 


\section{Capítulo 1}

\section{Introdução}

É crescente a utilização estrutural de materiais com propriedades anisotrópicas. Inicialmente seu emprego ocorreu no setor aéreo devido a suas propriedades de rigidez e resistência relativa a seu peso. Hoje, com o desenvolvimento de materiais baratos, especialmente fibras de vidro e resinas, o uso destes materiais se disseminou principalmente na indústria automotiva, construção civil e aplicação em artigos esportivos (Schclar, 1994).

Portanto, métodos precisos para a análise estrutural empregando este tipo de material é cada vez mais necessária. O Método dos Elementos de Contorno é uma ferramenta adequada para este tipo de análise. Considerando-se problemas da mecânica da fissura, o método apresenta uma vantagem em relação aos outros métodos por reduzir a dimensão do problema analisado. Ou seja, para um problema bidimensional é necessário descrever somente o seu contorno, enquanto que para um problema tridimensional faz-se necessário descrever somente sua superfície.

No entanto, sua utilização envolve o tratamento de integrais singulares ou quase-singulares, o que muitas vezes é visto como uma desvantagem do método. Neste trabalho, descreve-se uma técnica simples e direta de regularização de integrais impróprias. Mostra-se também a técnica da transformação de coordenadas para integração numérica de integrais quase-singulares.

Ressalta-se que neste trabalho adota-se a filosofia pregada por Brebbia e Dominguez (1992): a importância da tradução dos conceitos matemáticos para conceitos de engenharia de forma que o método possa ser compreendido e aplicado em situações reais.

\subsection{Objetivos}

O objetivo principal deste trabalho é implementar a formulação Dual do Método dos Elementos de Contorno utilizando a solução fundamental anisotrópica. 
As integrais singulares que surgem nesta formulação são tratadas por uma técnica específica de regularização de integrais, o método da subtração de singularidade.

Na discretização do contorno são empregados elementos isoparamétricos, os quais permitem a generalização da ordem de aproximação das grandezas envolvidas.

\subsection{Contribuições}

As principais contribuições deste trabalho são:

- Método dos Elementos de Contorno Dual. Detalhamento da formulação dual e tratamento das integrais impróprias que surgem.

- Elementos isoparamétricos. Utilização de polinômios de Lagrange para generalização da ordem de aproximação das grandezas envolvidas.

- Processamento em paralelo. O código computacional desenvolvido utilizando o paradigma da programação orientada a objetos permite o processamento em paralelo do problema analisado.

\subsection{Organização do Trabalho}

A revisão bibliográfica dos trabalhos consultados nesta pesquisa é apresentada no Capítulo 2.

No Capítulo 3, apresenta-se os conceitos fundamentais da Teoria da Elasticidade Linear e a solução fundamental para meio anisotrópico.

O Método dos Resíduos Ponderados apresentado no Capítulo 4 é o ponto de partida para a construção de diversos métodos numéricos. Em seguida, é mostrada como as integrais de domínio, obtidas pelo Método dos Resíduos Ponderados, podem ser transformadas em integrais de contorno.

Uma vez que tem-se o problema definido em variáveis de contorno, apresenta-se no Capítulo 5 o método numérico para resolução destas integrais, o Método dos Elementos de Contorno Dual. Neste capítulo também discuti-se as particularidades das integrais quase-singulares bem como o tratamento das integrais singulares de contorno.

No Capítulo 6, apresenta-se o código computacional desenvolvido detalhando sua estrutura e vantagens da utilização da programação orientada a objetos. Apresenta-se também o conceito da programação em paralelo empregada.

Para validação da formulação, apresenta-se no Capítulo 7 exemplos de sua aplicação com o código computacional desenvolvido. 
Por fim, discute-se algumas conclusões obtidas neste trabalho e sugestões de trabalhos futuros no Capítulo 8.

No Apêndice A apresenta-se o conceito do delta de Dirac do ponto de vista da engenharia e suas aplicações no Método dos Elementos de Contorno.

O processo de subtração de singularidade para um elemento linear é apresentado no Apêndice B e discute-se algumas das particularidades da formulação anisotrópica.

Com o propósito de agregar informação, detalha-se no Apêndice C uma das técnicas existentes para se avaliar as tensões sobre o contorno.

Os conceitos de erros absolutos e relativos utilizados para se avaliar a qualidade dos resultados obtidos são apresentados no Apêndice D.

No Apêndice E mostra-se o tempo de processamento para vários exemplos analisados com o algoritmo desenvolvido. 


\section{Capítulo 2}

\section{Revisão Bibliográfica}

De forma objetiva, neste capítulo apresentam-se as referências consultadas. Inicialmente são citados os trabalhos de relevância na Teoria da Elasticidade. Depois apresentam-se os trabalhos relacionados à formulação do Método dos Elementos de Contorno Dual, bem como as técnicas utilizadas para se avaliar integrais no sentido principal de Cauchy, parte finita de Hadamard e integrais quase-singulares. Conclui-se este capítulo com uma breve exposição dos textos que possibilitaram o desenvolvimento de um algoritmo para processamento em paralelo.

A teoria da elasticidade isotrópica é tema bastante estudado e pode-se citar trabalhos clássicos nessa área como Love (1944), Timoshenko (1970) e Muskhelishvili (1977), e mais recente Chou e Pagano (1992) e Sadd (2009). No entanto, a teoria da elasticidade anisotrópica possui poucas, mas completas, referências.

$\mathrm{Na}$ literatura existem duas abordagens diferentes para resolver problemas planos de elasticidade linear anisotrópica: o formalismo de Lekhnitskii e o de Stroh.

Lekhnitskii $(1968,1981)$ apresenta o formalismo de Lekhnitskii, o qual utiliza a abordagem baseada na representação da solução geral através de funções complexas introduzida por Kolosov (1935). A abordagem alternativa à de Kolosov envolvendo auto-valores, conhecida por formalismo de Stroh, introduzida por Stroh $(1958,1962)$ e Eshelby, Read, e Shockley (1953) pode ser encontrada detalhada em Ting (1996) e Rand e Rovenski (2004).

Hwu (2010) destaca que a diferença entre as duas estratégias é que o formalismo de Lekhnitskii parte das tensões para o estado plano, enquanto o formalismo de Stroh começa com os deslocamentos. Desta forma, devido a integração das deformações planas, o formalismo de Lekhnitskii permite relacionar os deslocamentos planos com o eixo coordenado perpendicular cobrindo campos de deslocamentos mais gerais que os permitidos pelo formalismo de Stroh. No entanto, Hwu ressalta a 
elegância matemática do formalismo de Stroh como vantagem desta estratégia para os problemas em que ela se aplica.

Finlayson e Scriven (1966) apresentam o método dos resíduos ponderados como uma ferramenta para se encontrar soluções aproximadas de equações diferenciais que governam vários tipos de problemas na engenharia. Sendo também a técnica para desenvolvimento do Método dos Elementos de Contorno.

Cheng e Cheng (2005) apresentam o Método dos Elementos de Contorno em seu contexto histórico desde os trabalhos iniciais com equações integrais realizados por Erik Ivar Fredholm em 1903, até a atualidade com os trabalhos desenvolvidos por Frank Joseph Rizzo, Thomas Allen Cruse e Carlos Alberto Brebbia.

Segundo Schclar (1994), a aplicação do Método dos Elementos de Contorno em problemas de anisotropia pode ser realizada de duas formas:

1. Solução fundamental isotrópica. Essa abordagem consiste em aplicar a solução fundamental isotrópica de referência resultando em integrais de domínio que necessitam de um processo iterativo para se encontrar os valores corretos de deslocamentos e forças de superfície. Alternativamente, pode-se aplicar o Método da Reciprocidade Dual (Partridge et al., 1992) às integrais de domínio para se trabalhar somente com integrais de contorno;

2. Solução fundamental anisotrópica. Essa abordagem é de aplicação natural e imediata. No entanto, envolve o emprego de funções complexas.

Um dos primeiros trabalhos a tratar de problemas não isotrópicos foi o de Rizzo e Shippy (1970). Depois dele, o trabalho de Cruse e Swedlow (1971) empregando a solução fundamental anisotrópica deu origem a uma série de trabalhos seguindo a mesma linha como Snyder e Cruse (1975), Cho et al. (1992), Tan e Gao (1992), Denda e Marante (2004) e Nourine et al. (2010).

Sollero e Aliabadi (1993) já apresentavam todos os fundamentos necessários para a formulação hiper-singular do problema plano anisotrópico. Mas somente em Sollero e Aliabadi (1995) foi apresentado formalmente o Método dos Elementos de Contorno Dual Anisotrópico.

A formulação do Método dos Elementos de Contorno Dual é ideal para analisar problemas da mecânica da fratura uma vez que a fissura pode ser discretizada de forma extremamente simples. No entanto, essa técnica gera a necessidade de se trabalhar com integrais singulares no sentido do valor principal de Cauchy (VPC) e parte finita de Hadamard (PFH) (Mukherjee, 2000). Para que o VPC e PFH existam é necessário que o núcleo da integral singular atenda às condições de continuidade de Hölder (Kim-Chuan e Mukherjee, 1994; Martin e Rizzo, 1996). 
Neste trabalho adota-se a técnica de regularização de integrais pelo método de subtração de singularidade (Sládek e Sladek, 1998) para tratar das integrais singulares. Para as quase-singulares, a técnica adotada foi a transformação de coordenadas auto-adaptativa proposta por Telles (1987).

Em qualquer método numérico que se desenvolva é necessário ter parâmetros para avaliar sua precisão. Uma maneira de fazer isso é comparando os resultados numéricos com as soluções analíticas disponíveis. Considerando os problemas de concentração de tensões, estas soluções tornam-se escassas. Nesse sentido, Savin (1961) apresenta um extenso trabalho com soluções analíticas para problemas de concentração de tensões ao redor de furos para meios anisotrópicos.

O desenvolvimento de um algoritmo que permita sua reutilização e expansão deve, obrigatoriamente, seguir os paradigmas da programação orientada a objetos (Deitel e Deitel, 2011). Conforme Smiley (2002) explica, Java possui uma série de vantagens sobre outras linguagens de programação, sendo uma delas sua extensa lista de bibliotecas, em geral, gratuitas e de código livre. Uma de suas bibliotecas nativas, a Concurrent, permite criar programas multi-threads. O processamento em paralelo, seja qual for a linguagem utilizada, gera problemas de sincronização entre as threads que devem ser tratados (Goetz et al., 2006). 


\section{Capítulo 3}

\section{Teoria da Elasticidade}

Neste capítulo apresenta-se uma breve exposição da Teoria da Elasticidade Linear seguindo a metodologia utilizada por Timoshenko (1970) e Ting (1996). Essa introdução permitirá o entendimento e construção do Método dos Elementos de Contorno Dual Anisotrópico, que é o objetivo deste trabalho.

\subsection{Deformação}

Considere que o ponto $P$ com coordenadas $\left(X_{1}, X_{2}\right)$ no estado indeformado seja deslocado para o ponto $P^{\prime}$ com coordenadas $\left(x_{1}, x_{2}\right)$ por uma deformação do corpo (Figura 3.1). O vetor deslocamento do ponto $P$ tem como coordenadas cartesianas $\left(u_{1}, u_{2}\right)$ em que

$$
\begin{aligned}
& u_{1}=x_{1}-X_{1} \\
& u_{2}=x_{2}-X_{2}
\end{aligned}
$$

Considere um elemento retangular $P Q R S$ no estado indeformado, com lados $\left(d X_{1}, d X_{2}\right)$ paralelo aos eixos coordenados (Figura 3.2). Depois de deformado, os pontos $P, Q, R$ e $S$ movem-se respectivamente para $P^{\prime}, Q^{\prime}, R^{\prime}$ e $S^{\prime}$. As coordenadas de $Q$ relativo a $P$ são $\left(d X_{1}, 0\right)$ e as coordenadas de $Q^{\prime}$ relativo a $P^{\prime}$ são $\left(d x_{1}, d x_{2}\right)$, em que

$$
\begin{aligned}
& d x_{1}=d X_{1}+d u_{1}=d X_{1}+\frac{\partial u_{1}}{\partial X_{1}} d X_{1} \\
& d x_{2}=d u_{2}=\frac{\partial u_{2}}{\partial X_{1}} d X_{1}
\end{aligned}
$$




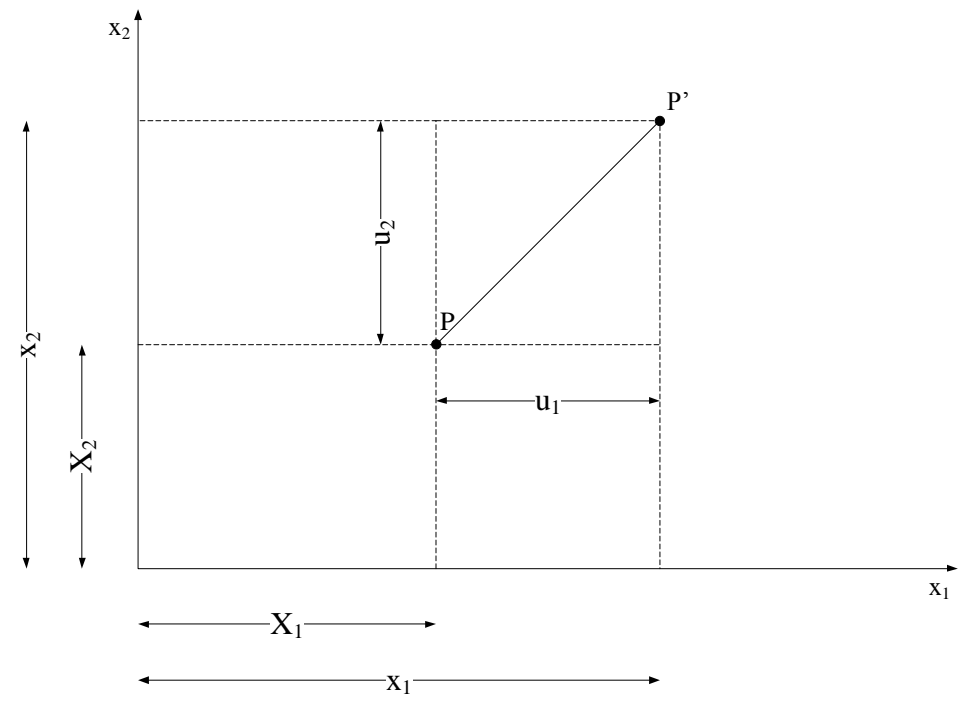

Figura 3.1: Vetor deslocamento.

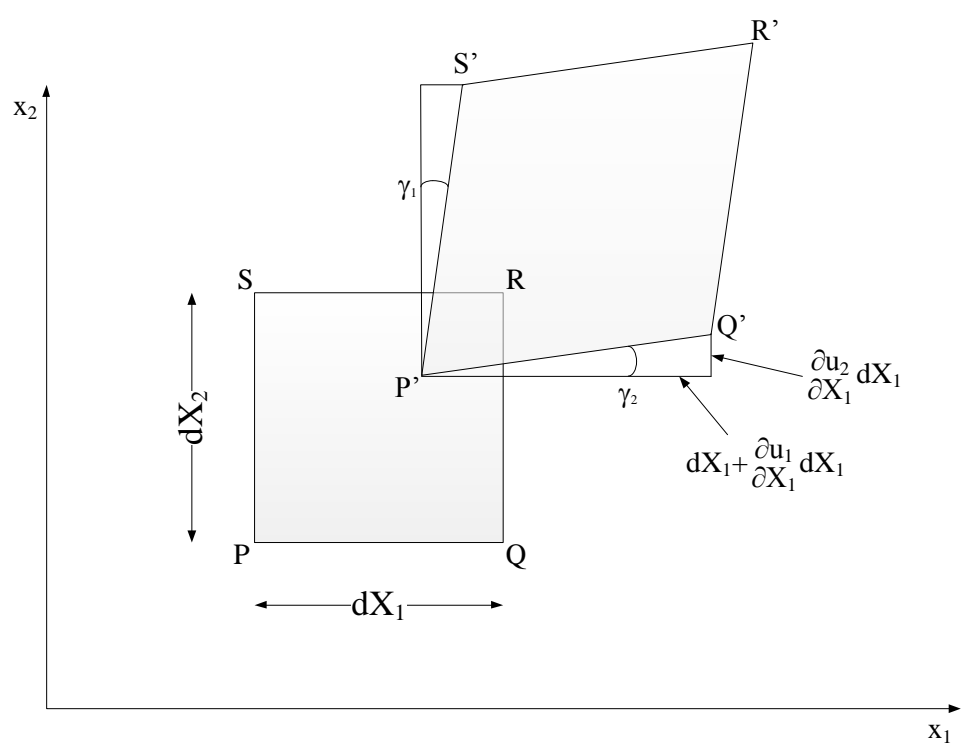

Figura 3.2: Deformação de um elemento infinitesimal.

Tem-se, portanto,

$$
\begin{aligned}
P^{\prime} Q^{\prime} & =\sqrt{d x_{1}^{2}+d x_{2}^{2}} \\
& \approx d X_{1}+\frac{\partial u_{1}}{\partial X_{1}} d X_{1}
\end{aligned}
$$

Em que foram desprezados os elementos diferenciais de ordem igual e superior a 2, conforme hipótese da teoria de pequenos deslocamentos e pequenas deformações. Portanto, o incremento no comprimento por unidade de comprimento do elemento $P Q$, denotado por $\varepsilon_{11}$, é dado por

$$
\varepsilon_{11}=\frac{P^{\prime} Q^{\prime}-P Q}{P Q}=\frac{\partial u_{1}}{\partial X_{1}}
$$


De forma similar, o incremento no comprimento por unidade de comprimento do elemento $P S$ é

$$
\varepsilon_{22}=\frac{\partial u_{2}}{\partial X_{2}}
$$

As grandezas $\varepsilon_{11}$ e $\varepsilon_{22}$ são conhecidas como deformações normais.

Seja $\gamma_{1}$ o ângulo entre $P^{\prime} Q^{\prime}$ e o eixo coordenado $x_{1}$, tem-se

$$
\tan \gamma_{1}=\frac{\partial u_{2} / \partial X_{1}}{1+\partial u_{1} / \partial X_{1}}
$$

Considerando-se que o ângulo $\gamma_{1}$, medido em radianos, seja pequeno e desprezando os elementos diferenciais de segunda ordem e superiores, tem-se

$$
\gamma_{1}=\frac{\partial u_{2}}{\partial X_{1}}
$$

De forma análoga, o ângulo $\gamma_{2}$ será

$$
\gamma_{2}=\frac{\partial u_{1}}{\partial X_{2}}
$$

Seja $2 \varepsilon_{12}$ o decréscimo no ângulo entre $P Q$ e $P S$, tem-se

$$
2 \varepsilon_{12}=\gamma_{1}+\gamma_{2}=\frac{\partial u_{2}}{\partial X_{1}}+\frac{\partial u_{1}}{\partial X_{2}}
$$

A grandeza $\varepsilon_{12}$ é conhecida como deformação angular. E o símbolo $\gamma_{12}=2 \varepsilon_{12}$ é comumente utilizado para denotar a deformação tangente em aplicações de engenharia.

Portanto, tem-se para o caso geral tridimensional as seguintes relações deformação-deslocamento

$$
\begin{aligned}
& \varepsilon_{11}=\frac{\partial u_{1}}{\partial X_{1}} \\
& \varepsilon_{22}=\frac{\partial u_{2}}{\partial X_{2}} \\
& \varepsilon_{33}=\frac{\partial u_{3}}{\partial X_{3}} \\
& \varepsilon_{12}=\frac{\gamma_{12}}{2}=\frac{1}{2}\left\{\frac{\partial u_{2}}{\partial X_{1}}+\frac{\partial u_{1}}{\partial X_{2}}\right\} \\
& \varepsilon_{13}=\frac{\gamma_{13}}{2}=\frac{1}{2}\left\{\frac{\partial u_{3}}{\partial X_{1}}+\frac{\partial u_{1}}{\partial X_{3}}\right\} \\
& \varepsilon_{23}=\frac{\gamma_{23}}{2}=\frac{1}{2}\left\{\frac{\partial u_{3}}{\partial X_{2}}+\frac{\partial u_{2}}{\partial X_{3}}\right\}
\end{aligned}
$$


As quais podem ser reescritas utilizando a notação indicial

$$
\varepsilon_{i j}=\frac{1}{2}\left(u_{i, j}+u_{j, i}\right) \quad i, j=1,2,3
$$

\subsection{Tensão}

Um corpo pode ser solicitado por dois tipos de forças externas: forças de corpo e forças de superfície. As forças de corpo atuam sobre todo o volume do corpo, enquanto as forças de superfície atuam sobre a superfície do mesmo. Existem também as forças internas, que atuam na interação entre as partes do corpo quando este é submetido à deformação.

Considere parte de um sólido ocupando uma região $V$ delimitada pela superfície $S$ no estado deformado (Figura 3.3). Sobre o contorno $S$ atuam forças de superfície causadas pela ação do material exterior a $V$ sobre o material interior a $V$. A tensão atuante na área $\delta S$ no ponto $P$ sobre $S$ é dada por

$$
\lim _{\delta S \rightarrow 0}\left(\frac{\delta \vec{p}}{\delta S}\right)
$$

Em que $\delta \vec{p}$ é o vetor de força que atua sobre o elemento infinitesimal de área $\delta S$. Esse limite é conhecido como traction ou vetor tensão, cujas componentes podem ser decompostas em normais e cisalhantes de acordo com um vetor normal à superfície em questão.

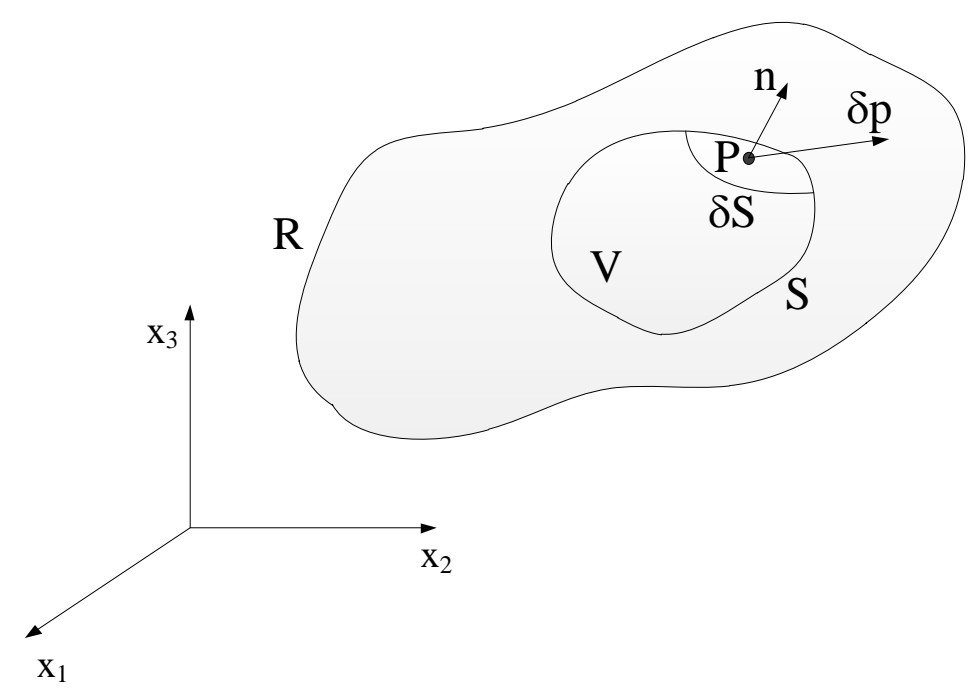

Figura 3.3: Força de superfície.

Considere um elemento cúbico com lados paralelos aos eixos coordenados (Figura 3.4). As componentes do vetor tensão atuando na face com vetor normal a direção positiva do eixo $x_{1}$ são $\sigma_{11}$, $\sigma_{12}$ e $\sigma_{13}$. Portanto o primeiro índice indica a direção do vetor normal da face do cubo em que atua e o segundo índice indica a direção da componente. 


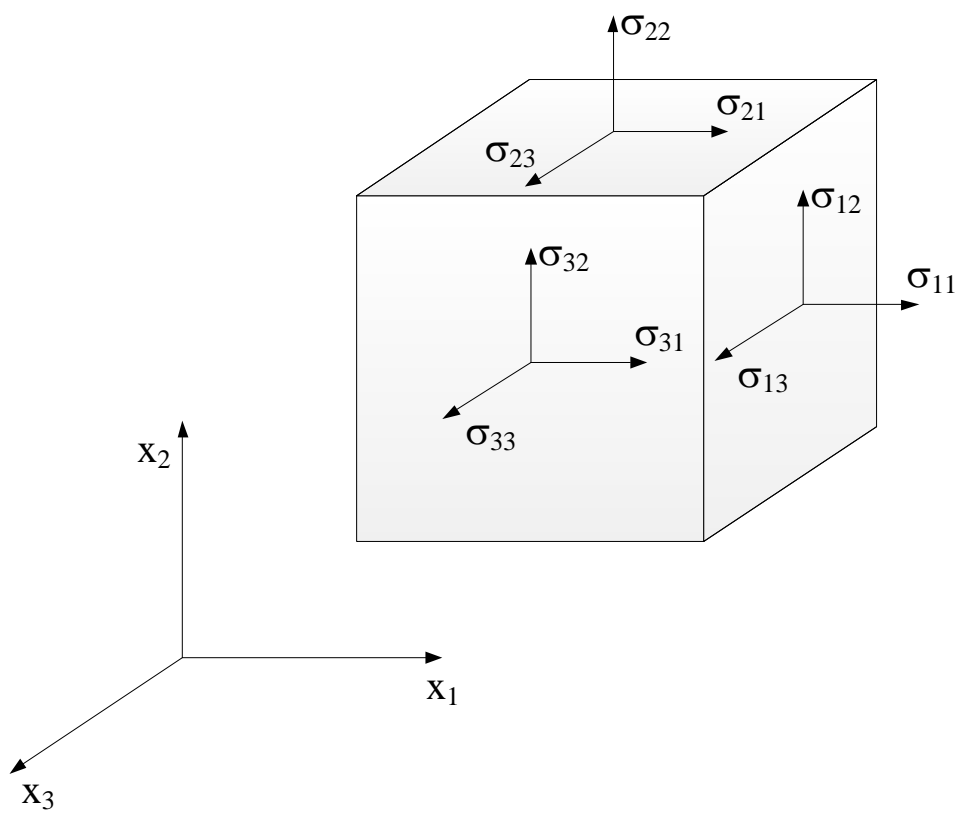

Figura 3.4: Componentes de tensão.

Podemos representar as componentes de tensão em sua forma matricial:

$$
\sigma=\left[\begin{array}{lll}
\sigma_{11} & \sigma_{12} & \sigma_{13} \\
\sigma_{21} & \sigma_{22} & \sigma_{23} \\
\sigma_{31} & \sigma_{32} & \sigma_{33}
\end{array}\right]
$$

\subsection{Equações de Equilíbrio}

Considere o equilíbrio de um cubo infinitesimal, centro em $P\left(x_{1}, x_{2}, x_{3}\right)$ e de lados $\delta x_{1}, \delta x_{2}$ e $\delta x_{3}$ paralelos aos eixos coordenados (Figura 3.5). Os centros das 6 faces do cubo são os pontos

$$
\left(x_{1} \pm \delta x_{1}, x_{2}, x_{3}\right), \quad\left(x_{1}, x_{2} \pm \delta x_{2}, x_{3}\right), \quad\left(x_{1}, x_{2}, x_{3} \pm \delta x_{3}\right)
$$

Se as componentes de tensão no ponto $P$ são $\sigma_{11}, \sigma_{12}, \sigma_{13}, \sigma_{21}, \sigma_{22}, \sigma_{23}, \sigma_{31}, \sigma_{32}$ e $\sigma_{33}$, então as forças de superfície que atuam na face com centro em $\left(x_{1}+\delta x_{1}, x_{2}, x_{3}\right)$ são

$$
\sigma_{11}+\frac{1}{2} \frac{\partial \sigma_{11}}{\partial x_{1}} \delta x_{1}, \quad \sigma_{12}+\frac{1}{2} \frac{\partial \sigma_{12}}{\partial x_{1}} \delta x_{1}, \quad \sigma_{13}+\frac{1}{2} \frac{\partial \sigma_{13}}{\partial x_{1}} \delta x_{1}
$$

$\mathrm{E}$ as forças de superfície que atuam na face com centro em $\left(x_{1}-\delta x_{1}, x_{2}, x_{3}\right)$ são

$$
-\left(\sigma_{11}-\frac{1}{2} \frac{\partial \sigma_{11}}{\partial x_{1}} \delta x_{1}\right), \quad-\left(\sigma_{12}-\frac{1}{2} \frac{\partial \sigma_{12}}{\partial x_{1}} \delta x_{1}\right), \quad-\left(\sigma_{13}-\frac{1}{2} \frac{\partial \sigma_{13}}{\partial x_{1}} \delta x_{1}\right)
$$




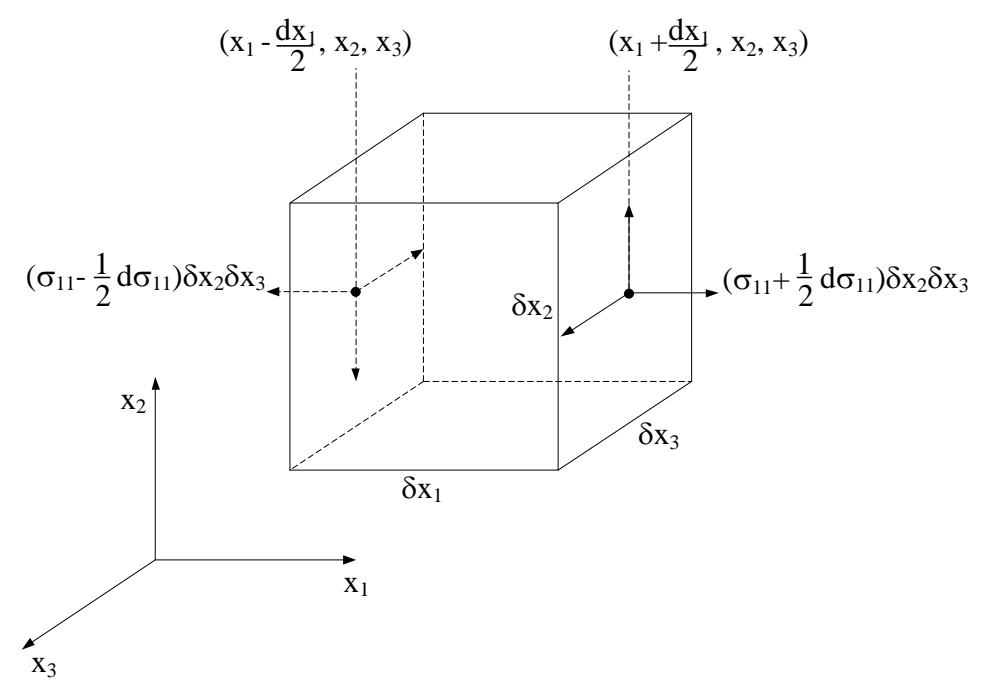

Figura 3.5: Equilíbrio de um elemento de volume.

De forma análoga, as forças de superfície podem ser escritas para as outras faces. Se $\left(f_{1}, f_{2}, f_{3}\right)$ denotam as forças externas de corpo por unidade de volume, então somando as forças que atuam na direção de $x_{1}$, tem-se

$$
\begin{aligned}
\left(\sigma_{11}+\right. & \left.\frac{1}{2} \frac{\partial \sigma_{11}}{\partial x_{1}} \delta x_{1}\right) \delta x_{2} \delta x_{3}-\left(\sigma_{11}-\frac{1}{2} \frac{\partial \sigma_{11}}{\partial x_{1}} \delta x_{1}\right) \delta x_{2} \delta x_{3} \\
+ & \left(\sigma_{21}+\frac{1}{2} \frac{\partial \sigma_{21}}{\partial x_{2}} \delta x_{2}\right) \delta x_{1} \delta x_{3}-\left(\sigma_{21}-\frac{1}{2} \frac{\partial \sigma_{21}}{\partial x_{2}} \delta x_{2}\right) \delta x_{1} \delta x_{3} \\
+ & \left(\sigma_{31}+\frac{1}{2} \frac{\partial \sigma_{31}}{\partial x_{3}} \delta x_{3}\right) \delta x_{1} \delta x_{2}-\left(\sigma_{31}-\frac{1}{2} \frac{\partial \sigma_{31}}{\partial x_{3}} \delta x_{3}\right) \delta x_{1} \delta x_{2} \\
& +f_{1} \delta x_{1} \delta x_{2} \delta x_{3}=0
\end{aligned}
$$

Dividindo por $\delta x_{1}, \delta x_{2}$ e $\delta x_{3}$, tem-se

$$
\frac{\partial \sigma_{11}}{\partial x_{1}}+\frac{\partial \sigma_{21}}{\partial x_{2}}+\frac{\partial \sigma_{31}}{\partial x_{3}}+f_{1}=0
$$

De forma análoga, para os eixos $x_{2}$ e $x_{3}$ tem-se

$$
\begin{aligned}
& \frac{\partial \sigma_{12}}{\partial x_{1}}+\frac{\partial \sigma_{22}}{\partial x_{2}}+\frac{\partial \sigma_{32}}{\partial x_{3}}+f_{2}=0 \\
& \frac{\partial \sigma_{13}}{\partial x_{1}}+\frac{\partial \sigma_{23}}{\partial x_{2}}+\frac{\partial \sigma_{33}}{\partial x_{3}}+f_{3}=0
\end{aligned}
$$

Estas equações são conhecidas como equações de equilíbrio em tensão de um sólido e podem ser reescritas em notação indicial

$$
\sigma_{i j, j}+f_{i}=0 \quad i, j=1,2,3
$$

Para o equilíbrio do elemento infinitesimal em consideração, deve haver também o equilíbrio 
de momentos. Fazendo o equilíbrio de momentos no eixo paralelo ao $x_{1}$ passando pelo ponto $P$ encontra-se

$$
\begin{aligned}
\frac{1}{2} \delta x_{2} & \left(\sigma_{23}+\frac{1}{2} \frac{\partial \sigma_{23}}{\partial x_{2}} \delta x_{2}\right) \delta x_{1} \delta x_{3}+\frac{1}{2} \delta x_{2}\left(\sigma_{23}-\frac{1}{2} \frac{\partial \sigma_{23}}{\partial x_{2}} \delta x_{2}\right) \delta x_{1} \delta x_{3} \\
- & \frac{1}{2} \delta x_{3}\left(\sigma_{32}+\frac{1}{2} \frac{\partial \sigma_{32}}{\partial x_{3}} \delta x_{3}\right) \delta x_{1} \delta x_{2}+\frac{1}{2} \delta x_{3}\left(\sigma_{32}-\frac{1}{2} \frac{\partial \sigma_{32}}{\partial x_{3}} \delta x_{3}\right) \delta x_{1} \delta x_{2}=0
\end{aligned}
$$

Dividindo por $\delta x_{1}, \delta x_{2}$ e $\delta x_{3}$, tem-se

$$
\sigma_{23}=\sigma_{32}
$$

De forma similar, fazendo o equilíbrio de momentos em relação aos eixos paralelos a $x_{2}$ e $x_{3}$ passando pelo ponto $P$ é possível provar que

$$
\begin{gathered}
\sigma_{12}=\sigma_{21} \\
\sigma_{13}=\sigma_{31}
\end{gathered}
$$

Essas relações de simetria implicam que das 9 componentes de tensão existentes, somente 6 delas são independentes.

É possível também provar que a força de superfície em um ponto sobre uma superfície arbitrária pode ser expressa como uma combinação linear das componentes de tensão naquele ponto. Para efeito de demonstração, considere que

$$
\sigma_{31}=\sigma_{32}=\sigma_{33}=0
$$

Considere o elemento infinitesimal da Figura (3.6). Fazendo o equilíbrio de forças no eixo $x_{1}$, tem-se

$$
t_{1} \overline{A B}-\sigma_{11} \overline{O B}-\sigma_{21} \overline{O A}=0
$$

Note que $\overline{O A}=\overline{A B} \sin \theta$ e $\overline{O B}=\overline{A B} \cos \theta$, então

$$
t_{1}=\sigma_{11} \cos \theta+\sigma_{21} \sin \theta
$$




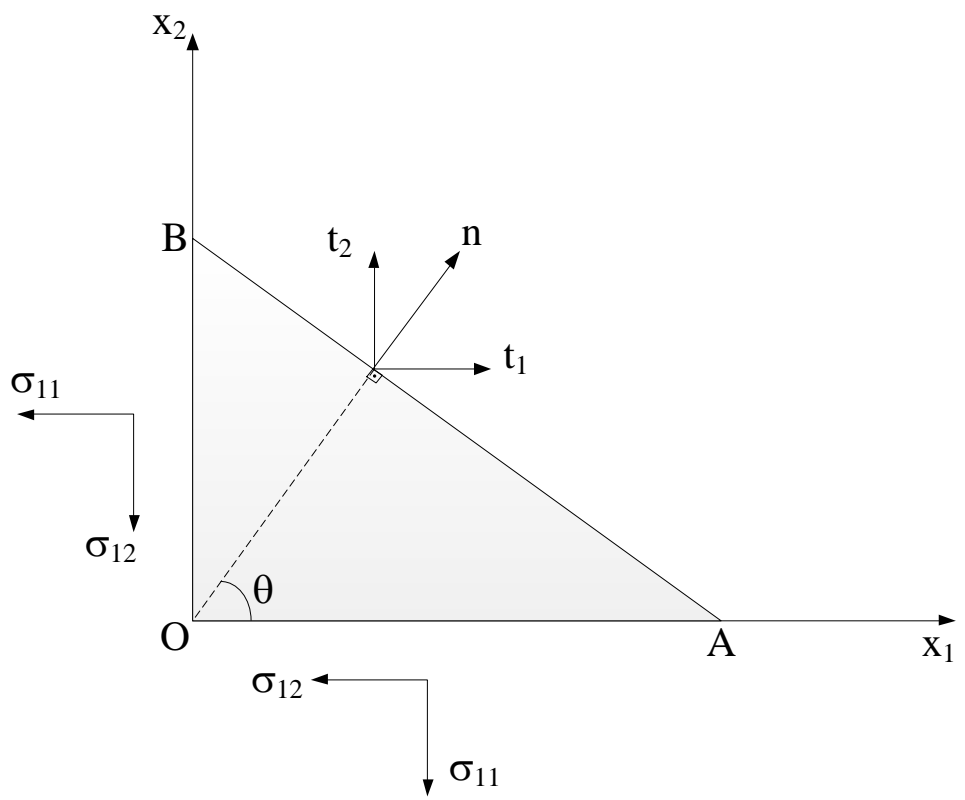

Figura 3.6: Equilíbrio de um elemento de prismático.

De forma similar, tem-se

$$
\begin{aligned}
& t_{2}=\sigma_{12} \cos \theta+\sigma_{22} \sin \theta \\
& t_{3}=0
\end{aligned}
$$

Estas equações podem ser expressas em forma matricial

$$
\left\{\begin{array}{l}
t_{1} \\
t_{2} \\
t_{3}
\end{array}\right\}=\left[\begin{array}{ccc}
\sigma_{11} & \sigma_{12} & 0 \\
\sigma_{21} & \sigma_{22} & 0 \\
0 & 0 & 1
\end{array}\right]\left\{\begin{array}{l}
n_{1} \\
n_{2} \\
n_{3}
\end{array}\right\}
$$

Ou em notação indicial

$$
t_{i}=\sigma_{i j} n_{j} \quad i, j=1,2,3
$$

Em que $\left(n_{1}, n_{2}, n_{3}\right)=(\cos \theta, \sin \theta, 0)$ são as componentes do vetor unitário normal à superfície.

\subsection{Equações de Compatibilidade}

Considere a relação deformação-deslocamento válida para pequenas deformações

$$
\varepsilon_{i j}=\frac{1}{2}\left(u_{i, j}+u_{j, i}\right) \quad i, j=1,2,3
$$

Quando as componentes de deslocamento são dadas, a deformação $\varepsilon_{i j}$ pode ser unicamente 
calculada através dela. No entanto, especificar $\varepsilon_{i j}$, em geral, não define uma solução única para $u_{i}$. A equação (3.11) pode ser considerada como um sistema de 6 equações diferenciais parciais com 3 incógnitas $u_{1}, u_{2}$ e $u_{3}$. Ou seja, as componentes de deformação não podem ser arbitrariamente prescritas. Portanto, para que as equações de deslocamentos possuam solução única é necessário impor algumas restrições sobre $\varepsilon_{i j}$.

Chou e Pagano (1992) apresentam uma forma simples de determinar as restrições sobre as deformações.

Derivando duas vezes a equação (3.10a) em relação a $x_{2}$, duas vezes a equação (3.10b) em relação a $x_{1}$ e somando os resultados, teremos

$$
\frac{\partial^{2} \varepsilon_{11}}{\partial x_{2}^{2}}+\frac{\partial^{2} \varepsilon_{22}}{\partial x_{1}^{2}}=\frac{\partial^{3} u_{1}}{\partial x_{2}^{2} \partial x_{1}}+\frac{\partial^{3} u_{2}}{\partial x_{1}^{2} \partial x_{2}}
$$

Derivando a equação (3.10d) com relação a $x_{1}$ e $x_{2}$, teremos

$$
\frac{\partial^{2} \gamma_{12}}{\partial x_{1} \partial x_{2}}=\frac{\partial^{2}}{\partial x_{1} \partial x_{2}}\left(\frac{\partial u_{2}}{\partial x_{1}}+\frac{\partial u_{1}}{\partial x_{2}}\right)
$$

Lembrando que o resultado da derivada de funções contínuas não se altera com a ordem de derivação, temos

$$
\frac{\partial^{2} \varepsilon_{11}}{\partial x_{2}^{2}}+\frac{\partial^{2} \varepsilon_{22}}{\partial x_{1}^{2}}=\frac{\partial^{2} \gamma_{12}}{\partial x_{1} \partial x_{2}}
$$

De forma similar podemos obter todas as 6 equações de compatibilidade, em notação indicial

$$
\varepsilon_{i j, k l}+\varepsilon_{k l, i j}-\varepsilon_{i k, j l}-\varepsilon_{j l, i k}=0 \quad i, j, k, l=1,2,3
$$

\subsection{Lei de Hooke Generalizada}

Para completar a formulação matemática da Teoria da Elasticidade Linear é necessário ainda introduzir equações adicionais que relacionem as componentes de tensão e deformação do sólido em consideração para um material linear elástico. Por material elástico entende-se que o material retornará ao seu estado indeformado original ao retirarmos o carregamento que o solicitava. E por material linear entende-se que a relação tensão-deformação seja linear.

Um gráfico típico da relação tensão-deformação para um corpo submetido a carregamento uniaxial é mostrado na Figura (3.7). A relação tensão-deformação é linear e elástica até o ponto limite de proporcionalidade. O comportamento do material é não linear, mas ainda elástico até a tensão 
de escoamento. O material apresenta deformação permanente caso seja solicitado além deste ponto, com deformação residual após a remoção completa do carregamento. Portanto, a lei de Hooke é válida para tensões inferiores ao limite de proporcionalidade.

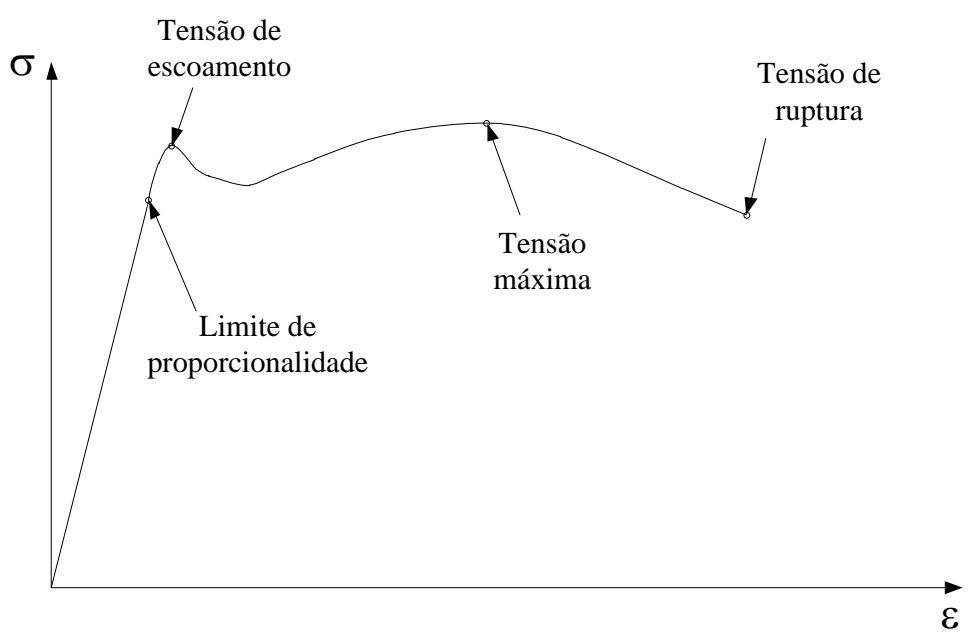

Figura 3.7: Diagrama tensão-deformação típica do aço.

Pela lei de Hooke generalizada, cada componente de tensão em qualquer ponto do sólido é uma combinação linear das componentes de deformação naquele ponto.

Se as propriedades do material são as mesmas em qualquer direção, ele é chamado isotrópico. Por outro lado, se suas propriedades mudam conforme a direção, ele é chamado anisotrópico. Se as propriedades do material são as mesmas por toda a extensão do sólido, então ele é chamado homogêneo. Este trabalho trata da análise de materiais lineares, elásticos, anisotrópicos e homogêneos.

Pode-se escrever a lei de Hooke generalizada:

$$
\left\{\begin{array}{l}
\varepsilon_{11} \\
\varepsilon_{22} \\
\varepsilon_{33} \\
\gamma_{23} \\
\gamma_{13} \\
\gamma_{12}
\end{array}\right\}=\left[\begin{array}{llllll}
c_{11} & c_{12} & c_{13} & c_{14} & c_{15} & c_{16} \\
& c_{22} & c_{23} & c_{24} & c_{25} & c_{26} \\
& & c_{33} & c_{34} & c_{35} & c_{36} \\
& & & c_{44} & c_{45} & c_{46} \\
& & & & c_{55} & c_{56} \\
& & & & & c_{66}
\end{array}\right]\left\{\begin{array}{c}
\sigma_{11} \\
\sigma_{22} \\
\sigma_{33} \\
\sigma_{23} \\
\sigma_{13} \\
\sigma_{12}
\end{array}\right\}
$$

Em que $c_{\zeta \vartheta}$, com $\zeta$ e $\vartheta$ variando de 1 a 6 , são as 21 constantes independentes que compõem a matriz de coeficientes elásticos de flexibilidade. 
A lei de Hooke generalizada escrita para tensões tem a forma

$$
\left\{\begin{array}{c}
\sigma_{11} \\
\sigma_{22} \\
\sigma_{33} \\
\sigma_{23} \\
\sigma_{13} \\
\sigma_{12}
\end{array}\right\}=\left[\begin{array}{llllll}
C_{11} & C_{12} & C_{13} & C_{14} & C_{15} & C_{16} \\
& C_{22} & C_{23} & C_{24} & C_{25} & C_{26} \\
& & C_{33} & C_{34} & C_{35} & C_{36} \\
& & & C_{44} & C_{45} & C_{46} \\
& & & & C_{55} & C_{56} \\
& & & & & C_{66}
\end{array}\right]\left\{\begin{array}{c}
\varepsilon_{11} \\
\varepsilon_{22} \\
\varepsilon_{33} \\
\gamma_{23} \\
\gamma_{13} \\
\gamma_{12}
\end{array}\right\}
$$

Em que $C_{\zeta \vartheta}$, matriz de coeficientes elásticos de rigidez, é a inversa de $c_{\zeta \vartheta}$.

Para um sólido homogêneo elástico anisotrópico é possível reescrever as constantes $c_{\zeta \vartheta}$ e $C_{\zeta \vartheta}$ introduzindo constantes de engenharia. Então, $c_{\zeta \vartheta}$ pode ser reescrita

$$
\left\{\begin{array}{c}
\varepsilon_{11} \\
\varepsilon_{22} \\
\varepsilon_{33} \\
\gamma_{23} \\
\gamma_{13} \\
\gamma_{12}
\end{array}\right\}=\left[\begin{array}{cccccc}
\frac{1}{E_{11}} & -\frac{\nu_{21}}{E_{11}} & -\frac{\nu_{31}}{E_{11}} & \frac{\eta_{23,1}}{E_{11}} & \frac{\eta_{31,1}}{E_{11}} & \frac{\eta_{12,1}}{E_{11}} \\
-\frac{\nu_{12}}{E_{22}} & \frac{1}{E_{22}} & -\frac{\nu_{32}}{E_{22}} & \frac{\eta_{23,2}}{E_{22}} & \frac{\eta_{31,2}}{E_{22}} & \frac{\eta_{12,2}}{E_{22}} \\
-\frac{\nu_{13}}{E_{33}} & -\frac{\nu_{23}}{E_{33}} & \frac{1}{E_{33}} & \frac{\eta_{13,3}}{E_{33}} & \frac{\eta_{31,3}}{E_{33}} & \frac{\eta_{12,3}}{E_{33}} \\
\frac{\eta_{1,23}}{G_{23}} & \frac{\eta_{2,23}}{G_{23}} & \frac{\eta_{3,23}}{G_{23}} & \frac{1}{G_{23}} & \frac{\rho_{31,23}}{G_{23}} & \frac{\rho_{12,23}}{G_{23}} \\
\frac{\eta_{1,31}}{G_{13}} & \frac{\eta_{2,31}}{G_{13}} & \frac{\eta_{3,31}}{G_{13}} & \frac{\rho_{23,31}}{G_{13}} & \frac{1}{G_{13}} & \frac{\rho_{12,31}}{G_{13}} \\
\frac{\eta_{1,12}}{G_{12}} & \frac{\eta_{2,12}}{G_{12}} & \frac{\eta_{3,12}}{G_{12}} & \frac{\rho_{23,12}}{G_{12}} & \frac{\rho_{31,12}}{G_{12}} & \frac{1}{G_{12}}
\end{array}\right]\left\{\begin{array}{c}
\sigma_{11} \\
\sigma_{22} \\
\sigma_{33} \\
\sigma_{23} \\
\sigma_{13} \\
\sigma_{12}
\end{array}\right\}
$$

Em que $E_{11}, E_{22}, E_{33}$ são os módulos de Young em tração-compressão nas direções $x_{1}, x_{2}$ e $x_{3} ; G_{23}, G_{13}, G_{12}$ são os módulos de cisalhamento para planos paralelos aos planos coordenados; $\nu_{21}, \nu_{31}, \nu_{12}, \nu_{32}, \nu_{13}, \nu_{23}$ são os coeficientes de Poisson caracterizando a contração na direção do eixo onde é tracionado na outra direção (por exemplo, $\nu_{21}$ é o coeficiente de contração na direção $x_{1}$ quando tração é aplicada na $x_{2}$ ). Estas constantes correspondem às já conhecidas constantes elásticas para um corpo isotrópico.

Os coeficientes $\rho_{31,23}, \rho_{12,23}, \rho_{23,31}, \rho_{12,31}, \rho_{23,12}, \rho_{31,12}$, são denominados coeficientes de Chentsov; eles caracterizam o cisalhamento em planos paralelos aos planos coordenados produzido por uma tensão de cisalhamento atuando em outro plano paralelo aos planos coordenados. As constantes $\eta_{23,1}, \eta_{31,1}, \eta_{12,1}, \eta_{23,2}, \eta_{31,2}, \eta_{12,2}, \eta_{13,3}, \eta_{31,3}, \eta_{12,3}$, são coeficientes de influência mútua do primeiro tipo; elas caracterizam a extensão na direção do eixo coordenado produzido por uma tensão de cisalhamento atuando no mesmo plano coordenado. Por fim, $\eta_{1,23}, \eta_{2,23}, \eta_{3,23}, \eta_{1,31}, \eta_{2,31}$, $\eta_{3,31}, \eta_{1,12}, \eta_{2,12}, \eta_{3,12}$, expressam o cisalhamento no plano coordenado causado por uma tensão normal atuando na direção dos eixos coordenados; eles são denominados coeficientes de influência 
mútua do segundo tipo.

Note que estas equações podem ser reescritas utilizando notação indicial se aplicada uma simples transformação:

1. $c_{\zeta \vartheta}=c_{i j k s}$, se $\zeta, \vartheta=1,2,3$

2. $c_{\zeta \vartheta}=2 c_{i j k s}$, se qualquer um dos índices, $\zeta$ ou $\vartheta$, forem iguais a $4,5,6$;

3. $c_{\zeta \vartheta}=4 c_{i j k s}$, se os dois índices $\zeta, \vartheta=4,5,6$.

Respeitando a relação entre $\zeta$ e $\vartheta$, e $i, j, k$ e $s$.

$$
\begin{array}{ccc}
i j(\text { ou } k s) & \leftrightarrow & \zeta(\text { ou } \vartheta) \\
11 & \leftrightarrow & 1 \\
22 & \leftrightarrow & 2 \\
33 & \leftrightarrow & 3 \\
23 \text { ou } 32 & \leftrightarrow & 4 \\
31 \text { ou } 13 & \leftrightarrow & 5 \\
12 \text { ou } 21 & \leftrightarrow & 6
\end{array}
$$

Desta forma, a Lei de Hooke Generalizada pode ser escrita em notação indicial

$$
\varepsilon_{i j}=c_{i j k l} \sigma_{k l} \quad i, j, k, l=1,2,3
$$

Ou para as componentes de tensão teremos

$$
\sigma_{i j}=C_{i j k l} \varepsilon_{k l} \quad i, j, k, l=1,2,3
$$

\subsection{Estado Plano de Deformação}

É possível admitir, sob certas condições, que as componentes de deslocamentos sejam independentes de uma das coordenadas cartesianas, por exemplo $x_{3}$.

Fisicamente, o estado plano de deformação é aplicável sempre que o sólido na direção de $x_{3}$ for grande o suficiente comparado com suas outras dimensões nas outras direções e quando tal corpo estiver sob carregamentos constantes e perpendiculares ao eixo $x_{3}$. Nestas condições, podemos admitir que não há deformação na direção $x_{3}$ e que o deslocamento de cada seção transversal perpendicular ao eixo $x_{3}$ não dependerá de $x_{3}$ (Figura 3.8). 


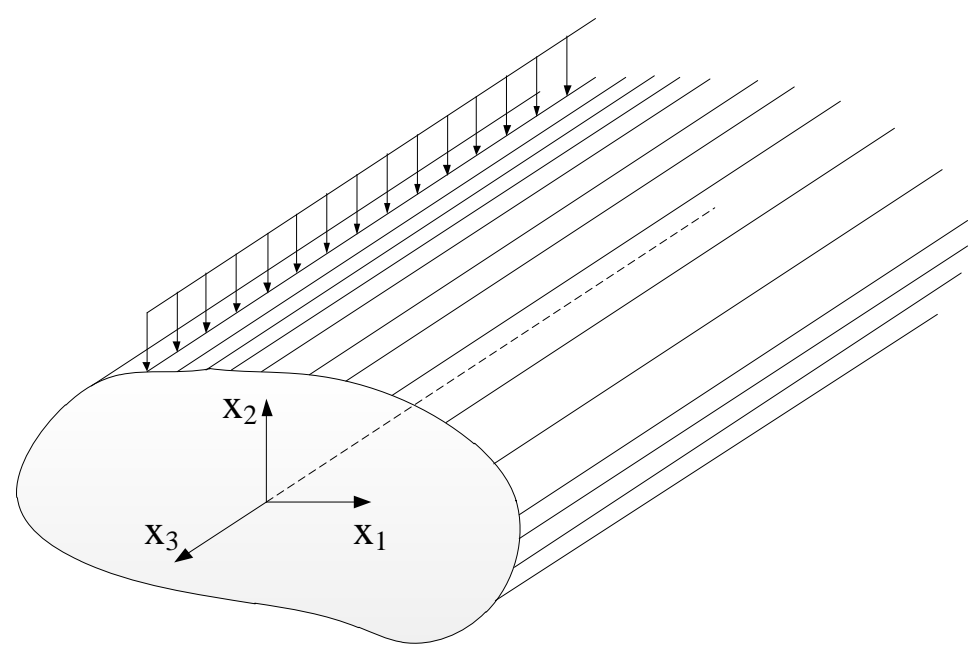

Figura 3.8: Estado plano de deformação.

Para problemas de estado plano de deformação paralelo ao plano $x_{1} x_{2}$, tem-se

$$
\begin{aligned}
& u_{1}=u_{1}\left(x_{1}, x_{2}\right) \\
& u_{2}=u_{2}\left(x_{1}, x_{2}\right) \\
& u_{3}=0
\end{aligned}
$$

Consequentemente, $\varepsilon_{13}=\varepsilon_{23}=\varepsilon_{33}=0$ e $\varepsilon_{11}$, $\varepsilon_{22}$ e $\varepsilon_{12}$ são independentes de $x_{3}$.

\subsection{Estado Plano de Tensão}

No estado plano de tensão as tensões em uma direção podem ser consideradas nulas. Isso ocorre quando uma dimensão do sólido é muito pequena quando comparada às outras dimensões.

Escolhendo-se o plano $x_{1} x_{2}$ para descrever o problema, o domínio é limitado por dois planos, $x_{3}= \pm h / 2$, como mostrado na Figura (3.9). Admite-se que estes planos sejam livres de tensões, e portanto $\sigma_{13}=\sigma_{23}=\sigma_{33}=0$ em cada face. Uma vez que a espessura é pequena na direção de $x_{3}$, a variação destas tensões também o são e podem ser consideradas nulas em toda a sua extensão. Consequentemente $\sigma_{11}(x, y), \sigma_{22}(x, y)$ e $\sigma_{12}(x, y)$ independem de $x_{3}$. 


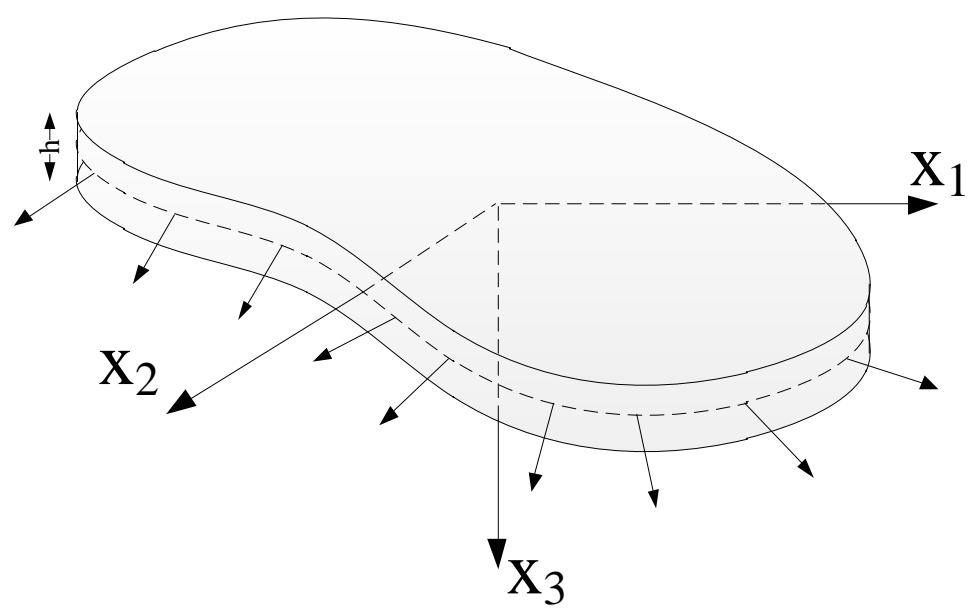

Figura 3.9: Estado plano de tensão.

\subsection{Solução Fundamental}

A equação de equilíbrio

$$
\sigma_{i j, j}=0
$$

É satisfeita pela introdução da função de tensão, $F$, considerando que

$$
\sigma_{i k}=-F_{, i k}+\delta_{i k} F_{, j j}
$$

Em que $\delta_{i k}$ é o delta de Kronecker.

Substituindo (3.48) em (3.42) e expressando as deformações em função das funções de tensão, tem-se

$$
c_{22} \frac{\partial^{4} F}{\partial x_{1}^{4}}-2 c_{26} \frac{\partial^{4} F}{\partial x_{1}^{3} \partial x_{2}}+\left(2 c_{12}+c_{66}\right) \frac{\partial^{4} F}{\partial x_{1}^{2} \partial x_{2}^{2}}-2 c_{16} \frac{\partial^{4} F}{\partial x_{1} \partial x_{2}^{3}}+c_{11} \frac{\partial^{4} F}{\partial x_{2}^{4}}=0
$$

Que pode ser integrada em sua forma geral utilizando quatro operadores diferenciais lineares

$$
D_{1} D_{2} D_{3} D_{4} F=0
$$

Em que $D_{k}$ é o operador linear

$$
D_{k}=\frac{\partial}{\partial x_{2}}-\mu_{k} \frac{\partial}{\partial x_{1}} \quad k=1,2,3,4
$$

E $\mu_{k}$ são as raízes da equação característica

$$
c_{11} \mu^{4}-2 c_{16} \mu^{3}+\left(2 c_{12}+c_{66}\right) \mu^{2}-2 c_{26} \mu+c_{22}=0
$$


Lekhnitskii (1968) prova que, dependendo das constantes elásticas, existem dois casos possíveis para a solução desta equação:

1. As raízes de (3.52) são todas distintas

$$
\mu_{1}=\alpha+\beta i, \quad \mu_{2}=\gamma+\delta i, \quad \bar{\mu}_{1}=\alpha-\beta i, \quad \bar{\mu}_{2}=\gamma-\delta i
$$

Em que $\alpha, \beta, \gamma, \delta$ são números reais e $\beta>0, \delta>0$;

2. As raízes de (3.52) são iguais em pares

$$
\mu_{1}=\mu_{2}=\alpha+\beta i, \quad \bar{\mu}_{1}=\bar{\mu}_{2}=\alpha-\beta i
$$

Em que $\alpha, \beta$ são números reais e $\beta>0$.

As raízes $\mu_{1}$ e $\mu_{2}$ são conhecidas por parâmetros complexos. Parâmetros complexos podem ser entendidos como números que caracterizam o grau de anisotropia do meio no caso de problemas planos. De acordo com seus valores é possível julgar o quanto um corpo difere do isotrópico, para o qual tem-se sempre

$$
\mu_{1}=\mu_{2}=i
$$

Desta forma, é possível compreender melhor a determinação das funções $F$, definidas no plano complexo, dada pelo mapeamento do problema real nos planos complexos (Figura 3.10) por

$$
z_{k}=x_{1}+\mu_{k} x_{2} \quad k=1,2
$$
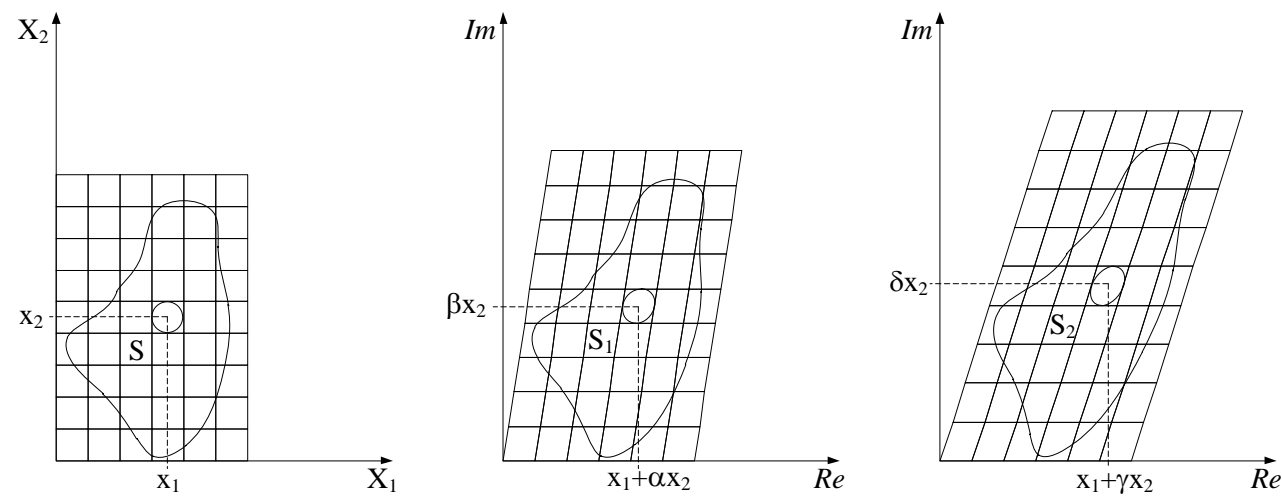

Figura 3.10: Mapeamento no plano complexo.

Na Teoria da Elasticidade Linear são conhecidas soluções analíticas para poucos problemas, em sua maioria com geometrias e carregamentos simples. A solução fundamental é uma solução 
particular da equação diferencial que estamos tentando aproximar.

Considere uma carga concentrada e unitária aplicada em um meio infinito anisotrópico (Figura 3.11), para o qual é válida a equação de equilíbrio

$$
\sigma_{k i j, j}+\delta_{k i} \delta\left(z-z^{\prime}\right)=0 \quad k, i, j=1,2
$$

Em que $\delta\left(z^{\prime}, z\right)$ é o delta de Dirac e representa a carga concentrada unitária.

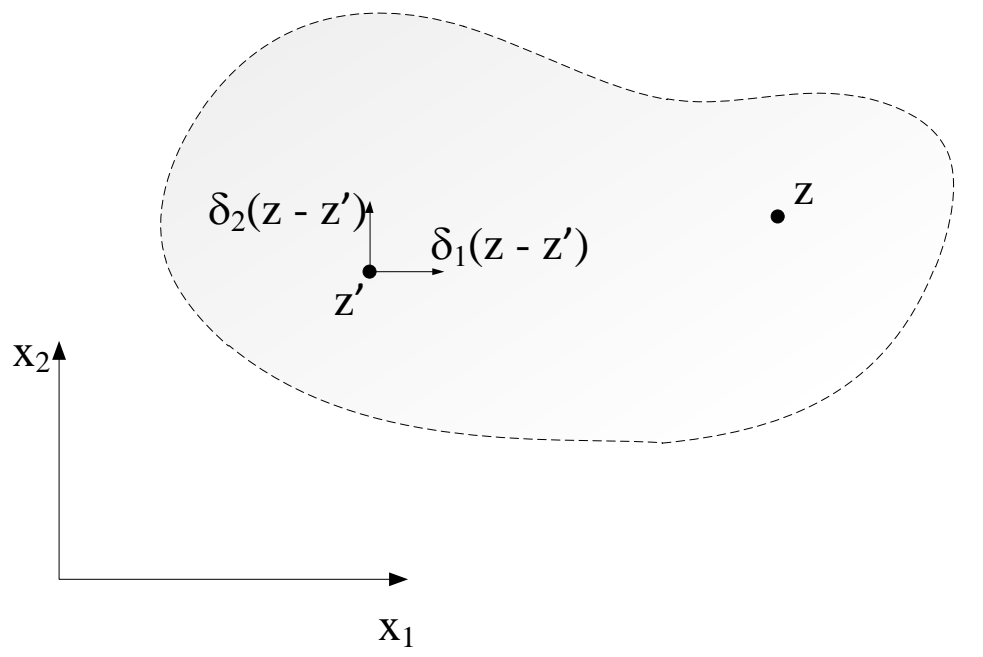

Figura 3.11: Solução fundamental.

O conceito do ponto fonte como sendo uma carga unitária concentrada, apesar de ser puramente uma abstração matemática e sem sentido físico, possui propriedades importantes, descritas no Apêndice A, para a formulação do Método dos Elementos de Contorno (Kane, 1993).

Desenvolvida por Lekhnitskii (1981) e apresentada por Sollero e Aliabadi (1993) em notação indicial, a solução fundamental em deslocamento para problemas planos com um ponto fonte, $z^{\prime}$, e um ponto campo, $z$, mapeados no plano complexo pela equação (3.54) é o tensor dado por

$$
U_{k i}\left(z^{\prime}, z\right)=2 \operatorname{Re}\left[q_{i 1} A_{k 1} \ln \left(z_{1}-z_{1}^{\prime}\right)+q_{i 2} A_{k 2} \ln \left(z_{2}-z_{2}^{\prime}\right)\right]
$$

Em que o índice $k$ indica a direção de aplicação da carga unitária e o índice $i$ indica a direção da resposta do deslocamento.

A força de superfície fundamental é dada por

$$
T_{k i}\left(z^{\prime}, z\right)=2 R e\left[\frac{1}{\left(z_{1}-z_{1}^{\prime}\right)} g_{i 1} A_{k 1}\left(\mu_{1} n_{1}-n_{2}\right)+\frac{1}{\left(z_{2}-z_{2}^{\prime}\right)} g_{i 2} A_{k 2}\left(\mu_{2} n_{1}-n_{2}\right)\right]
$$

Em que $n_{1}$ e $n_{2}$ são as componentes do vetor normal à superfície considerada e em que $q_{i k}, A_{i k}$ 
e $g_{i k}$ são constantes definidas por

$$
\begin{gathered}
q_{i k}=\left[\begin{array}{c}
c_{11} \mu_{k}^{2}+c_{12}-c_{16} \mu_{k} \\
c_{12} \mu_{k}+c_{22} / \mu_{k}-c_{26}
\end{array}\right] \quad g_{i k}=\left[\begin{array}{cc}
\mu_{1} & \mu_{2} \\
-1 & -1
\end{array}\right] \\
{\left[\begin{array}{cccc}
1 & -1 & 1 & -1 \\
\mu_{1} & \bar{\mu}_{1} & \mu_{2} & \bar{\mu}_{2} \\
q_{11} & -\bar{q}_{11} & q_{12} & -\bar{q}_{12} \\
q_{21} & -\bar{q}_{21} & q_{22} & -\bar{q}_{22}
\end{array}\right]\left\{\begin{array}{c}
A_{k 1} \\
\bar{A}_{k 1} \\
A_{k 2} \\
\bar{A}_{k 2}
\end{array}\right\}=\left\{\begin{array}{c}
\delta_{k 2} /(2 \pi i) \\
-\delta_{k 1} /(2 \pi i) \\
0 \\
0
\end{array}\right\}}
\end{gathered}
$$

Fica evidente a necessidade de se obter as derivadas de $U_{k i}\left(z^{\prime}, z\right)$ e $T_{k i}\left(z^{\prime}, z\right)$ para se calcular as deformações e tensões fundamentais em um ponto qualquer. As expressões destas derivadas são apresentadas detalhadamente por Vanalli (2004) e são dadas por

$$
\begin{aligned}
& U_{j i, k}\left(z^{\prime}, z\right)=2 \operatorname{Re}\left[\frac{1}{\left(z_{1}-z_{1}^{\prime}\right)} R_{k 1} q_{i 1} A_{j 1}+\frac{1}{\left(z_{2}-z_{2}^{\prime}\right)} R_{k 2} q_{i 2} A_{j 2}\right] \\
& T_{j i, k}\left(z^{\prime}, z\right)=2 \operatorname{Re}\left[\frac{1}{\left(z_{1}-z_{1}^{\prime}\right)^{2}} R_{k 1} g_{i 1} A_{j 1}\left(\mu_{1} n_{1}-n_{2}\right)+\frac{1}{\left(z_{2}-z_{2}^{\prime}\right)^{2}} R_{k 2} g_{i 2} A_{j 2}\left(\mu_{2} n_{1}-n_{2}\right)\right]
\end{aligned}
$$

Em que a constante $R_{i k}$ é

$$
R_{i k}=\left[\begin{array}{cc}
1 & 1 \\
\mu_{1} & \mu_{2}
\end{array}\right]
$$




\section{Capítulo 4}

\section{Equações Integrais de Contorno}

\subsection{Método dos Resíduos Ponderados}

O método dos resíduos ponderados é uma ferramenta para encontrar soluções aproximadas de equações diferenciais que governam vários tipos de problemas. Sendo também a técnica para desenvolvimento do Método dos Elementos de Contorno (Finlayson e Scriven, 1966).

Suponha um operador diferencial linear $D(\cdot)$ atuando sobre uma função $u(x)$ para produzir uma função $p(x)$.

$$
D(u(x))=p(x)
$$

Deseja-se aproximar $u(x)$ por uma função $\tilde{u}(x)$, que é uma combinação linear de funções bases escolhidas de um grupo linearmente independente. Ou seja,

$$
u(x) \cong \tilde{u}(x)=\sum_{i=1}^{n} u_{i} \phi_{i}(x)
$$

Em que $u_{i}$ são coeficientes a serem determinados para alguns pontos $i$, e $\phi_{i}(x)$ são funções linearmente independentes chamadas funções de forma. Agora, quando substituída no operador diferencial, $D(\cdot)$, o resultado não é, em geral, $p(x)$. Portanto, um erro residual existirá:

$$
R(x)=D(\tilde{u}(x))-p(x) \neq 0
$$

A idéia do método dos resíduos ponderados é forçar o erro ser zero, em média, sobre o domínio. Para isto, o erro residual é ponderado por uma função apropriada e integrado sobre o domínio. Isto é,

$$
\int_{\Omega} R(x) W_{i} d \Omega \quad i=1,2, \cdots, n
$$


Em que o número de funções ponderadoras é exatamente igual ao número de constantes incógnitas $u_{i}$ em $\tilde{u}(x)$. O resultado é um conjunto de $n$ equações algébricas para as constantes incógnitas $u_{i}$.

A equação (4.4) é também chamada de forma fraca da equação diferencial original, chamada de forma forte, porque a solução que a satisfaz nem sempre satisfaz a equação diferencial original (4.1) e as condições de contorno.

\subsection{Equações Integrais de Contorno}

O Método dos Elementos de Contorno consiste na idéia de que podemos aproximar a solução da equação diferencial parcial somente olhando para a solução no contorno do problema e depois usar estes resultados para encontrar a solução dentro do domínio.

Partindo do método dos resíduos ponderados para a equação de equilíbrio e escolhendo a função ponderadora como sendo a solução fundamental (Eq. 3.56) apresentada anteriormente, aqui representada pelas variáveis com *, tem-se

$$
\int_{\Omega} \sigma_{i j, j} U_{k i}^{*} d \Omega=0
$$

Usando o teorema de Green-Gauss, tem-se

$$
\int_{\Gamma} \sigma_{i j} n_{j} U_{k i}^{*} d \Gamma-\int_{\Omega} \sigma_{i j} U_{k i, j}^{*} d \Omega=0
$$

Aplicando a propriedade da força de superfície (Eq. 3.32) na primeira parcela da equação (4.6) e aplicando a lei de Hooke generalizada (Eq. 3.43) no segundo termo, tem-se

$$
\int_{\Gamma} t_{i} U_{k i}^{*} d \Gamma-\int_{\Omega} u_{i, j} \sigma_{k i j}^{*} d \Omega=0
$$

Integrando por partes o segundo termo da equação (4.7) de forma a obtermos a derivada da função ponderadora $\sigma_{k i j}^{*}$, tem-se

$$
\int_{\Gamma} t_{i} U_{k i}^{*} d \Gamma-\int_{\Gamma} u_{i} n_{j} \sigma_{k i j}^{*} d \Gamma+\int_{\Omega} u_{i} \sigma_{k i j, j}^{*} d \Omega=0
$$

Aplicando novamente a propriedade da força de superfície na segunda parcela da equação (4.8), 
tem-se

$$
\int_{\Gamma} t_{i} U_{k i}^{*} d \Gamma-\int_{\Gamma} u_{i} T_{k i}^{*} d \Gamma+\int_{\Omega} u_{i} \sigma_{k i j, j}^{*} d \Omega=0
$$

Aplicando a equação de equilíbrio para o problema da solução fundamental (3.55), o último termo da equação (4.9) resulta

$$
\int_{\Omega} u_{i} \sigma_{k i j, j}^{*} d \Omega=-\int_{\Omega} u_{i} \delta_{k i} \delta^{*}\left(z-z^{\prime}\right) d \Omega=-c\left(z^{\prime}\right) u_{k}
$$

Em que $c\left(z^{\prime}\right)$ é uma constante que depende da posição do ponto fonte $z^{\prime}$

$$
c\left(z^{\prime}\right)=\left\{\begin{array}{lll}
0 & \text { se } & z^{\prime} \notin \Omega, \\
1 / 2 & \text { se } & z^{\prime} \in \Gamma_{\text {suave }} \\
1 & \text { se } & z^{\prime} \in \Omega-\Gamma
\end{array}\right.
$$

Considerando que $z^{\prime}$ pertence ao domínio, mas não ao contorno, tem-se a equação integral de contorno

$$
u_{k}+\int_{\Gamma} u_{i} T_{k i}^{*} d \Gamma=\int_{\Gamma} t_{i} U_{k i}^{*} d \Gamma
$$

A equação (4.12), também chamada de Identidade Somigliana, nos diz que podemos encontrar $u$ em um ponto arbitrário do domínio simplesmente avaliando $u$ e $t$ sobre o contorno. Isso não nos ajuda muito a menos que saibamos os valores e $u$ e $t$ sobre o contorno. Então, para resolvermos este problema veremos o que acontece se $z^{\prime}$ pertence ao contorno.

Primeiro, se $z^{\prime}$ não pertente ao domínio tem-se

$$
\int_{\Gamma} u_{i} T_{k i}^{*} d \Gamma=\int_{\Gamma} t_{i} U_{k i}^{*} d \Gamma
$$

Considere agora que o ponto $z^{\prime}$ esteja sobre o contorno. Observe, no entanto, que as equações de deslocamento fundamental e força de superfície fundamental apresentam respostas do tipo $\ln (r)$ e $r^{-1}$ e, portanto, apresentam singularidade no ponto $z^{\prime}$ sobre o contorno. Para lidar com este comportamento é necessário observar o que ocorre com estas integrais no limite em que o ponto $z^{\prime}$ se aproxima do contorno pelo domínio. Definindo um disco de raio $\epsilon$ em volta de $z^{\prime}$ (Figura 4.1) e tomando o limite de $\epsilon \rightarrow 0$ pode-se verificar o que acontece com os núcleos das integrais

$$
\lim _{\epsilon \rightarrow 0}\left\{u_{k}+\int_{\Gamma-\bar{\Gamma}_{\epsilon}+\Gamma_{\epsilon}} u_{i} T_{k i}^{*} d \Gamma=\int_{\Gamma-\bar{\Gamma}_{\epsilon}+\Gamma_{\epsilon}} t_{i} U_{k i}^{*} d \Gamma\right\}
$$




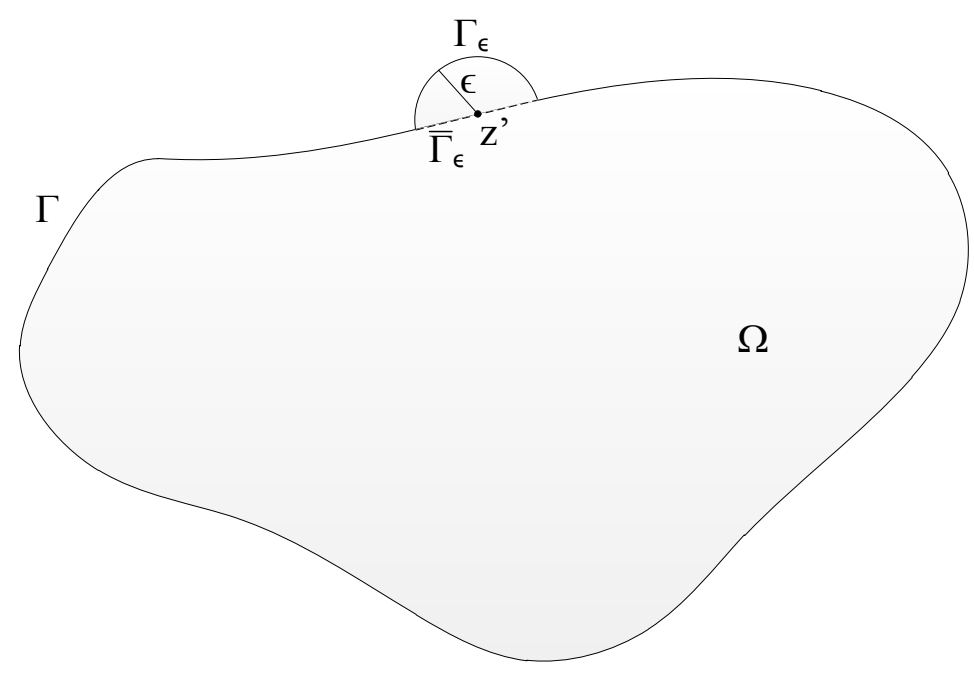

Figura 4.1: Ponto fonte sobre o contorno.

Tomando cada um dos limites individualmente, é fácil perceber que o primeiro termo resulta simplesmente em

$$
\lim _{\epsilon \rightarrow 0}\left\{u_{k}\right\}=u_{k}
$$

É possível analisar o limite do segundo termo separando-o em uma parcela sobre o contorno onde a integral é regular, $\Gamma-\bar{\Gamma}_{\epsilon}$, e outro sobre o contorno onde a integral apresenta singularidade, $\Gamma_{\epsilon}$,

$$
\int_{\Gamma} u_{i} T_{k i}^{*} d \Gamma=\lim _{\epsilon \rightarrow 0}\left\{\int_{\Gamma-\bar{\Gamma}_{\epsilon}} u_{i} T_{k i}^{*} d \Gamma\right\}+\lim _{\epsilon \rightarrow 0}\left\{\int_{\Gamma_{\epsilon}} u_{i} T_{k i}^{*} d \Gamma\right\}
$$

O segundo termo do lado direito de (4.16) pode ser integrado analiticamente e, para $z^{\prime}$ sobre um contorno suave, resulta em

$$
\lim _{\epsilon \rightarrow 0}\left\{\int_{\Gamma_{\epsilon}} u_{i} T_{k i}^{*} d \Gamma\right\}=-\frac{1}{2} \delta_{k i} u_{i}=-\frac{1}{2} u_{k}
$$

Desta forma, no limite, a equação (4.16) resulta em

$$
\int_{\Gamma} u_{i} T_{k i}^{*} d \Gamma=f_{\Gamma} u_{i} T_{k i}^{*} d \Gamma-\frac{1}{2} u_{k}
$$

Em que a integral indicada por $f$ deve ser avaliada no sentido do valor principal de Cauchy (VPC).

Procedendo de forma análoga para o terceiro termo da equação (4.14), é possível demonstrar que a parcela da integral sobre o contorno $\Gamma_{\epsilon}$ se anula. E no limite, o terceiro termo resulta em uma integral imprópria e integrável no sentido do valor principal de Cauchy.

Portanto, no limite em que $\epsilon \rightarrow 0$ e o ponto $z^{\prime}$ tende para o contorno, a equação (4.12) pode ser 
avaliada por

$$
\frac{1}{2} u_{k}+f_{\Gamma} u_{i} T_{k i}^{*} d \Gamma=f_{\Gamma} t_{i} U_{k i}^{*} d \Gamma
$$

Derivando a equação anterior, tem-se

$$
\frac{1}{2} u_{k, j}+f_{\Gamma} u_{i} T_{k i, j}^{*} d \Gamma=f_{\Gamma} t_{i} U_{k i, j}^{*} d \Gamma
$$

Em que a integral indicada por f deve ser avaliada no sentido da parte finita de Hadamard (Hsiao e Wendland, 2010).

A relação deformação-deslocamento pode ser aplicada à equação anterior resultando nas equações integrais de contorno para deformação para $z^{\prime}$ sobre o contorno

$$
\varepsilon_{k j}+f_{\Gamma} u_{i}\left(T_{k i, j}^{*}+T_{j i, k}^{*}\right) d \Gamma=f_{\Gamma} t_{i}\left(U_{k i, j}^{*}+U_{j i, k}^{*}\right) d \Gamma
$$

As equações integrais de contorno para tensão são obtidas aplicando a lei de Hooke generalizada (Eq. 3.43)

$$
\sigma_{k j}+C_{k j l m} f_{\Gamma} u_{i}\left(T_{l i, m}^{*}+T_{m i, l}^{*}\right) d \Gamma=C_{k j l m} f_{\Gamma} t_{i}\left(U_{l i, m}^{*}+U_{m i, l}^{*}\right) d \Gamma
$$

A qual, usualmente, é escrita da forma

$$
\frac{1}{2} \sigma_{k j}+f_{\Gamma} u_{i} S_{k i j}^{*} d \Gamma=f_{\Gamma} t_{i} D_{k i j}^{*} d \Gamma
$$

Por fim, as equações integrais de contorno para forças de superfície são obtidas aplicando-se a equação (3.32) na equação integral de contorno para tensão

$$
\frac{1}{2} t_{k}+n_{j}\left(z^{\prime}\right) f_{\Gamma} u_{i} S_{k i j}^{*} d \Gamma=n_{j}\left(z^{\prime}\right) f_{\Gamma} t_{i} D_{k i j}^{*} d \Gamma
$$

Em que $n_{j}\left(z^{\prime}\right)$ é o vetor normal ao elemento avaliado em $z^{\prime}$. 


\section{Capítulo 5}

\section{Método dos Elementos de Contorno Dual}

O Método dos Elementos de Contorno é uma técnica bem estabelecida para análise da mecânica da fratura linear. No entanto, a solução de problemas deste tipo não pode ser obtida através da aplicação direta do método.

Considere o sólido com fissura da Figura (5.1). Em que $\Gamma^{+}$e $\Gamma^{-}$representam as faces da fissura. No limite em que $\Delta \rightarrow 0$ os pontos fontes, $z^{\prime+}$ e $z^{\prime-}$, coincidirão e fornecerão equações idênticas. Essa situação dá origem a um sistema singular de equações algébricas.

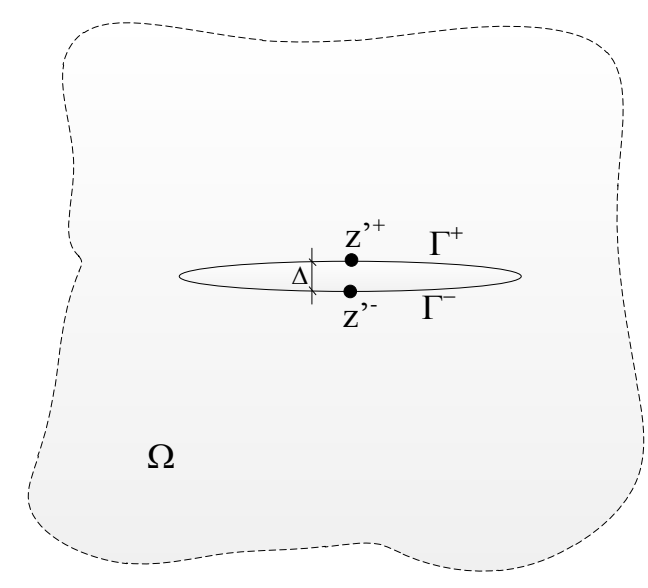

Figura 5.1: Método dos elementos de contorno dual.

O Método de Elementos de Contorno Dual contorna este problema considerando duas equações independentes, as equações integrais de contorno em deslocamento e em força de superfície. Para $z^{\prime+}$ utiliza-se uma formulação e para $z^{\prime-}$ outra. As faces da fratura podem, então, ser representadas por dois elementos ocupando a mesma região.

A principal dificuldade desta abordagem, segundo Wrobel e Aliabadi (2002), é desenvolver uma maneira geral e precisa de se avaliar as integrais no sentido do valor principal de Cauchy e parte finita de Hadamard. Neste trabalho, apresenta-se o método de regularização das integrais de contorno pela 
técnica de subtração da singularidade de aplicação geral.

\subsection{Elementos Isoparamétricos de Contorno}

Com o objetivo de formular o Método dos Elementos de Contorno é preciso dividir o domínio em $N$ elementos de contorno (Figura 5.2).

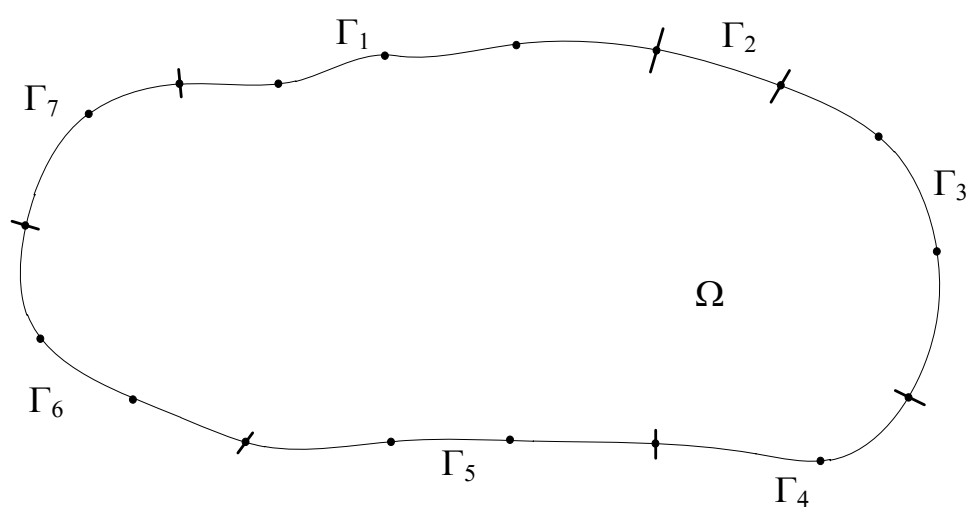

Figura 5.2: Discretização do contorno.

Desta forma, as equações (4.19) e (4.24) podem ser reescritas

$$
\begin{aligned}
& \frac{1}{2} u_{k}\left(z^{\prime}\right)+\sum_{s=1}^{N}\left[f_{\Gamma_{s}} u_{i}(z) T_{k i}^{*}\left(z^{\prime}, z\right) d \Gamma\right]=\sum_{s=1}^{N}\left[f_{\Gamma_{s}} t_{i}(z) U_{k i}^{*}\left(z^{\prime}, z\right) d \Gamma\right] \\
& \frac{1}{2} t_{k}\left(z^{\prime}\right)+n_{j}\left(z^{\prime}\right) \sum_{s=1}^{N}\left[f_{\Gamma_{s}} u_{i}(z) S_{k i j}^{*}\left(z^{\prime}, z\right) d \Gamma\right]=n_{j}\left(z^{\prime}\right) \sum_{s=1}^{N}\left[f_{\Gamma_{s}} t_{i}(z) D_{k i j}^{*}\left(z^{\prime}, z\right) d \Gamma\right]
\end{aligned}
$$

O Método dos Elementos de Contorno não se limita a aproximações de elementos constantes ou lineares e sua extensão para utilização de polinômios de qualquer ordem é direta (Kzam, 2009). Considere o elemento da Figura (5.3).

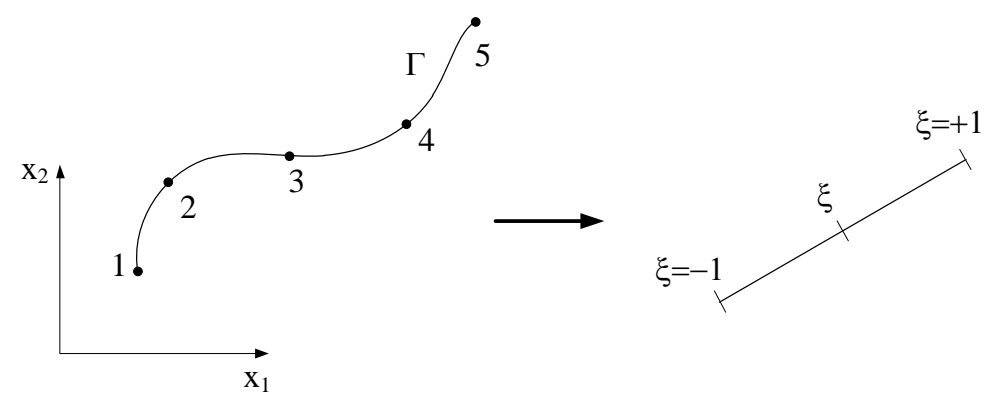

Figura 5.3: Parametrização da geometria de um elemento. 
Sua geometria pode ser aproximada pelas funções paramétricas

$$
\begin{aligned}
& x_{1}(\xi)=\phi^{l}(\xi) x_{1}^{l} \\
& x_{2}(\xi)=\phi^{l}(\xi) x_{2}^{l}
\end{aligned}
$$

Em que $\xi$ é a coordenada paramétrica, $\phi^{l}(\xi)$ são as funções de forma de cada nó $l$ e $x_{1}^{l}$ e $x_{2}^{l}$ são as coordenadas do nó $l$ nos eixos $x_{1}$ e $x_{2}$ respectivamente.

Para um elemento de ordem qualquer, as coordenadas adimensionais, $\xi_{i}$, dos nós podem ser determinadas adicionando-se nós, geralmente igualmente espaçados, entre os nós das extremidades, $\xi= \pm 1$, através da equação

$$
\xi_{i}=\frac{2(i-1)}{n-1}-1
$$

Em que $n$ é o número de nós do elemento e $i$ é a identificação de cada nó.

Prenter (1975) ressalta que a introdução de mais e mais nós igualmente espaçados nem sempre força a sequência de Lagrange, que interpola $f(x)$, a convergir para $f(x)$. Considere a função

$$
f(x)=\frac{1}{\left(1+x^{2}\right)}
$$

A Figura (5.4) mostra a função $f(x)$ e os polinômios interpoladores de Lagrange de grau seis e dez.

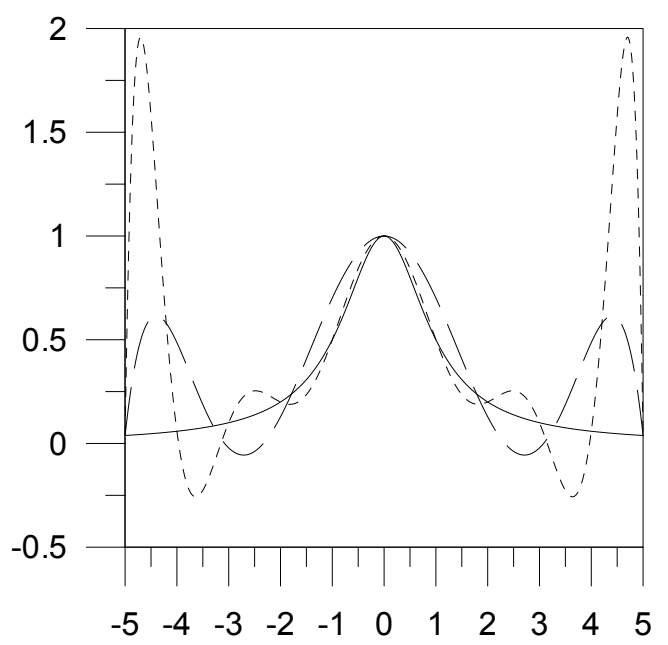

Figura 5.4: Efeito Runge para a função $f(x)$ (—) sendo aproximada por um polinômio de Lagrange de sexto grau (-- -) e décimo grau (-----).

Observe que utilizando um polinômio de interpolação de ordem superior a aproximação começa a oscilar em seus extremos. Este efeito, conhecido por efeito Runge, pode ser contornado de di- 
versas formas (Runge, 1901) sendo as mais comuns: utilização de nós desigualmente espaçados; e, aproximação da função $f(x)$ por trechos.

As funções de forma são definidas por um polinômio completo, válido no intervalo $[-1,1]$ e impondo-se a condição que cada função base seja igual a unidade em seu nó e nula em todos os demais do mesmo elemento. Ou seja,

$$
\phi^{l}\left(\xi_{i}\right)=\left\{\begin{array}{lll}
1 & \text { se } & i=l, \\
0 & \text { se } & i \neq l
\end{array}\right.
$$

Os coeficientes dos polinômios das funções de forma para o polinômio completo

$$
\phi^{l}\left(\xi_{i}\right)=c_{1} \xi_{i}^{n-1}+c_{2} \xi_{i}^{n-2}+\cdots+c_{n-1} \xi_{i}+c_{n}
$$

Podem ser calculados resolvendo o sistema de equações lineares

$$
\left[\begin{array}{ccccc}
\xi_{1}^{n-1} & \xi_{1}^{n-2} & \cdots & \xi_{1} & 1 \\
\xi_{2}^{n-1} & \xi_{2}^{n-2} & \cdots & \xi_{2} & 1 \\
\vdots & \vdots & \ddots & \vdots & \vdots \\
\xi_{n}^{n-1} & \xi_{n}^{n-2} & \cdots & \xi_{n} & 1
\end{array}\right]\left\{\begin{array}{c}
c_{1} \\
c_{2} \\
\vdots \\
c_{n}
\end{array}\right\}=\left\{\begin{array}{c}
\phi^{l}\left(\xi_{1}\right) \\
\phi^{l}\left(\xi_{2}\right) \\
\vdots \\
\phi^{l}\left(\xi_{n}\right)
\end{array}\right\}
$$

Em que a matriz é conhecida por matriz de Vandermonde.

O jacobiano da transformação de coordenadas (Figura 5.5) é dado por

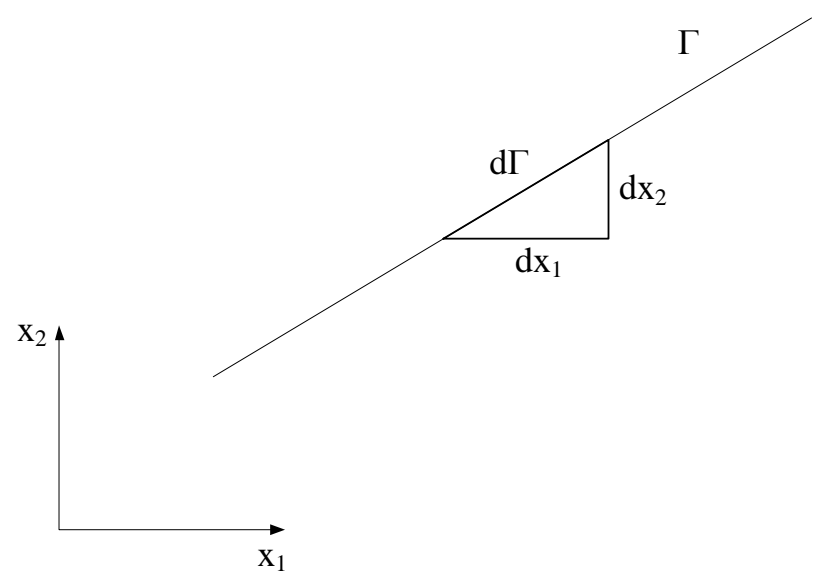

Figura 5.5: Jacobiano da transformação de coordenadas. 


$$
\begin{aligned}
J(\xi)=d \Gamma & =\sqrt{\left(d x_{1}\right)^{2}+\left(d x_{2}\right)^{2}} \\
& =\sqrt{\left(x_{1, \xi}\right)^{2}+\left(x_{2, \xi}\right)^{2}} \\
& =\sqrt{\left(\phi_{, \xi}^{l}(\xi) x_{1}^{l}\right)^{2}+\left(\phi_{, \xi}^{l}(\xi) x_{2}^{l}\right)^{2}}
\end{aligned}
$$

Utilizando o mesmo conjunto de funções de forma para aproximar tanto a geometria quanto os deslocamentos e forças de superfície, temos os elementos isoparamétricos e podemos reescrever os deslocamentos e forças de superfície

$$
\begin{array}{r}
u_{i}(\xi)=\phi^{l}(\xi) u_{i}^{l} \\
t_{i}(\xi)=\phi^{l}(\xi) t_{i}^{l}
\end{array}
$$

Finalmente, introduzindo as funções de aproximação para geometria, deslocamentos e forças de superfície podemos reescrever as equações (5.1a) e (5.1b)

$$
\begin{aligned}
& \frac{1}{2} \phi^{l}\left(\xi^{\prime}\right) u_{k}^{l}+\sum_{s=1}^{N}\left[f_{\Gamma_{s}} \phi^{l}(\xi) u_{i}^{l} T_{k i}^{*}\left(\xi^{\prime}, \xi\right) d \Gamma\right]=\sum_{s=1}^{N}\left[f_{\Gamma_{s}} \phi^{l}(\xi) t_{i}^{l} U_{k i}^{*}\left(\xi^{\prime}, \xi\right) d \Gamma\right] \\
& \frac{1}{2} \phi^{l}\left(\xi^{\prime}\right) t_{k}^{l}+n_{j}\left(z^{\prime}\right) \sum_{s=1}^{N}\left[f_{\Gamma_{s}} \phi^{l}(\xi) u_{i}^{l} S_{k i j}^{*}\left(\xi^{\prime}, \xi\right) d \Gamma\right]=n_{j}\left(z^{\prime}\right) \sum_{s=1}^{N}\left[f_{\Gamma_{s}} \phi^{l}(\xi) t_{i}^{l} D_{k i j}^{*}\left(\xi^{\prime}, \xi\right) d \Gamma\right](5.10
\end{aligned}
$$

Brebbia e Dominguez (1992) ao descrever o emprego de elementos descontínuos muitas vezes são erroneamente interpretados e cria-se a ilusão que para se discretizar descontinuidades as funções de forma dos elementos precisam ser alteradas. Esse erro de conceito fica ainda mais evidente quando se discute a formulação em forças de superfície onde os pesquisadores, em geral, confundem a utilização de elementos descontínuos com as condições de continuidade do integrando.

A técnica de alterar as funções de forma dos elementos, nada mais é do que um "atalho" para lidar com o inconveniente de ter que se calcular a contribuição do termo livre em cada nó do elemento. Observe que o termo livre pode ser escrito em termos das funções de forma. Escrevendo o termo livre desta forma, pode-se utilizar elementos contínuos até mesmo para a formulação em força de superfície uma vez que o ponto fonte pode estar em qualquer ponto dentro do contorno do elemento.

\subsection{Método da Subtração de Singularidade}

O método da subtração de singularidade baseia-se na existência de integrais singulares que podem ser analiticamente avaliadas. 
No método da subtração de singularidade termos com o mesmo comportamento singular do integrando na singularidade são subtraídos da integral que estamos interessados em avaliar, resultando em uma diferença de integrandos que agora é regular e pode ser integrada numericamente. O termo singular subtraído é, então, analiticamente integrado e adicionado novamente ao resultado da integral regular:

$$
\int_{-1}^{1} K(t, s) f(s) d s=\underbrace{\int_{-1}^{1} K(t, s)[f(s)-f(t)] d s}_{\begin{array}{c}
\text { Integrado } \\
\text { numericamente }
\end{array}}+\underbrace{\int_{-1}^{1} K(t, s) f(t) d s}_{\begin{array}{c}
\text { Integrado } \\
\text { analiticamente }
\end{array}}-1 \leq t \leq 1
$$

Em que $K(t, s)$ é uma função com singularidade em $s=t, f(s)$ é uma função regular dentro do intervalo de integração e $f(t)$ é a função $f(s)$ avaliada em $s=t$.

Anselone (2009) apresenta o método do ponto de vista matemático, enquanto Sládek e Sladek (1998) apresentam o mesmo trabalho do ponto de vista físico. Outros trabalhos desenvolvidos sobre o tema podem ser encontrados em Kzam (2009), Wrobel e Aliabadi (2002), Khayat e Wilton (2005) e Delves e Mohamed (1988).

\subsubsection{Singularidades do Tipo $\ln |r|$}

Considere a integral

$$
f_{-1}^{1} \phi^{l}(\xi) t_{i}^{l} U_{k i}^{*}\left(\xi^{\prime}, \xi\right) J(\xi) d \xi
$$

Em que $\phi^{l}(\xi)$ e $J(\xi)$ são funções regulares e $U_{k i}^{*}\left(\xi^{\prime}, \xi\right)$ apresenta singularidade em $\xi=\xi^{\prime}$.

Pode-se proceder com a regularização desta integral aplicando o método da subtração da singularidade

$$
\begin{aligned}
f_{-1}^{1} \phi^{l}(\xi) t_{i}^{l} U_{k i}^{*}\left(\xi^{\prime}, \xi\right) J(\xi) d \xi= & t_{i}^{l} \int_{-1}^{1} U_{k i}^{*}\left(\xi^{\prime}, \xi\right)\left[\phi^{l}(\xi) J(\xi)-\phi^{l}\left(\xi^{\prime}\right) J\left(\xi^{\prime}\right)\right] d \xi \\
& +\phi^{l}\left(\xi^{\prime}\right) t_{i}^{l} J\left(\xi^{\prime}\right) f_{-1}^{1} U_{k i}^{*}\left(\xi^{\prime}, \xi\right) d \xi
\end{aligned}
$$

Em que $\phi^{l}\left(\xi^{\prime}\right)$ e $J\left(\xi^{\prime}\right)$ são as funções regulares avaliadas em $\xi=\xi^{\prime}$.

A primeira integral da equação (5.13), agora regular, pode ser integrada numericamente e a 
segunda integral pode ser avaliada analiticamente no sentido do valor principal de Cauchy

$$
\begin{aligned}
f_{-1}^{1} U_{k i}^{*}\left(\xi^{\prime}, \xi\right) d \xi= & f_{-1}^{1} 2 \operatorname{Re}\left[q_{i 1} A_{k 1} \ln \left(J\left(\xi^{\prime}\right)\left|\xi-\xi^{\prime}\right|\left(t_{1}\left(\xi^{\prime}\right)+\mu_{1} t_{2}\left(\xi^{\prime}\right)\right)\right)\right] d \xi \\
& +f_{-1}^{1} 2 \operatorname{Re}\left[q_{i 2} A_{k 2} \ln \left(J\left(\xi^{\prime}\right)\left|\xi-\xi^{\prime}\right|\left(t_{1}\left(\xi^{\prime}\right)+\mu_{2} t_{2}\left(\xi^{\prime}\right)\right)\right)\right] d \xi
\end{aligned}
$$

Em que $t_{1}\left(\xi^{\prime}\right)$ e $t_{2}\left(\xi^{\prime}\right)$ são os valores da tangente ao elemento nas direções de $x_{1}$ e $x_{2}$, respectivamente, avaliados em $\xi=\xi^{\prime}$.

Pode-se resolver esta integral analiticamente conforme demonstra Davis et al. (2007). Utilizando a transformação de coordenadas, $\epsilon=\xi-\xi^{\prime}$, tem-se

$$
\begin{aligned}
& f_{-1-\xi^{\prime}}^{1-\xi^{\prime}} 2 \operatorname{Re}\left[q_{i 1} A_{k 1} \ln \left(J\left(\xi^{\prime}\right)|\epsilon|\left(t_{1}\left(\xi^{\prime}\right)+\mu_{1} t_{2}\left(\xi^{\prime}\right)\right)\right)\right] d \epsilon \\
& \quad+f_{-1-\xi^{\prime}}^{1-\xi^{\prime}} 2 \operatorname{Re}\left[q_{i 2} A_{k 2} \ln \left(J\left(\xi^{\prime}\right)|\epsilon|\left(t_{1}\left(\xi^{\prime}\right)+\mu_{2} t_{2}\left(\xi^{\prime}\right)\right)\right)\right] d \epsilon
\end{aligned}
$$

Expressando a integral da equação (5.15) em termos de um limite onde exclui-se uma parte infinitesimal do intervalo de integração contendo $\xi=\xi^{\prime}$, tem-se

$$
\begin{aligned}
\lim _{\Delta \rightarrow 0}\left\{f_{-1-\xi^{\prime}}^{-\Delta} 2 \operatorname{Re}\left[q_{i 1} A_{k 1} \ln \left(J\left(\xi^{\prime}\right)|\epsilon|\left(t_{1}\left(\xi^{\prime}\right)+\mu_{1} t_{2}\left(\xi^{\prime}\right)\right)\right)\right] d \epsilon\right. \\
+f_{-1-\xi^{\prime}}^{-\Delta} 2 \operatorname{Re}\left[q_{i 2} A_{k 2} \ln \left(J\left(\xi^{\prime}\right)|\epsilon|\left(t_{1}\left(\xi^{\prime}\right)+\mu_{2} t_{2}\left(\xi^{\prime}\right)\right)\right)\right] d \epsilon \\
\quad+f_{+\Delta}^{1-\xi^{\prime}} 2 \operatorname{Re}\left[q_{i 1} A_{k 1} \ln \left(J\left(\xi^{\prime}\right)|\epsilon|\left(t_{1}\left(\xi^{\prime}\right)+\mu_{1} t_{2}\left(\xi^{\prime}\right)\right)\right)\right] d \epsilon \\
\left.\quad+f_{+\Delta}^{1-\xi^{\prime}} 2 \operatorname{Re}\left[q_{i 2} A_{k 2} \ln \left(J\left(\xi^{\prime}\right)|\epsilon|\left(t_{1}\left(\xi^{\prime}\right)+\mu_{2} t_{2}\left(\xi^{\prime}\right)\right)\right)\right] d \epsilon\right\}
\end{aligned}
$$

Integrando as duas parcelas

$$
\begin{aligned}
\lim _{\Delta \rightarrow 0}\left\{2 \operatorname { R e } \left[\left.\left(q_{i 1} A_{k 1} \ln \left(J\left(\xi^{\prime}\right)|\epsilon|\left(t_{1}\left(\xi^{\prime}\right)+\mu_{1} t_{2}\left(\xi^{\prime}\right)\right)\right)-q_{i 1} A_{k 1} \epsilon\right)\right|_{-1-\xi^{\prime}} ^{-\Delta}\right.\right. \\
+\left.\left(q_{i 2} A_{k 2} \ln \left(J\left(\xi^{\prime}\right)|\epsilon|\left(t_{1}\left(\xi^{\prime}\right)+\mu_{2} t_{2}\left(\xi^{\prime}\right)\right)\right)-q_{i 2} A_{k 2} \epsilon\right)\right|_{-1-\xi^{\prime}} ^{-\Delta} \\
+\left.\left(q_{i 1} A_{k 1} \ln \left(J\left(\xi^{\prime}\right)|\epsilon|\left(t_{1}\left(\xi^{\prime}\right)+\mu_{1} t_{2}\left(\xi^{\prime}\right)\right)\right)-q_{i 1} A_{k 1} \epsilon\right)\right|_{+\Delta} ^{1-\xi^{\prime}} \\
\left.\left.\quad+\left.\left(q_{i 2} A_{k 2} \ln \left(J\left(\xi^{\prime}\right)|\epsilon|\left(t_{1}\left(\xi^{\prime}\right)+\mu_{2} t_{2}\left(\xi^{\prime}\right)\right)\right)-q_{i 2} A_{k 2} \epsilon\right)\right|_{+\Delta} ^{1-\xi^{\prime}}\right]\right\}
\end{aligned}
$$

Por fim, temos

$$
f_{-1}^{1} U_{k i}^{*}\left(\xi^{\prime}, \xi\right) d \xi=2 \operatorname{Re}\left[q_{i 1} A_{k 1}\left(V P C_{1}\right)+q_{i 2} A_{k 2}\left(V P C_{2}\right)\right]
$$


Em que

$$
\begin{aligned}
V P C_{1}= & \left(1+\xi^{\prime}\right) \ln \left(J\left(\xi^{\prime}\right)\left(1+\xi^{\prime}\right)\left(t_{1}\left(\xi^{\prime}\right)+\mu_{1} t_{2}\left(\xi^{\prime}\right)\right)\right) \\
& +\left(1-\xi^{\prime}\right) \ln \left(J\left(\xi^{\prime}\right)\left(1-\xi^{\prime}\right)\left(t_{1}\left(\xi^{\prime}\right)+\mu_{1} t_{2}\left(\xi^{\prime}\right)\right)\right)-\left[\left(1+\xi^{\prime}\right)+\left(1-\xi^{\prime}\right)\right] \\
V P C_{2}= & \left(1+\xi^{\prime}\right) \ln \left(J\left(\xi^{\prime}\right)\left(1+\xi^{\prime}\right)\left(t_{1}\left(\xi^{\prime}\right)+\mu_{2} t_{2}\left(\xi^{\prime}\right)\right)\right) \\
& +\left(1-\xi^{\prime}\right) \ln \left(J\left(\xi^{\prime}\right)\left(1-\xi^{\prime}\right)\left(t_{1}\left(\xi^{\prime}\right)+\mu_{2} t_{2}\left(\xi^{\prime}\right)\right)\right)-\left[\left(1+\xi^{\prime}\right)+\left(1-\xi^{\prime}\right)\right]
\end{aligned}
$$

\subsubsection{Singularidades do Tipo $|r|^{-1}$}

Considere a integral

$$
f_{-1}^{1} \phi^{l}(\xi) t_{i}^{l} T_{k i}^{*}\left(\xi^{\prime}, \xi\right) J(\xi) d \xi
$$

Em que $\phi^{l}(\xi)$ e $J(\xi)$ são funções regulares e $T_{k i}^{*}\left(\xi^{\prime}, \xi\right)$ apresenta singularidade em $\xi=\xi^{\prime}$.

Pode-se proceder com a regularização desta integral aplicando o método da subtração da singularidade, exatamente como feito para a regularização da integral com singularidade do tipo $\ln |r|$.

$$
\begin{aligned}
f_{-1}^{1} \phi^{l}(\xi) & u_{i}^{l} T_{k i}^{*}\left(\xi^{\prime}, \xi\right) J(\xi) d \xi \\
= & u_{i}^{l} \int_{-1}^{1} T_{k i}^{*}\left(\xi^{\prime}, \xi\right)\left[\phi^{l}(\xi) J(\xi)-\phi^{l}\left(\xi^{\prime}\right) J\left(\xi^{\prime}\right)\right] d \xi \\
& \quad+\phi^{l}\left(\xi^{\prime}\right) u_{i}^{l} J\left(\xi^{\prime}\right) f_{-1}^{1} T_{k i}^{*}\left(\xi^{\prime}, \xi\right) d \xi
\end{aligned}
$$

Em que $\phi^{l}\left(\xi^{\prime}\right)$ e $J\left(\xi^{\prime}\right)$ são as funções regulares avaliadas em $\xi=\xi^{\prime}$.

Desta forma, tem-se a primeira integral regular, e a segunda integral que será integrada analiticamente

$$
\begin{aligned}
f_{-1}^{1} & T_{k i}^{*}\left(\xi^{\prime}, \xi\right) d \xi \\
= & f_{-1}^{1} 2 \operatorname{Re}\left[\frac{1}{J\left(\xi^{\prime}\right)\left|\xi-\xi^{\prime}\right|\left(t_{1}\left(\xi^{\prime}\right)+\mu_{1} t_{2}\left(\xi^{\prime}\right)\right)} g_{i 1} A_{k 1}\left(\mu_{1} n_{1}\left(\xi^{\prime}\right)-n_{2}\left(\xi^{\prime}\right)\right)\right] d \xi \\
& \quad+f_{-1}^{1} 2 \operatorname{Re}\left[\frac{1}{J\left(\xi^{\prime}\right)\left|\xi-\xi^{\prime}\right|\left(t_{1}\left(\xi^{\prime}\right)+\mu_{2} t_{2}\left(\xi^{\prime}\right)\right)} g_{i 2} A_{k 2}\left(\mu_{2} n_{1}\left(\xi^{\prime}\right)-n_{2}\left(\xi^{\prime}\right)\right)\right] d \xi
\end{aligned}
$$

Em que $n_{1}\left(\xi^{\prime}\right)$ e $n_{2}\left(\xi^{\prime}\right)$ são os valores da normal ao elemento nas direções de $x_{1}$ e $x_{2}$, respectivamente, avaliados em $\xi=\xi^{\prime}$. 
De forma análoga ao realizado na Seção 5.2.1, tem-se

$$
\begin{aligned}
f_{-1}^{1} T_{k i}^{*}\left(\xi^{\prime}, \xi\right) d \xi \\
=2 \operatorname{Re}\left[\frac{V P C}{J\left(\xi^{\prime}\right)\left(t_{1}\left(\xi^{\prime}\right)+\mu_{1} t_{2}\left(\xi^{\prime}\right)\right)} g_{i 1} A_{k 1}\left(\mu_{1} n_{1}\left(\xi^{\prime}\right)-n_{2}\left(\xi^{\prime}\right)\right)\right. \\
\left.\quad+\frac{V P C}{J\left(\xi^{\prime}\right)\left(t_{1}\left(\xi^{\prime}\right)+\mu_{2} t_{2}\left(\xi^{\prime}\right)\right)} g_{i 2} A_{k 2}\left(\mu_{2} n_{1}\left(\xi^{\prime}\right)-n_{2}\left(\xi^{\prime}\right)\right)\right]
\end{aligned}
$$

Em que

$$
V P C=\ln \left(1-\xi^{\prime}\right)-\ln \left(1+\xi^{\prime}\right)
$$

\subsubsection{Singularidades do Tipo $|r|^{-2}$}

Por fim, considere a integral hipersingular

$$
n_{j}\left(\xi^{\prime}\right) f_{-1}^{1} \phi^{l}(\xi) u_{i}^{l} S_{k i j}^{*}\left(\xi^{\prime}, \xi\right) J(\xi) d \xi
$$

Em que $\phi^{l}(\xi)$ e $J(\xi)$ são funções regulares e $S_{k i j}^{*}\left(\xi^{\prime}, \xi\right)$ apresenta singularidade em $\xi=\xi^{\prime}$.

Sládek e Sladek (1998) provam que é possível regularizar a integral hipersingular subtraindo do integrando a expansão em série de Taylor até o segundo termo

$$
\begin{aligned}
& n_{j}\left(\xi^{\prime}\right) f_{-1}^{1} \phi^{l}(\xi) u_{i}^{l} \frac{\bar{S}_{k i j}^{*}(\xi)}{\left(z-z^{\prime}\right)^{2}} J(\xi) d \xi \\
& =n_{j}\left(\xi^{\prime}\right) u_{i}^{l} \int_{-1}^{1}\left[\frac{\bar{S}_{k i j}^{*}(\xi)}{\left(z-z^{\prime}\right)^{2}} \phi^{l}(\xi) J(\xi)-\frac{\bar{S}_{k i j}^{*}\left(\xi^{\prime}\right)}{\left(z-z^{\prime}\right)^{2}} \phi^{l}\left(\xi^{\prime}\right) J\left(\xi^{\prime}\right)-\frac{\bar{S}_{k i j}^{*}\left(\xi^{\prime}\right)}{\left(z-z^{\prime}\right)} \phi_{, \xi}^{l}\left(\xi^{\prime}\right) J\left(\xi^{\prime}\right)\right] d \xi \\
& \quad+n_{j}\left(\xi^{\prime}\right) u_{i}^{l} \phi^{l}\left(\xi^{\prime}\right) J\left(\xi^{\prime}\right) f_{-1}^{1} \frac{\bar{S}_{k i j}^{*}\left(\xi^{\prime}\right)}{\left(z-z^{\prime}\right)^{2}} d \xi \\
& \quad+n_{j}\left(\xi^{\prime}\right) u_{i}^{l} \phi_{, \xi}^{l}\left(\xi^{\prime}\right) J\left(\xi^{\prime}\right) f_{-1}^{1} \frac{\bar{S}_{k i j}^{*}\left(\xi^{\prime}\right)}{\left(z-z^{\prime}\right)} d \xi
\end{aligned}
$$

Em que $\phi_{, \xi}^{l}\left(\xi^{\prime}\right)$ é a derivada da função de forma em relação a $\xi$ avaliada em $\xi=\xi^{\prime}$.

Desta forma, tem-se a primeira integral regular, a segunda e terceira integrais que serão integradas analiticamente no sentido da parte finita de Hadamard e valor principal de Cauchy, respec- 
tivamente. Comecemos pela segunda integral

$$
\begin{aligned}
& n_{j}\left(\xi^{\prime}\right) u_{i}^{l} \phi^{l}\left(\xi^{\prime}\right) J\left(\xi^{\prime}\right) f_{-1}^{1} \frac{\bar{S}_{k i j}^{*}\left(\xi^{\prime}\right)}{\left(z-z^{\prime}\right)^{2}} d \xi \\
&=-n_{j}\left(\xi^{\prime}\right) u_{i}^{l} \phi^{l}\left(\xi^{\prime}\right) J\left(\xi^{\prime}\right) C_{k j l m} \\
& \times\left\{f_{-1}^{1} \operatorname{Re}\left[\frac{\left(\mu_{1} n_{1}\left(\xi^{\prime}\right)-n_{2}\left(\xi^{\prime}\right)\right)}{\left(J\left(\xi^{\prime}\right)\left|\xi-\xi^{\prime}\right|\left(t_{1}\left(\xi^{\prime}\right)+\mu_{1} t_{2}\left(\xi^{\prime}\right)\right)\right)^{2}}\left(R_{l 1} g_{i 1} A_{m 1}+R_{m 1} g_{i 1} A_{l 1}\right)\right] d \xi\right. \\
&\left.+f_{-1}^{1} \operatorname{Re}\left[\frac{\left(\mu_{2} n_{1}\left(\xi^{\prime}\right)-n_{2}\left(\xi^{\prime}\right)\right)}{\left(J\left(\xi^{\prime}\right)\left|\xi-\xi^{\prime}\right|\left(t_{1}\left(\xi^{\prime}\right)+\mu_{2} t_{2}\left(\xi^{\prime}\right)\right)\right)^{2}}\left(R_{l 2} g_{i 2} A_{m 2}+R_{m 2} g_{i 2} A_{l 2}\right)\right] d \xi\right\}
\end{aligned}
$$

De forma análoga ao realizado na Seção 5.2.1, tem-se

$$
\begin{aligned}
n_{j}\left(\xi^{\prime}\right) u_{i}^{l} \phi^{l}\left(\xi^{\prime}\right) J\left(\xi^{\prime}\right) f_{-1}^{1} \frac{\bar{S}_{k i j}^{*}\left(\xi^{\prime}\right)}{\left(z-z^{\prime}\right)^{2}} d \xi \\
=-n_{j}\left(\xi^{\prime}\right) u_{i}^{l} \phi^{l}\left(\xi^{\prime}\right) C_{k j l m} P F H \\
\times \operatorname{Re}\left[\frac{\left(\mu_{1} n_{1}\left(\xi^{\prime}\right)-n_{2}\left(\xi^{\prime}\right)\right)}{J\left(\xi^{\prime}\right)\left(t_{1}\left(\xi^{\prime}\right)+\mu_{1} t_{2}\left(\xi^{\prime}\right)\right)^{2}}\left(R_{l 1} g_{i 1} A_{m 1}+R_{m 1} g_{i 1} A_{l 1}\right)\right. \\
\left.+\frac{\left(\mu_{2} n_{1}\left(\xi^{\prime}\right)-n_{2}\left(\xi^{\prime}\right)\right)}{J\left(\xi^{\prime}\right)\left(t_{1}\left(\xi^{\prime}\right)+\mu_{2} t_{2}\left(\xi^{\prime}\right)\right)^{2}}\left(R_{l 2} g_{i 2} A_{m 2}+R_{m 2} g_{i 1} A_{l 2}\right)\right]
\end{aligned}
$$

Em que

$$
P F H=-\left[\frac{1}{\left(1-\xi^{\prime}\right)}+\frac{1}{\left(1+\xi^{\prime}\right)}\right]
$$

Da Seção 5.2.2 é fácil perceber que a terceira integral resultará em

$$
\begin{aligned}
& n_{j}\left(\xi^{\prime}\right) u_{i}^{l} \phi_{, \xi}^{l}\left(\xi^{\prime}\right) J\left(\xi^{\prime}\right) f_{-1}^{1} \frac{\bar{S}_{k i j}^{*}\left(\xi^{\prime}\right)}{\left(z-z^{\prime}\right)} d \xi \\
&=- n_{j}\left(\xi^{\prime}\right) u_{i}^{l} \phi_{, \xi}^{l}\left(\xi^{\prime}\right) C_{k j l m} V P C \\
& \quad \times \operatorname{Re}\left[\frac{\left(\mu_{1} n_{1}\left(\xi^{\prime}\right)-n_{2}\left(\xi^{\prime}\right)\right)}{\left(t_{1}\left(\xi^{\prime}\right)+\mu_{1} t_{2}\left(\xi^{\prime}\right)\right)}\left(R_{l 1} g_{i 1} A_{m 1}+R_{m 1} g_{i 1} A_{l 1}\right)\right. \\
&\left.\quad+\frac{\left(\mu_{2} n_{1}\left(\xi^{\prime}\right)-n_{2}\left(\xi^{\prime}\right)\right)}{\left(t_{1}\left(\xi^{\prime}\right)+\mu_{2} t_{2}\left(\xi^{\prime}\right)\right)}\left(R_{l 2} g_{i 2} A_{m 2}+R_{m 2} g_{i 2} A_{l 2}\right)\right]
\end{aligned}
$$

Em que

$$
V P C=\ln \left(1-\xi^{\prime}\right)-\ln \left(1+\xi^{\prime}\right)
$$

É importante observar que as equações (5.13), (5.21) e (5.26) são regulares e podem ser numericamente integradas. Para efeitos de demonstração, estas equações são avaliadas analiticamente no Apêndice B para o caso particular de elementos lineares. Observa-se que as expressões tornam-se 
demasiadamente longas e perdem sua generalidade, reforçando a necessidade de se utilizar uma quadratura numérica.

A Figura (5.6) ilustra o processo de regularização com as curvas de cada um dos integrandos da primeira integral do lado direito da equação (5.26), para um elemento isotrópico com $E=1.0 \mathrm{MPa}$, $\nu=0.4$, coordenadas dos nós $(0,0),(1,1),(2,0)$ e $(3,1)$, e singularidade em $\xi^{\prime}=0.3$.

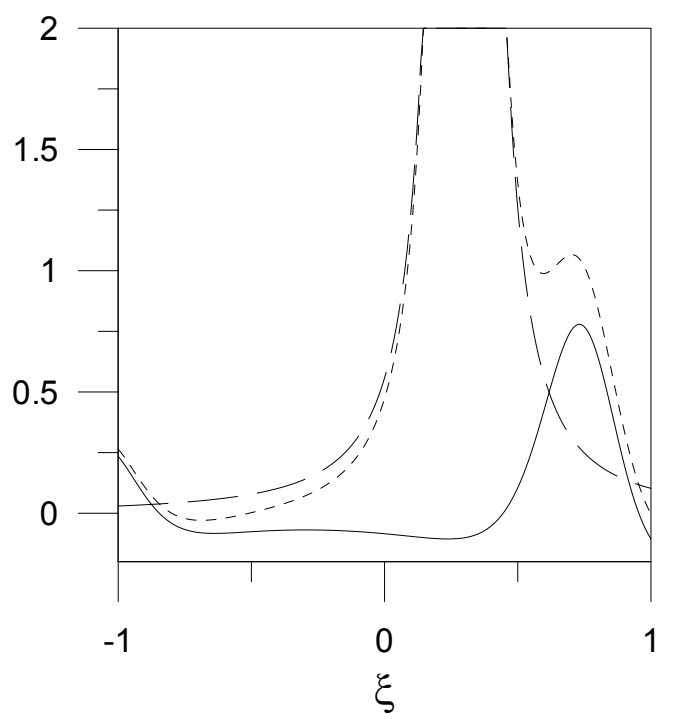

Figura 5.6: Processo de regularização com o integrando regularizado (—— ), o primeiro termo da série de Taylor (_- - ) e o integrando singular (-----).

\subsection{Integração Numérica}

Com a generalização do grau de aproximação do elemento isoparamétrico, a integração analítica das integrais regularizadas torna-se impraticável ou impossível. Em tal situação é necessário usar alguma técnica de integração numérica.

Segundo Scarborough (1930) a quadratura de uso corrente mais precisa é a quadratura de Gauss. Uma fórmula de Gauss particular é obtida com a escolha de determinado intervalo de integração. O método conhecido por quadratura de Gauss-Legendre é aquele no qual o intervalo de integração é $[-1,1]$, então a quadratura aproxima a integral

$$
\int_{-1}^{1} f(\xi) d \xi \approx \sum_{i=1}^{n} w_{i} f\left(\xi_{i}\right)
$$

Se o $f(\xi)$ é um polinômio de ordem $2 n-1$, então a quadratura de Gauss será exata para $n$ pontos de integração. Caso contrário, a quadratura será inexata, mas será tão mais precisa quantos forem os pontos de Gauss utilizados. 
Uma vez que as integrais de contorno foram regularizadas pelo método de subtração de singularidade podemos então avaliá-las utilizando a quadratura de Gauss.

No entanto, ainda temos que lidar com o boundary layer effect, situação que ocorre quando avaliamos uma grandeza no interior do domínio próxima ao contorno. Neste caso, a singularidade dos núcleos das integrais está num ponto onde não pertence ao caminho de integração, mas pode estar muito perto dele. Tais integrais são denominadas integrais quase-singulares. Este tipo de integral é computacionalmente cara de se avaliar através de quadraturas comuns, uma vez que o integrando, apesar de regular, varia muito rapidamente no intervalo de integração. Nestes casos, adotou-se a transformação cúbica proposta por Telles (1987) e aperfeiçoado por Telles e Oliveira (1994).

A idéia desta transformação é aproximar da singularidade os pontos de Gauss à medida que o ponto fonte se aproxima do contorno. Considere uma integral quase-singular que se quer integrar sobre o elemento de contorno da Figura (5.7) aplicando a transformação de coordenadas

$$
\eta(\xi)=a \xi^{3}+b \xi^{2}+c \xi+d
$$

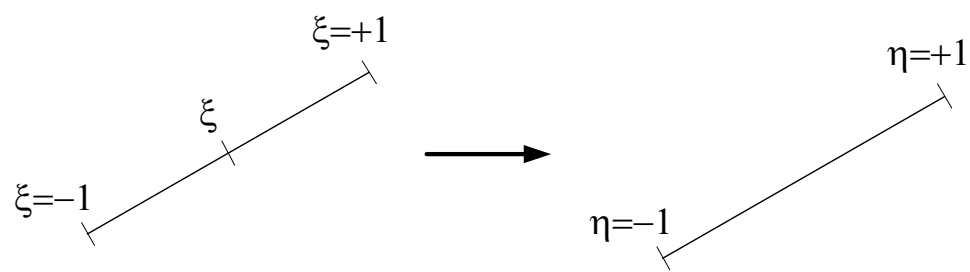

Figura 5.7: Transformação cúbica de coordenadas.

Desta forma tem-se

$$
\int_{-1}^{1} f(\xi) d \xi=\int_{-1}^{1} f(\eta) J(\eta) d \eta
$$

Para determinar as constantes da equação (5.33) pode-se impor as condições de contorno

$$
\begin{gathered}
\eta(1)=1 \\
\eta(-1)=-1 \\
\left.\frac{\mathrm{d} \eta}{\mathrm{d} \xi}\right|_{\xi^{\prime}}=r \\
\left.\frac{\mathrm{d}^{2} \eta}{\mathrm{d} \xi^{2}}\right|_{\xi^{\prime}}=0
\end{gathered}
$$


Em que $\xi^{\prime}$ é a coordenada adimensional correspondente a $R_{\min }$.

As duas primeiras condições são imediatas a fim de manter o intervalo de integração original. A quarta condição impõe que o jacobiano em $\xi^{\prime}$ tenha valor mínimo. Por fim, a terceira condição determina que o jacobiano desta transformação cúbica seja igual ao parâmetro adimensional $r$ que varia no intervalo de $[0,1]$ em função de $R_{\text {min }}$. Ou seja, quando o ponto fonte estiver bem próximo do contorno teremos $r=0$ e o jacobiano desta transformação, idealmente, reduzirá a ordem de singularidade em $\xi^{\prime}$. Por outro lado, se o ponto fonte estiver longe do contorno, $r=1$, a transformação de coordenadas será degenerada e resultará simplesmente na equação original (5.34).

Na Figura (5.8) ilustra-se o processo de transformação não-linear de coordenadas, em que as abscissas representam o domínio do elemento, $\xi= \pm 1$, e as ordenadas representam os pesos da integração numérica. Observa-se que a transformação não-linear de coordenadas envolve a alteração da posição dos pontos de integração à medida que o ponto fonte se aproxima do contorno, com singularidade em $\xi^{\prime}=0,50$, mantendo-se constantes os pesos da integração numérica.

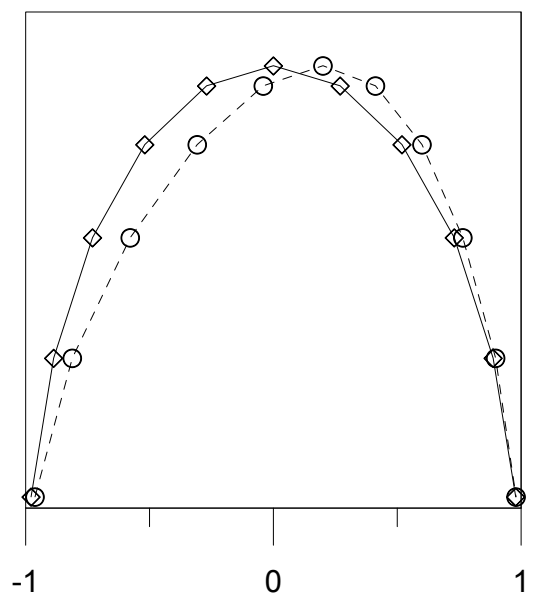

(a)

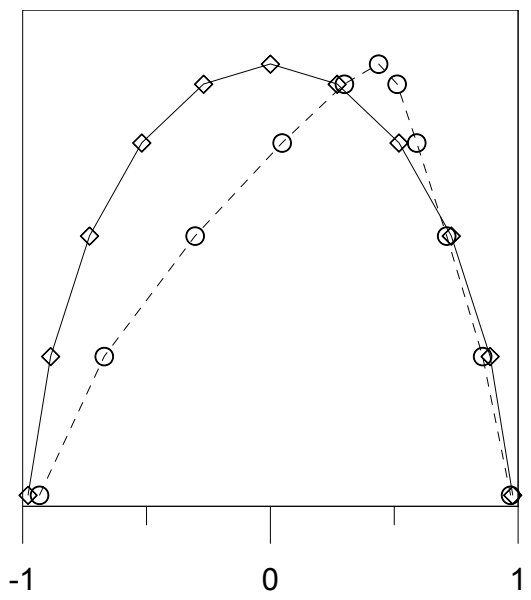

(c)

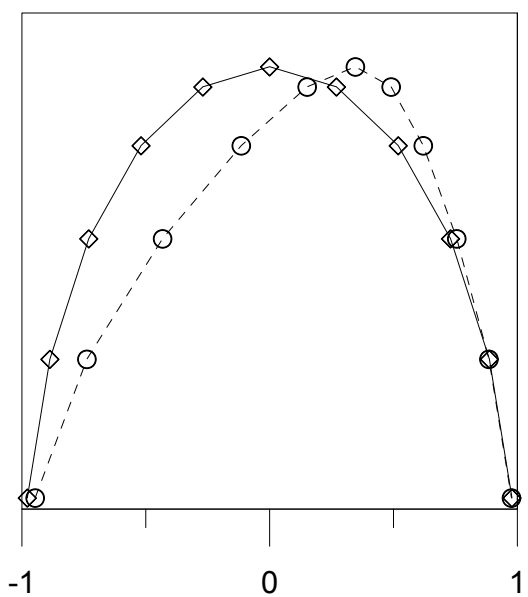

(b)

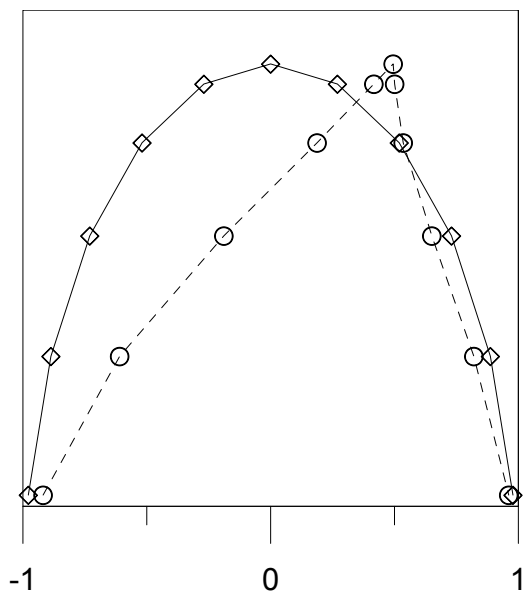

(d)

Figura 5.8: Pontos de integração de Gauss ( $\diamond)$ passando pela transformação de coordenadas (०) para singularidade em $\xi^{\prime}=0,50$ com: (a) $r=0,75$; (b) $r=0,50$; (c) $r=0,25$; e, (d) $r=0$. 
Este método é conhecido por transformação de coordenadas auto-adaptativo uma vez que automaticamente concentra próximo da singularidade os pontos de integração conforme o ponto fonte se aproxima do contorno.

\subsection{Sistema de Equações Algébricas}

Considere a formulação em deslocamento para o ponto fonte $k$ sobre o contorno

$$
\frac{1}{2} \phi^{l}\left(\xi^{\prime}\right) u_{k}^{l}+\sum_{s=1}^{N}\left[f_{\Gamma_{s}} \phi^{l}(\xi) u_{i}^{l} T_{k i}^{*}\left(\xi^{\prime}, \xi\right) d \Gamma\right]=\sum_{s=1}^{N}\left[f_{\Gamma_{s}} \phi^{l}(\xi) t_{i}^{l} U_{k i}^{*}\left(\xi^{\prime}, \xi\right) d \Gamma\right]
$$

Isto resulta em duas integrais que precisa-se resolver

$$
\begin{aligned}
H_{k i}^{l} & =\sum_{s=1}^{N}\left[f_{\Gamma_{s}} \phi^{l}(\xi) T_{k i}^{*}\left(\xi^{\prime}, \xi\right) d \Gamma\right] \\
G_{k i}^{l} & =\sum_{s=1}^{N}\left[f_{\Gamma_{s}} \phi^{l}(\xi) U_{k i}^{*}\left(\xi^{\prime}, \xi\right) d \Gamma\right]
\end{aligned}
$$

Estas integrais resultam da influência de algum nó $i$ na solução fundamental no ponto fonte $k$ e por isso são chamadas de coeficientes de influência.

$$
\frac{1}{2} \phi^{l}\left(\xi^{\prime}\right) u_{k}^{l}+H_{k i}^{l} u_{i}^{l}=G_{k i}^{l} t_{i}^{l}
$$

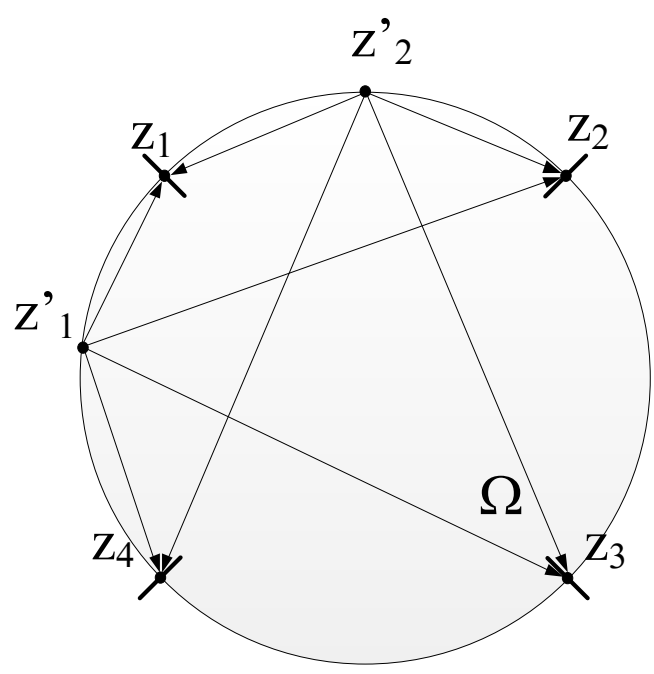

Figura 5.9: Geração das matrizes de influência.

Considerando que o deslocamento ou a força de superfície será prescrita em cada nó pelas condições de contorno, nós precisamos de $2 l$ equações (5.41). Isto é obtido movendo-se o ponto fonte $k$ sobre o contorno e avaliando sua influência em cada nó $i$ (Figura 5.9) que resulta no sistema 
matricial $H U=G Q$ em que $H$ e $G$ são, geralmente, matrizes quadradas $2 l \times 2 l$ e $U$ e $Q$ são vetores de comprimento $2 l$

$$
\left[\begin{array}{ccccccc}
H_{11}^{1} & H_{12}^{1} & H_{11}^{2} & H_{12}^{2} & \cdots & H_{11}^{l} & H_{12}^{l} \\
H_{21}^{1} & H_{22}^{1} & H_{21}^{2} & H_{22}^{2} & \cdots & H_{21}^{l} & H_{22}^{l} \\
H_{31}^{1} & H_{32}^{1} & H_{31}^{2} & H_{32}^{2} & \cdots & H_{31}^{l} & H_{32}^{l} \\
H_{41}^{1} & H_{42}^{1} & H_{41}^{2} & H_{42}^{2} & \cdots & H_{41}^{l} & H_{42}^{l} \\
\vdots & \vdots & \vdots & \vdots & \ddots & \vdots & \vdots \\
H_{k 1}^{1} & H_{k 2}^{1} & H_{k 1}^{2} & H_{k 2}^{2} & \cdots & H_{k 1}^{l} & H_{k 2}^{l}
\end{array}\right\}\left\{\begin{array}{c}
u_{1}^{1} \\
u_{2}^{1} \\
u_{1}^{2} \\
u_{2}^{2} \\
\vdots \\
u_{1}^{l} \\
u_{2}^{l}
\end{array}\right\}=\left[\begin{array}{ccccccc}
G_{11}^{1} & G_{12}^{1} & G_{11}^{2} & G_{12}^{2} & \cdots & G_{11}^{l} & G_{12}^{l} \\
G_{21}^{1} & G_{22}^{1} & G_{21}^{2} & G_{22}^{2} & \cdots & G_{21}^{l} & G_{22}^{l} \\
G_{31}^{1} & G_{32}^{1} & G_{31}^{2} & G_{32}^{2} & \cdots & G_{31}^{l} & G_{32}^{l} \\
G_{41}^{1} & G_{42}^{1} & G_{41}^{2} & G_{42}^{2} & \cdots & G_{41}^{l} & G_{42}^{l} \\
\vdots & \vdots & \vdots & \vdots & \ddots & \vdots & \vdots \\
G_{k 1}^{1} & G_{k 2}^{1} & G_{k 1}^{2} & G_{k 2}^{2} & \cdots & G_{k 1}^{l} & G_{k 2}^{l}
\end{array}\right]\left\{\begin{array}{c}
t_{1}^{1} \\
t_{2}^{1} \\
t_{1}^{2} \\
t_{2}^{2} \\
\vdots \\
t_{1}^{l} \\
t_{2}^{l}
\end{array}\right\}
$$

Essa formulação do problema deve ser rearranjada uma vez que os deslocamentos são prescritos em alguns nós e em outros temos a força de superfície prescrita. Para resolver este sistema linear de equações é necessário colocar todas as incógnitas do lado esquerdo da equação e os valores prescritos do lado direito. Por fim, tem-se o sistema linear de equações $A \cdot x=B$, que resulta nos valores de $u$ e $t$ para todos os pontos no contorno.

Uma vez conhecidos os valores de $u$ e $t$ no contorno, pode-se facilmente calcular os valores de deslocamento para qualquer ponto no domínio pelas equações

$$
u_{k}=G_{k i}^{l} t_{i}^{l}-H_{k i}^{l} u_{i}^{l}
$$

De forma similar, pode-se aplicar a formulação em deformação, em tensão e em forças de superfície para gerar as equações que encontrarão os valores de $u$ e $t$ para todos os pontos no contorno e também para avaliar estas grandezas no interior do domínio. 


\section{Capítulo 6}

\section{Implementação Computacional}

Neste capítulo discute-se superficialmente os conceitos e vantagens da programação orientada a objetos, os motivos que levaram à escolha da linguagem de programação Java e, por fim, expõe-se a estrutura geral do software desenvolvido através de um pseudo diagrama UML.

\subsection{Programação Orientada a Objetos}

A programação orientada a objetos (POO) nada mais é do que uma maneira de se escrever programas de forma mais parecida com o modo em que as pessoas pensam e lidam com o mundo real.

No antigo estilo de programação o programador devia pensar em uma sequência de instruções a serem executadas para resolver um problema. Na POO, ao invés de instruções, deve-se pensar em termos de objetos que interagem e cooperam entre si para resolver o problema. Este novo estilo de programação permite que o desenvolvimento do programa ocorra de forma mais natural e fácil de se alcançar o resultado desejado.

Os conceitos básicos do paradigma da POO são:

- Abstração. Na POO a complexidade do problema é administrada utilizando os conceitos da abstração. Abstração é o processo que envolve identificar a essência do comportamento de um objeto e eliminar detalhes irrelevantes. Por exemplo, imagine um software desenvolvido para calcular a média das notas de um aluno. Um objeto Aluno seria criado. Um aluno pode ter diferentes idades, tamanhos, cores e gostos. Mas em termos de um software para calcular seu desempenho acadêmico, um Aluno pode conter somente seu nome e nota, sendo as outras características irrelevantes para o propósito deste software. 
- Encapsulamento. Na POO objetos conversam entre si através de mensagens. A única coisa que um objeto conhece sobre outro objeto é sua interface. Cada objeto tem sua informação e lógica de funcionamento encapsulada e, claro, invisível a outros objetos. Este recurso permite separar a implementação de um objeto de seu comportamento. Para deixar claro este conceito, imagine um objeto que realiza a integração numérica de uma função qualquer. Ele recebe um objeto Função e os intervalos de integração, e retorna o resultado da integração. O usuário não precisa saber, necessariamente, qual o método de integração numérica foi implementado para poder utilizar este objeto.

- Herança. Herança é a habilidade de definir uma nova classe que herda o comportamento de uma classe existente. Por exemplo, um carro é um veículo. Assim como um barco ou uma bicicleta são um tipo de veículo. Na POO, a classe Veículo define propriedades e comportamentos comuns aos veículos. As subclasses de Veículo devem definir as propriedades e comportamentos específicos de cada subtipo de veículo. O entendimento deste conceito é fundamental para o desenvolvimento de um POO. No entanto, sua aplicação nem sempre é direta como pode parecer. Um círculo é um tipo de elipse? Um quadrado é um tipo de retângulo? A melhor forma de resolver questões como essas é por tentativa e erro buscando a melhor estrutura que representa um problema.

- Polimorfismo. Polimorfismo permite que dois ou mais objetos diferentes responderem a uma mesma mensagem. A vantagem do polimorfismo é que o objeto que envia a mensagem não precisa saber o tipo da classe que a recebe. O que envia a mensagem precisa somente saber que quem a recebe é capaz de realizar uma determinada tarefa com essa mensagem. Um exemplo de polimorfismo pode ser demonstrado com figuras geométricas. Suponha uma classe Triângulo, Retângulo e, outra, Elipse. Todas são um subtipo da classe Forma e todas tem um método area() que retorna o valor da área de cada objeto. Um objeto que esteja interessado somente no valor da área pode chamar o método area() de qualquer uma destas classes e ainda assim se manter ignorante ao tipo de forma com o qual esta trabalhando.

O emprego destes conceitos por si só não é suficiente para garantir um código reutilizável, expansível e passível de manutenção.

Uma das crenças mais nocivas ao se desenvolver um programa é acreditar que se a estrutura é bem projeta e o código bem escrito, ele não necessitará de documentação. A documentação é fundamental para que outros programadores possam utilizar e participar do seu desenvolvimento. 


\section{$6.2 \quad$ Java}

Ferreira (2008) apresenta uma excelente síntese das vantagens de Java:

1. Java é obrigatoriamente orientada a objetos;

2. Java é simples;

3. Java é portável;

4. Java é gratuita;

5. Java é robusta;

6. Java tem bibliotecas prontas para diversas aplicações.

Se somente o fato de Java ser obrigatoriamente orientada a objetos não for o suficiente para sua escolha, talvez o fato de possuir diversas bibliotecas prontas o seja.

A menos que este seja o objetivo do trabalho, hoje é inconcebível se escrever um algoritmo para encontrar as raízes de um polinômio de ordem qualquer. Commons Math: The Apache Commons Mathematics Library ${ }^{1}$ é apenas um exemplo de bibliotecas matemáticas para Java que supre, possivelmente, qualquer necessidade.

Uma provável explicação para não se escolher Java pode ser a existência de um extenso código em outra linguagem. Java Native Interface é uma biblioteca nativa que permite sua integração com qualquer outra linguagem.

\subsection{Implementação}

A Figura (6.1) apresenta a estrutura principal do programa desenvolvido. Tem-se uma classe Model que contém todas as informações referentes a geometria, material e condições de contorno do problema. A classe Assembler é responsável por montar as matrizes de influência para o Método dos Elementos de Contorno Dual. E a classe Solver lida com a solução do sistema linear do tipo $A \cdot x=b$.

Com a finalidade de destacar as possibilidades de manutenção e expansão do programa, detalhase cada componente da estrutura principal.

\footnotetext{
${ }^{1}$ Disponível em: http://commons.apache.org/math/
} 


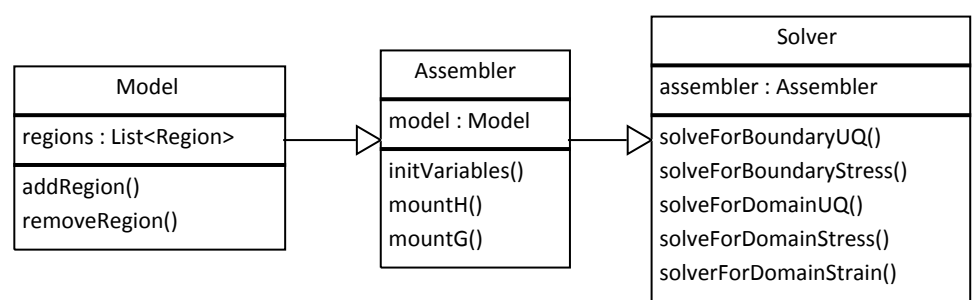

Figura 6.1: Estrutura principal do programa.

\subsubsection{Model}

O modelo contém uma lista de Region (Figura 6.2). Cada Region, região, possui uma lista de Element's que são os elementos que definem o seu contorno. Por sua vez, cada Element possui uma lista de Node's que são os nós do respectivo elemento. Cada Node herda de Point uma coordenada no espaço. Além da posição, Node possui um vetor deslocamento, um vetor força de superfície, uma matriz de deformações e outra de tensões.

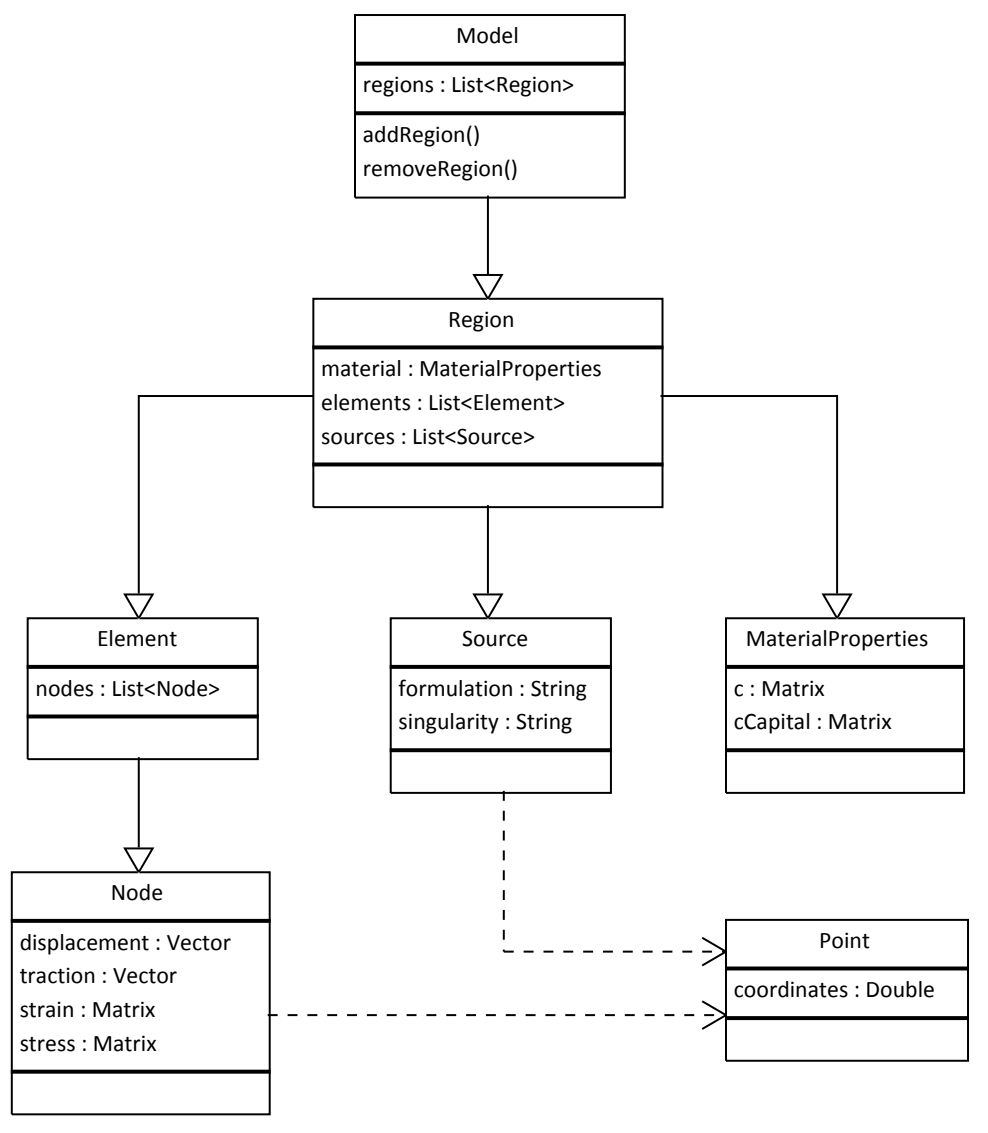

Figura 6.2: Estrutura do Model.

Observe que não há qualquer restrição para a quantidade de elementos que descrevem o contorno ou o número de nós em cada elemento. Ou seja, podemos ter uma região definida por um único elemento de 15 nós, ou 5 elementos de 3 nós, ou ainda 1 elemento de 5 nós e outro de 10 nós, ou qualquer outra combinação equivalente. 
Considera-se que em cada Region as propriedades elásticas sejam constantes, por isso, cada Region contem um único MaterialProperties. MaterialProperties possui duas matriz $3 \times 3$ suficientes para descrever os coeficientes elásticos de rigidez e flexibilidade do problema plano anisotrópico.

Por fim, Region possui uma lista de Source, que são os pontos fontes. Source é criado, a princípio, definindo-se somente sua formulação e posição. As formulações implementadas e possíveis de serem utilizadas são: Displacement; Traction; Strain; e, Stress. De acordo com a posição de Source, Region determina se ele está fora do domínio, sobre o contorno ou dentro do domínio. Caso ele esteja fora do domínio ou sobre o contorno, ele será utilizado para gerar equações e solucionar o problema com a formulação definida. Caso ele esteja dentro do domínio, ele será utilizado para avaliar a grandeza em seu ponto. Ou seja, um Source com formulação Displacement fora do domínio ou sobre o contorno, será utilizado para gerar equações que resolvam o problema em formulação de deslocamento, ou caso esteja dentro do domínio, ele fornecerá os deslocamentos no domínio naquele ponto.

\subsubsection{Assembler}

O Assembler é a parte responsável por montar as matrizes de influência (Figura 6.3). O processo começa com Assembler inicializando as variáveis e estados dos Nodes, Elements e Sources contidos em Model.

Caso o usuário tenha escolhido a solução do problema através de AssemblerSingleThread o fluxo continua com AssemblerSingleThread percorrendo as listas de Source, verificando qual a sua formulação e criando seu respectivo assembler para cada elemento da lista. Ou seja, o DisplacementAssembler, TractionAssembler, StrainAssembler e StressAssembler são responsáveis por gerar as matrizes de influência para um único elemento considerando um único ponto fonte. Após percorrer toda a lista de todos elementos para cada um dos pontos fontes, temos as matrizes de influência $\mathrm{H}$ e G.

O trecho de código abaixo esclarece o funcionamento de AssemblerSingleThread.

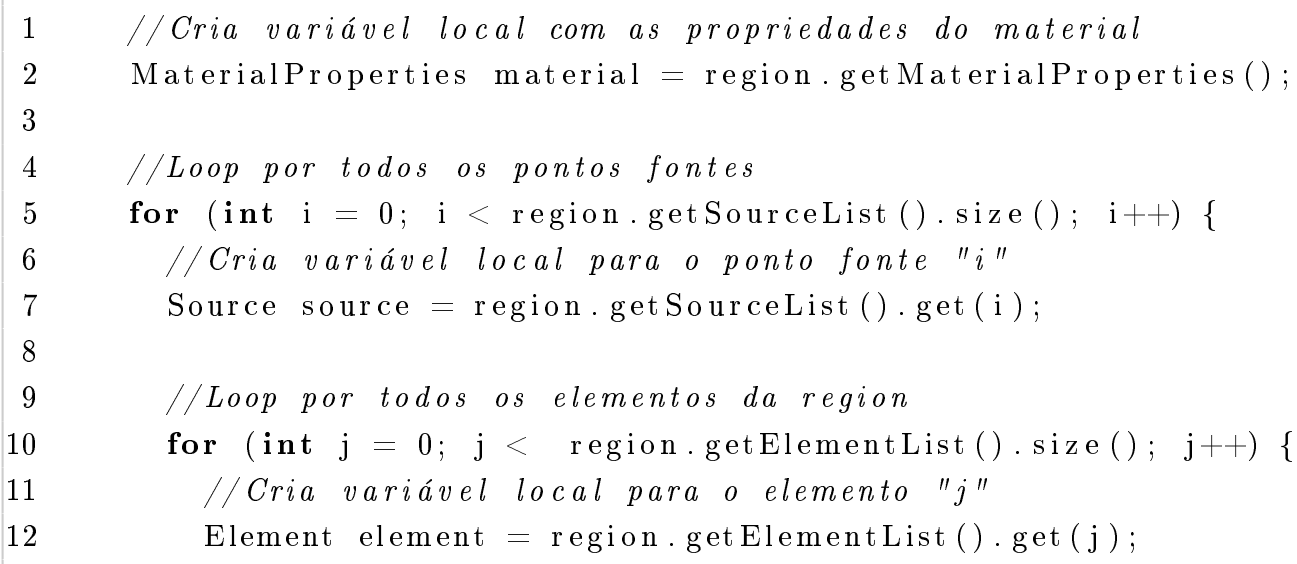



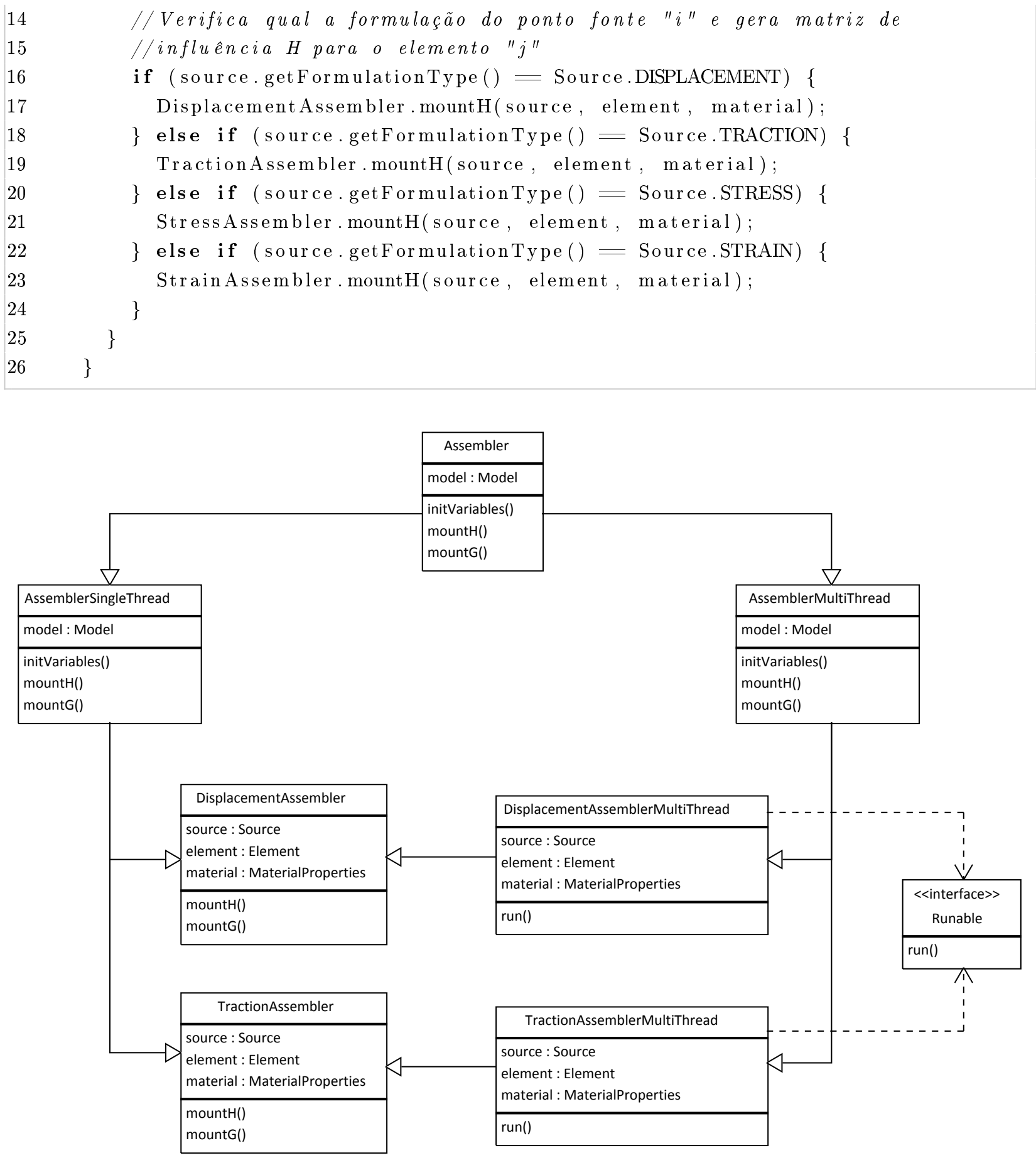

Figura 6.3: Estrutura do Assembler.

O que acontece na solução através do AssemblerMultiThread é que DisplacementAssemblerMultiThread, TractionAssemblerMultiThread, StrainAssemblerMultiThread e StressAssemblerMultiThread implementam a interface Runable da linguagem Java. Isso significa que cada vez que o comando run() é executado, ele cria uma Thread independente que executa os métodos de seu correspondente SingleThread. Em outras palavras, é como se fosse criado, em paralelo ao programa principal, um outro programa para cada combinação entre elemento e ponto fonte.

Essa técnica de processamento em paralelo apesar de parecer simples envolve o mesmo problema 
gerado em todas as técnicas: sincronização (Goetz et al., 2006). Imagine que cada Thread esta tentando escrever em uma mesma matriz ao mesmo tempo. É possível, e bastante provável, que em algum momento uma Thread sobrescreverá o resultado de uma outra Thread. Esse problema é resolvido sincronizando todas as Threads permitindo que apenas uma por vez consiga escrever na matriz. A Thread após terminar o processamento, fica aguardando na fila sua vez de descarregar os resultados. Isso, no entanto, não impede que o processamento em paralelo prossiga ou tenha seu desempenho reduzido.

Vale ressaltar que esta técnica, extremamente robusta e eficaz, só é possível devido a POO. Existem pacotes Open-Source, como o Grid Gain ${ }^{2}$, em Java que permitem com algumas poucas modificações gozar dos recursos de processamento distribuído. Ou seja, os problemas poderiam ser divididos e analisados em virtualmente infinitos processadores simultaneamente. No entanto, não sentiu-se necessidade de adotar tal solução, sendo o processamento em paralelo suficiente para os problemas analisados.

\subsubsection{Solver}

O Solver nada mais é do que uma classe para resolver sistemas do tipo $A \cdot x=b$. No entanto, ela possui algumas funcionalidades interessantes. Aqui é importante destacar o trabalho de Press et al. (2007), o qual fornece inúmeros algoritmos de alta performance para diversos tipos de problemas.

Observe que em momento algum se impôs restrição sobre a quantidade de pontos fontes a serem criados. Isso significa que podemos gerar mais equações do que as necessárias para determinar as incógnitas do problema, resultando em um sistema sobredeterminado. Sistemas desse tipo podem ser resolvidos pelo método dos mínimos quadrados (Shilov, 1977). O método consiste basicamente em resolver o sistema equivalente $\left(A^{T} A\right) \cdot x=A^{T} \cdot b$. Então, ao receber as matrizes $H_{m \times n}$ e $G_{m \times n}$ de Assembler o Solver faz as verificações:

1. Se $m=n$, procede-se com a solução do sistema linear da forma usual;

2. Se $m>n$, o sistema é sobredeterminado e aplica-se o método dos mínimos quadrados;

3. Se $m<n$, o sistema é indeterminado.

Outra funcionalidade interessante é a melhora iterativa da solução do sistema linear. A aplicação desta técnica é direta e fornece excelentes resultados para sistemas mal-condicionados. Considere o sistema mal-condicionado do tipo $A \cdot x=b$. A solução deste sistema será, em geral, $x+\delta x$, em que

\footnotetext{
${ }^{2}$ Disponível em: http://www.gridgain.com
} 
$\delta x$ é o erro introduzido na solução. Quando a solução $x+\delta x$ for multiplicada pela matriz $A$, teremos $A \cdot(x+\delta x)=(b+\delta b)$, e $\delta x$ pode ser avaliado resolvendo o sistema $A \cdot \delta x=A \cdot(x+\delta x)-b$. Essa técnica é aplicada em todo problema analisado e o processo iterativo se encerra quando $|\delta x|<10^{-12}$. 


\section{Capítulo 7}

\section{Exemplos}

Com o objetivo de validar a formulação apresentada para o Método dos Elementos de Contorno Dual Anisotrópico, serão analisados exemplos com soluções analíticas obtidas pela Teoria da Elasticidade Linear.

Nos exemplos (7.1) e (7.2), com a finalidade de comparar as duas formulações, analisa-se simplesmente a qualidade dos resultados obtidos através da formulação em deslocamento e em força de superfície.

No exemplo (7.3) avalia-se, além da precisão dos resultados, o tempo gasto de processamento de acordo com variáveis como número de nós utilizados para discretização do problema, número de pontos de integração e número de processadores disponíveis. E propõe-se uma equação para estimar o tempo de processamento de um problema com o algoritmo desenvolvido neste trabalho.

A influência da transformação de Telles é estudada no exemplo (7.4). A melhoria da precisão obtida entre a integração numérica de Gauss-Legendre e após a transformação de Telles é comparada com a solução analítica.

A solução analítica para o problema de um furo elíptico em meio anisotrópico infinito é exposta no exemplo (7.5). Esta solução também pode ser utilizada para o estudo de fissuras em meio anisotrópico infinito e no exemplo (7.6) mostra-se um exemplo da aplicação do Método dos Elementos de Contorno Dual.

\subsection{Chapa sob Tensão Uniforme}

Considere a chapa de polímero reforçado com fibras (Figura 7.1), com dimensões $L=0.5 \mathrm{~m}$, $b=0.2 \mathrm{~m}$ e constantes elásticas $E_{11}=124.04 \mathrm{GPa}, E_{22}=10.09 \mathrm{GPa}, G_{12}=6.03 \mathrm{GPa}, \nu_{21}=0.344$, $\eta_{12,1}=1.255$ e $\eta_{12,2}=-0.031$, solicitada por uma tensão de tração $p=10.0 \mathrm{MPa}$. 


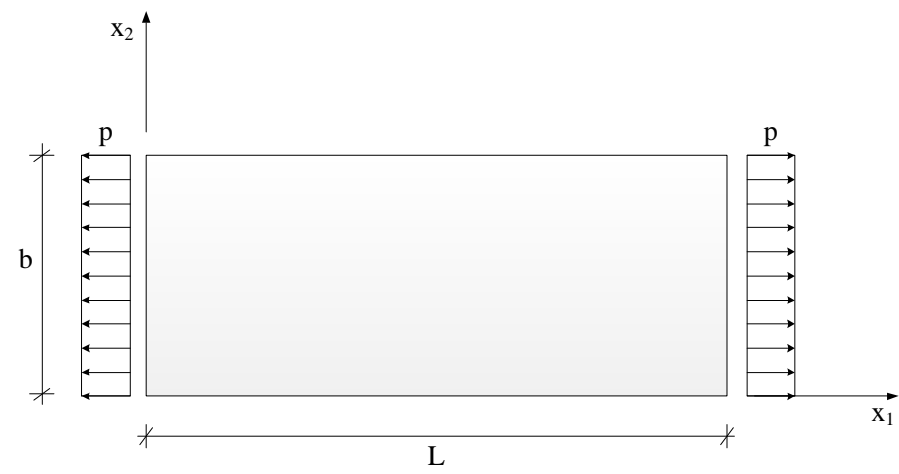

Figura 7.1: Chapa sob tensão uniforme.

A solução analítica geral (Lekhnitskii, 1968) em deslocamentos para este problema é

$$
\begin{aligned}
& u_{1}=c_{11} p x_{1}+c_{16} p x_{2} \\
& u_{2}=c_{12} p x_{2}
\end{aligned}
$$

E para deformações e tensões são

$$
\begin{gathered}
\varepsilon_{11}=c_{11} p, \quad \varepsilon_{22}=c_{12} p, \quad 2 \varepsilon_{12}=c_{16} p \\
\sigma_{11}=P, \quad \sigma_{22}=\sigma_{12}=0
\end{gathered}
$$

A chapa foi discretizada conforme Figura (7.2) utilizando 4 elementos lineares.

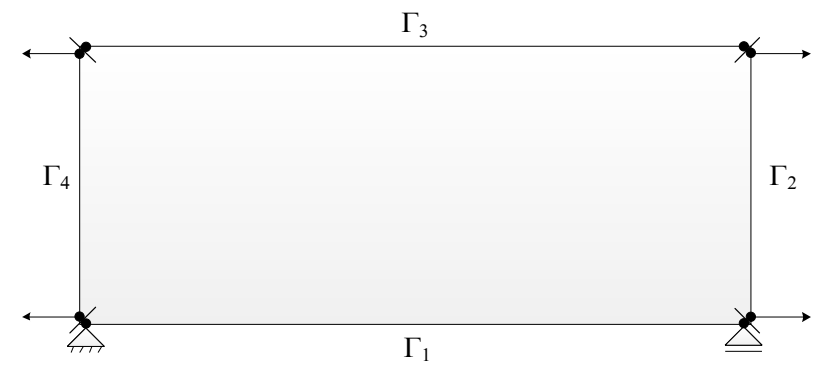

Figura 7.2: Discretização do problema chapa sob tensão uniforme.

Os resultados obtidos através das formulações singulares em deslocamentos e forças de superfície são comparados à solução analítica na Tabela (7.1) e, mesmo para uma discretização grosseira, apresentaram erro relativo máximo de $0.0925 \%$ oo.

A configuração deformada do problema é mostrada na Figura (7.3) com os deslocamentos ampliados em 1000 vezes.

Através deste exemplo, demonstra-se que tanto a formulação em deslocamentos como a formulação em força de superfície apresentadas neste trabalho são adequadas para analisar problemas 
Tabela 7.1: Deslocamentos nodais do problema chapa sob tensão uniforme $\left(10^{-05} \mathrm{~m}\right)$

\begin{tabular}{crrr}
\hline$u_{i}\left(x_{1}, x_{2}\right)$ & \multicolumn{1}{c}{ Analítico } & Deslocamento & Força de Superfície \\
\hline$u_{1}(0.50,0.00)$ & 4.031066 & 4.031068 & 4.031068 \\
$u_{1}(0.50,0.25)$ & 6.560559 & 6.560570 & 6.560570 \\
$u_{1}(0.00,0.25)$ & 2.529494 & 2.529505 & 2.529505 \\
\hline$u_{2}(0.50,0.00)$ & 0.000000 & 0.000000 & 0.000000 \\
$u_{2}(0.50,0.25)$ & -0.693343 & -0.693350 & -0.693350 \\
$u_{2}(0.00,0.25)$ & -0.693343 & -0.693341 & -0.693341 \\
\hline
\end{tabular}

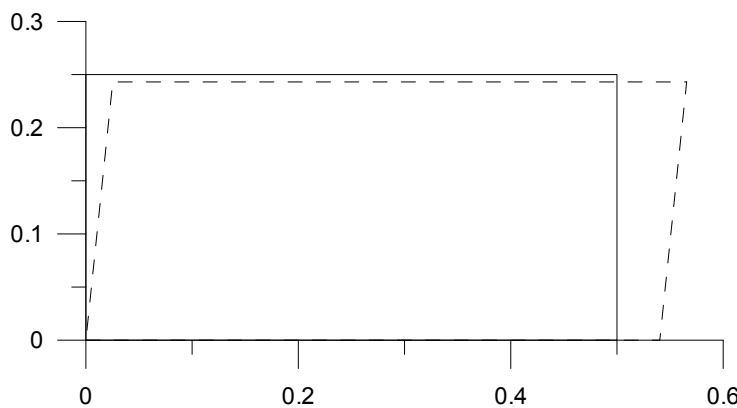

Figura 7.3: Configuração indeformada (—) e deformada (----) do problema chapa sob tensão uniforme.

planos de anisotropia.

\subsection{Chapa sob Cisalhamento Puro}

Considere a mesma chapa do exemplo (7.1). Agora, porém, submetida a cisalhamento puro de intensidade $t=1.0 \mathrm{MPa}$ (Figura 7.4).

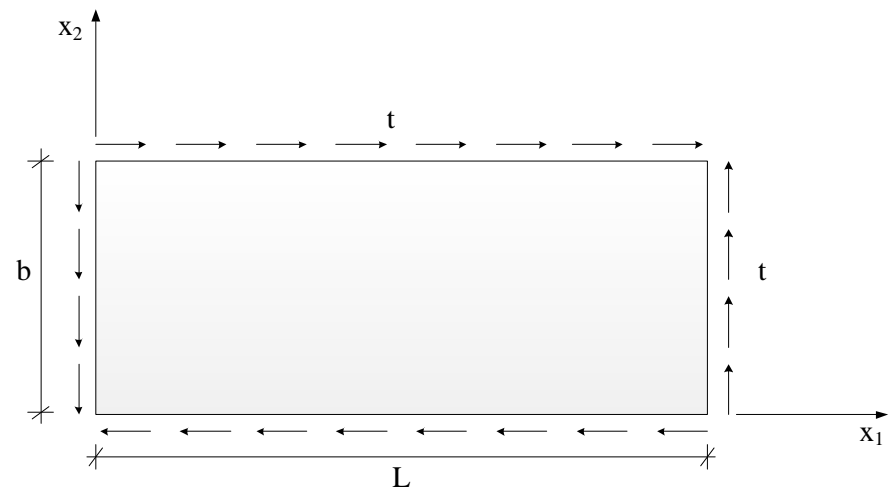

Figura 7.4: Chapa sob cisalhamento puro.

A solução analítica geral (Lekhnitskii, 1968) em deslocamentos para este problema é

$$
\begin{aligned}
& u_{1}=c_{16} t x_{1}+c_{66} t x_{2} \\
& u_{2}=c_{26} t x_{2}
\end{aligned}
$$


E para deformações e tensões são

$$
\begin{gathered}
\varepsilon_{11}=c_{16} t, \quad \varepsilon_{22}=c_{26} t, \quad 2 \varepsilon_{12}=c_{26} t \\
\sigma_{12}=t, \quad \sigma_{11}=\sigma_{22}=0
\end{gathered}
$$

Este problema foi discretizado exatamente como no exemplo anterior, alterando-se, no entanto, as condições de contorno.

Os resultados obtidos através das formulações singulares em deslocamentos e forças de superfície são comparados à solução analítica na Tabela (7.2) e apresentaram erro relativo máximo de 0.08996 $\% 00$.

Tabela 7.2: Deslocamentos nodais do problema chapa sob cisalhamento puro $\left(10^{-05} \mathrm{~m}\right)$

\begin{tabular}{crrr}
\hline$u_{i}\left(x_{1}, x_{2}\right)$ & Analítico & Deslocamento & Força de Superfície \\
\hline$u_{1}(0.50,0.00)$ & 0.505899 & 0.505902 & 0.505902 \\
$u_{1}(0.50,0.25)$ & 4.654575 & 4.654587 & 4.654587 \\
$u_{1}(0.00,0.25)$ & 4.148677 & 4.148691 & 4.148690 \\
\hline$u_{2}(0.50,0.00)$ & 0.000000 & 0.000000 & 0.000000 \\
$u_{2}(0.50,0.25)$ & -0.076779 & -0.076786 & -0.076786 \\
$u_{2}(0.00,0.25)$ & -0.076779 & -0.076776 & -0.076775 \\
\hline
\end{tabular}

A configuração deformada do problema é mostrada na Figura (7.5) com os deslocamentos ampliados em 1000 vezes.

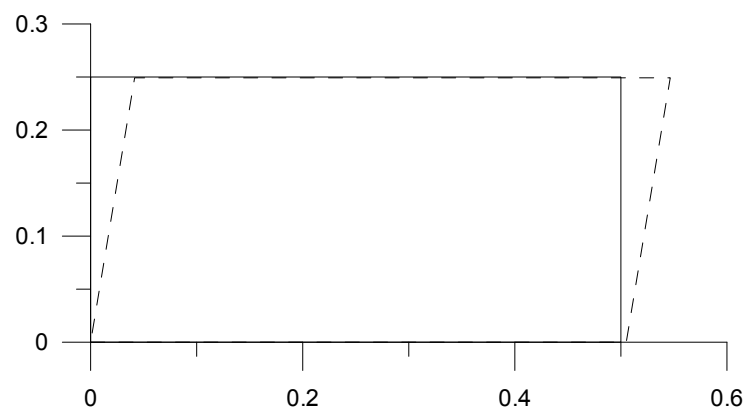

Figura 7.5: Configuração indeformada (—) e deformada (-----) do problema chapa sob cisalhamento puro.

Através deste segundo exemplo, acredita-se ter demonstrado a precisão alcançada com as formulações expostas.

\subsection{Viga sob Flexão Pura}

Considere a viga de madeira (Figura 7.6), com dimensões $L=2.0 \mathrm{~m}, b=0.5 \mathrm{~m}$ e constantes elásticas $E_{11}=9.81 \mathrm{GPa}, E_{22}=0.41 \mathrm{GPa}, G_{12}=0.74 \mathrm{GPa}$ e $\nu_{21}=-0.01$ solicitada por uma tensão 
linearmente distribuída $p= \pm 1.0 \mathrm{MPa}$.
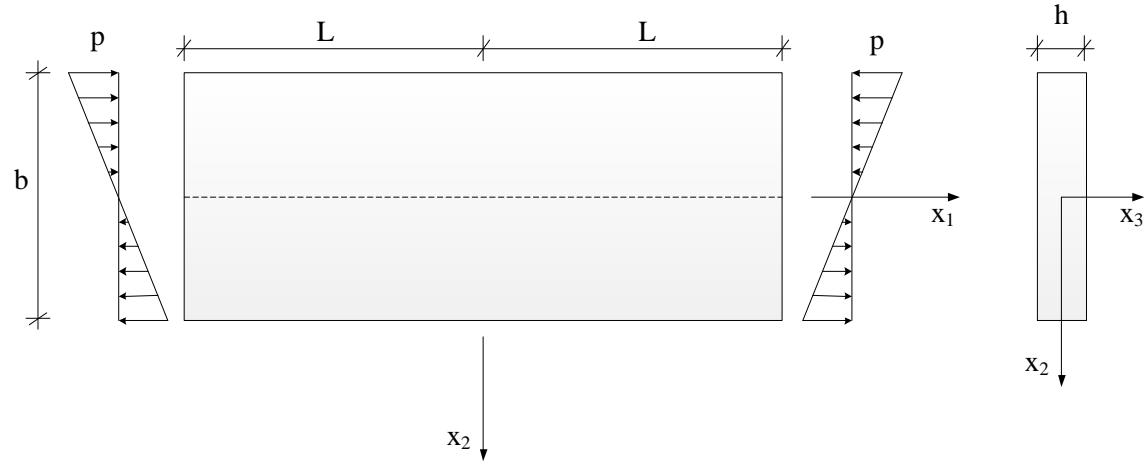

Figura 7.6: Viga sob flexão pura.

A solução analítica (Lekhnitskii, 1968) em deslocamentos para o caso ortotrópico é

$$
\begin{aligned}
& u_{1}=(2 p / h) c_{11} x_{1} x_{2} \\
& u_{2}=(p / h)\left(c_{12} x_{2}^{2}-c_{11} x_{1}^{2}+c_{11} L^{2}\right)
\end{aligned}
$$

E para deformações e tensões são

$$
\begin{gathered}
\varepsilon_{11}=(2 p / h) c_{11} x_{2}, \quad \varepsilon_{22}=(2 p / h) c_{12} x_{2}, \quad 2 \varepsilon_{12}=(2 p / h) c_{16} x_{2} \\
\sigma_{11}=(2 p / h) x_{2}, \quad \sigma_{22}=\sigma_{12}=0
\end{gathered}
$$

Este problema foi discretizado conforme Figura (7.7) utilizando 4 elementos quadráticos.

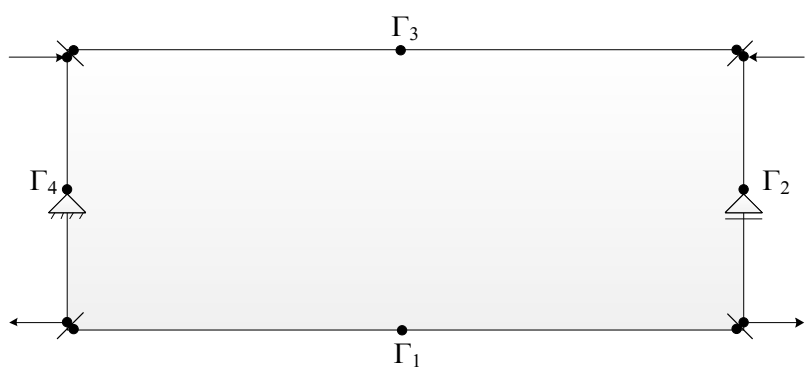

Figura 7.7: Discretização do problema viga sob flexão pura.

Os resultados obtidos através das formulações singulares em deslocamentos e forças de superfície são comparados à solução analítica na Tabela (7.3) e apresentaram erro relativo máximo de 0.00234 $\%$ \%.

A configuração deformada do problema é mostrada na Figura (7.8) com os deslocamentos ampliados em 1000 vezes.

Neste exemplo analisou-se a influência que variáveis como a formulação utilizada, número de 
Tabela 7.3: Deslocamentos nodais do problema viga sob flexão pura $\left(10^{-05} \mathrm{~m}\right)$

\begin{tabular}{crrr}
\hline$u_{i}\left(x_{1}, x_{2}\right)$ & \multicolumn{1}{c}{ Analítico } & Deslocamento & Força de Superfície \\
\hline$u_{1}(-1.00,-0.25)$ & -1.019716 & -1.019717 & -1.019717 \\
$u_{1}(+0.00,-0.25)$ & 0.000000 & 0.000000 & 0.000000 \\
$u_{1}(+1.00,-0.25)$ & 1.019716 & 1.019717 & 1.019717 \\
$u_{1}(+1.00,+0.25)$ & -1.019716 & -1.019717 & -1.019717 \\
$u_{1}(+0.00,+0.25)$ & 0.000000 & 0.000000 & 0.000000 \\
$u_{1}(-1.00,+0.25)$ & 1.019716 & 1.019717 & 1.019717 \\
\hline$u_{2}(-1.00,-0.25)$ & 0.030349 & 0.030349 & 0.030349 \\
$u_{2}(+0.00,-0.25)$ & -2.009084 & -2.009085 & -2.009085 \\
$u_{2}(+1.00,-0.25)$ & 0.030349 & 0.030349 & 0.030349 \\
$u_{2}(+1.00,+0.25)$ & 0.030349 & 0.030349 & 0.030349 \\
$u_{2}(+0.00,+0.25)$ & -2.009084 & -2.009084 & -2.009085 \\
$u_{2}(-1.00,+0.25)$ & 0.030349 & 0.030349 & 0.030349 \\
\hline
\end{tabular}

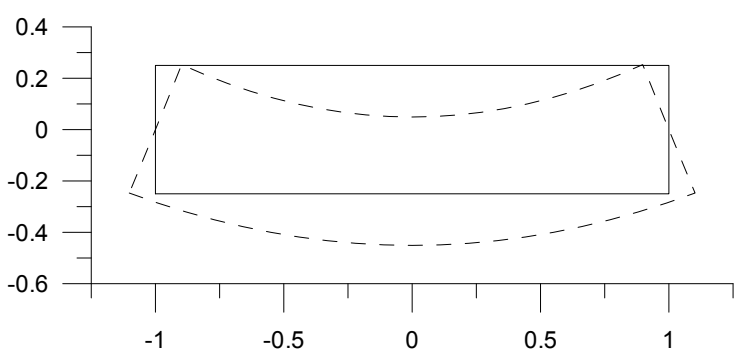

Figura 7.8: Configuração indeformada (—) e deformada (-----) do problema viga sob flexão pura.

nós e pontos de integração tem sobre o tempo de processamento.

Através da Figura (7.9) observa-se que o tempo de processamento aumenta de forma quadrática com o número de pontos de integração. O tempo de processamento também varia linearmente com o número de nós utilizados na discretização do problema. Ainda, observa-se uma variação linear do tempo de processamento em relação ao número de núcleos de processadores.

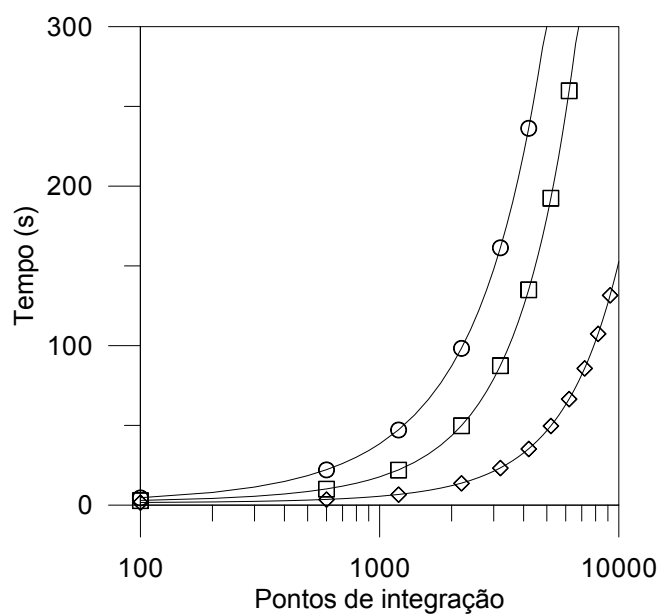

(a)

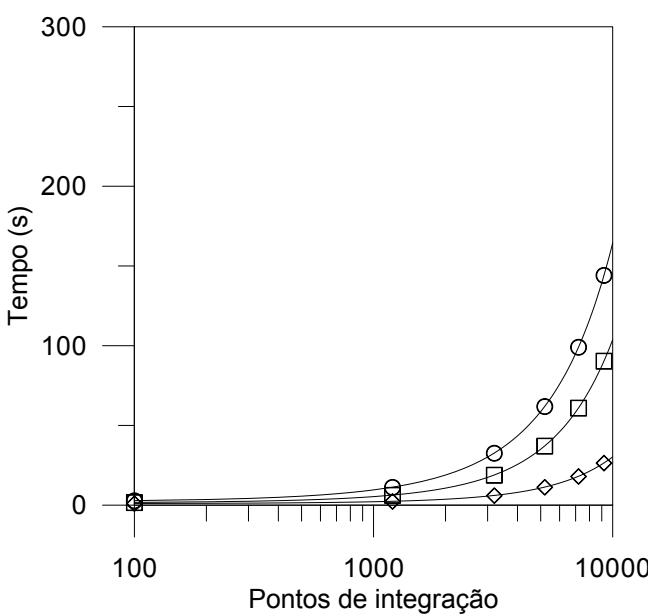

(b)

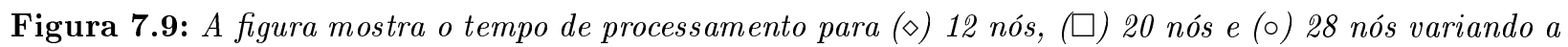
quantidade de pontos de integração com: (a) processamento single-thread; e, (b) processamento multi-thread. 
Desta forma, é possível propor uma equação para estimar o tempo de processamento através do Método dos Elementos de Contorno Anisotrópico em função do número de nós, quantidade de pontos de integração e números de núcleos de processadores.

Através dos dados obtidos dos diversos exemplos analisados neste trabalho (Apêndice E) chegouse a seguinte equação geral para estimar o tempo de processamento:

$$
T\left(N_{P G}, N_{N P}, N_{N O S}\right)=\left(C_{1} N_{P G}^{2}+C_{2} N_{P G}+C_{3}\right)\left(C_{4} N_{N P}+C_{5}\right)\left(C_{6} N_{N O S}+C_{7}\right)
$$

Em que $N_{P G}$ é o número de pontos de gauss, $N_{N P}$ é o número de núcleos processadores, $N_{N O S}$ é o número de nós, e $C_{1} \cdots C_{7}$ são constantes.

É importante lembrar que a equação acima foi obtida para o algoritmo desenvolvido neste trabalho e as constantes $C_{1} \cdots C_{7}$ devem ser determinadas para cada configuração de hardware.

Ressalta-se a diferença observada entre o tempo de processamento da formulação dual anisotrópica para a formulação dual isotrópica, a qual, em geral, é cerca de $25 \%$ mais rápida. O que já era esperado, uma vez que o modelo anisotrópico utiliza-se de variáveis complexas o que requer maior número de operações algébricas para resolver o mesmo problema.

\subsection{Viga Engastada sob Carregamento Uniforme}

Considere a mesma viga do exemplo (7.3). Agora, porém, engastada na extremidade direta e submetida a carregamento uniformemente distribuído de intensidade $p=1.0 \mathrm{MPa}$ (Figura 7.10).
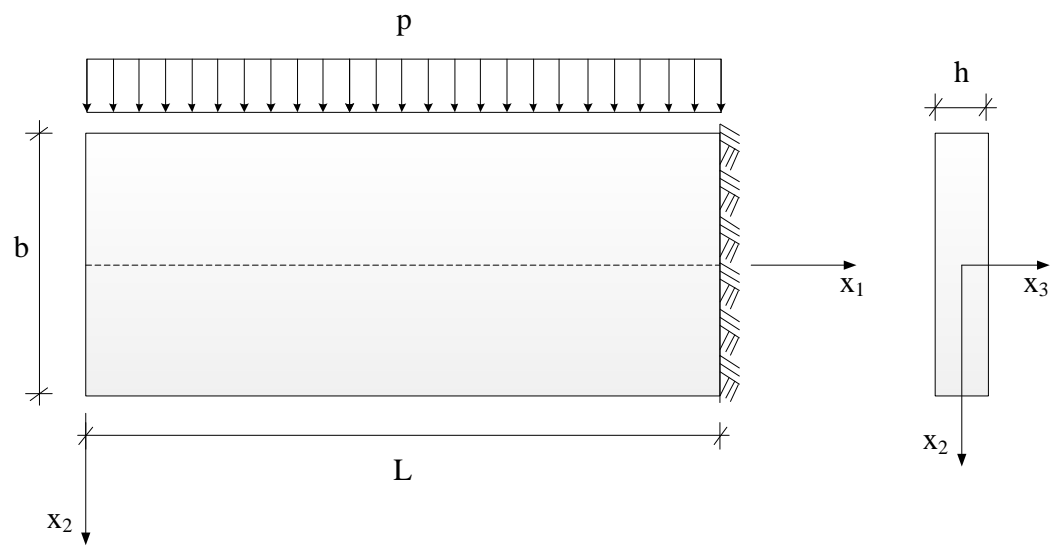

Figura 7.10: Viga engastada sob carregamento uniforme. 
A equação para tensões da solução analítica (Lekhnitskii, 1968) é

$$
\begin{aligned}
& \sigma_{11}=-\frac{q x_{1}^{2} x_{2}}{2 J}+\frac{q}{h}\left[\frac{c_{16}}{c_{11}} \cdot \frac{x_{1}}{b}\left(1-12 \frac{x_{2}^{2}}{b^{2}}\right)+2\left(\frac{2 c_{12}+c_{66}}{4 c_{11}}-\frac{c_{16}^{2}}{c_{11}}\right)\left(\frac{4 x_{2}^{3}}{b^{3}}-\frac{3 x_{2}}{5 b}\right)\right] \\
& \sigma_{22}=-\frac{q}{2 h}\left(-1+3 \frac{x_{2}}{b}-4 \frac{x_{2}^{3}}{b^{3}}\right) \\
& \sigma_{12}=-\frac{q x_{1}}{2 J}\left(\frac{b^{2}}{4}-x_{2}^{2}\right)-\frac{q}{h} \frac{c_{16}}{c_{11}}\left(\frac{x_{2}}{b}-\frac{4 x_{2}^{3}}{b^{3}}\right)
\end{aligned}
$$

Este problema foi discretizado conforme Figura (7.11) utilizando 8 elementos de quarta ordem, sendo que todos os nós dos elementos $\Gamma_{3}$ e $\Gamma_{4}$ tiveram seus deslocamentos em $x_{1}$ e $x_{2}$ restringidos.

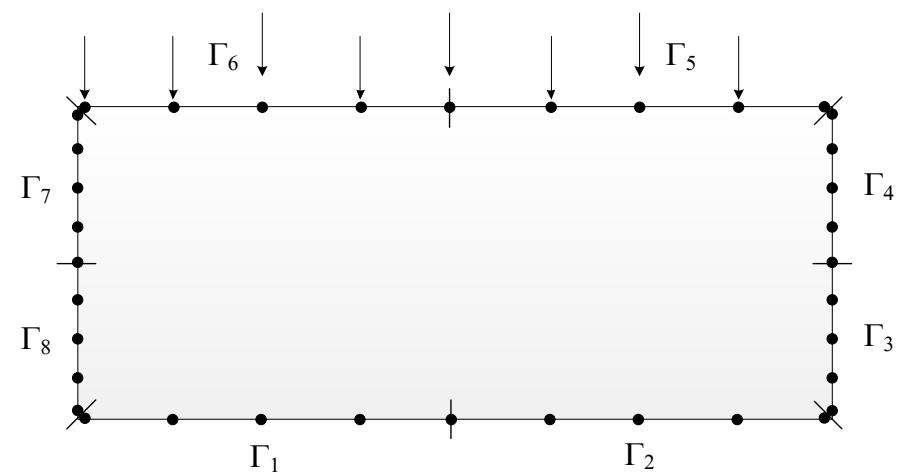

Figura 7.11: Discretização do problema viga engastada sob carregamento uniforme.

A configuração deformada do problema é mostrada na Figura (7.12) com os deslocamentos ampliados em 10 vezes.

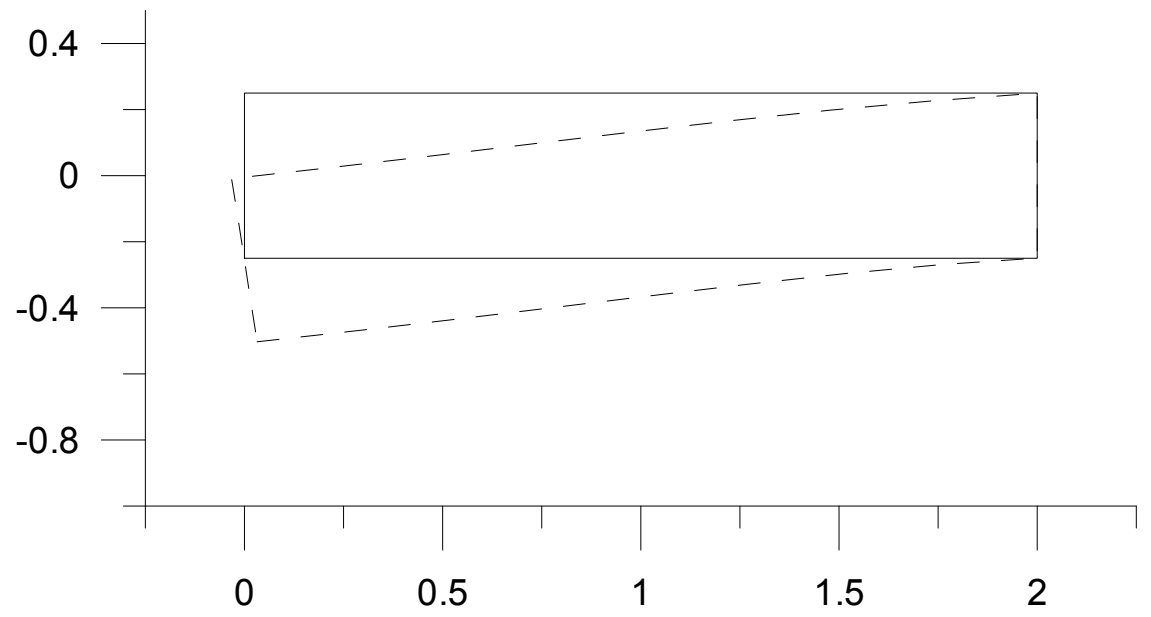

Figura 7.12: Configuração indeformada (—) e deformada (-----) do problema viga engastada sob carregamento uniforme.

A Figura (7.13) mostra as distribuições de tensões $\sigma_{11}, \sigma_{22}$ e $\sigma_{12}$ na viga.

Agora demonstra-se, numericamente, a vantagem em se aplicar a transformação não-linear de Telles e Oliveira (1994) aos pontos de Gauss e sua melhoria na precisão da integração.

Considere a seção da viga em $x_{1}=1.00 \mathrm{~m}$ para a qual se deseja avaliar o estado de tensões $\sigma_{12}$. 


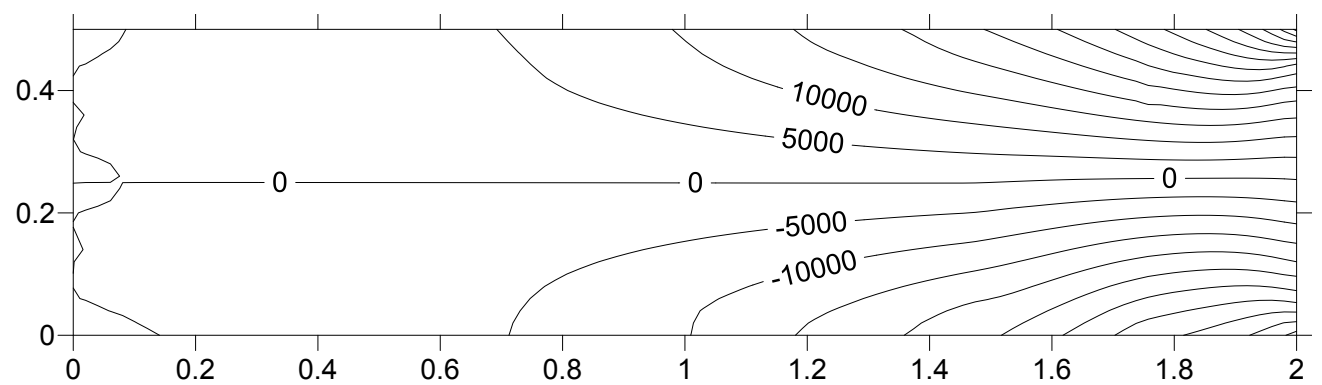

(a)

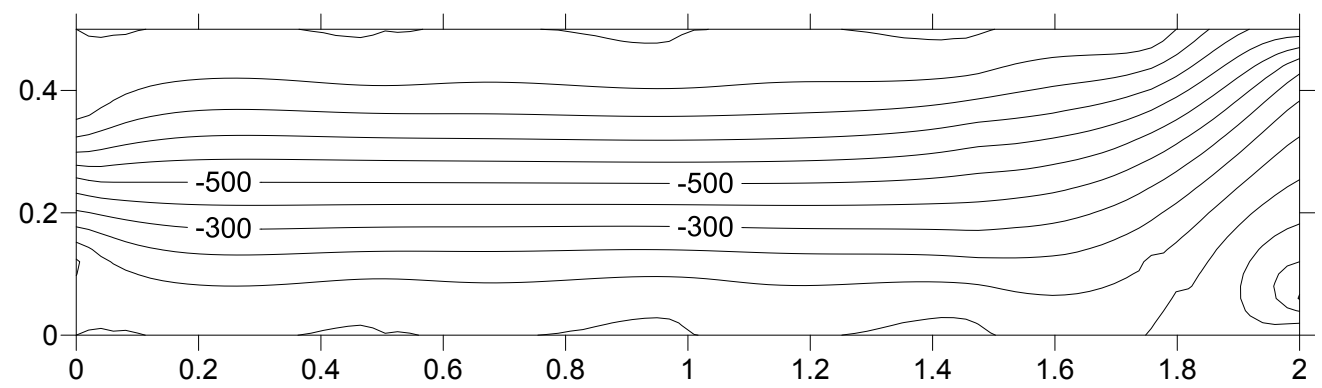

(b)

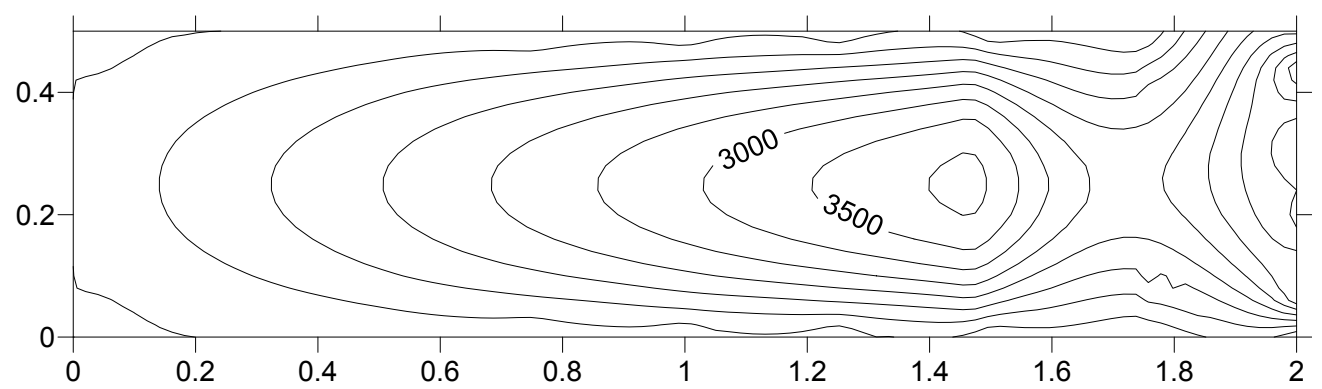

(c)

Figura 7.13: A figura mostra as distribuições de tensões, em Pa, para o problema viga engastada sob carregamento uniforme: (a) $\sigma_{11}$; (b) $\sigma_{22} ;$ e, (c) $\sigma_{12}$.

A Tabela (7.4) mostra as tensões $\sigma_{12}$ obtidas pela solução analítica, pela integração numérica de Gauss-Legendre e através da transformação de Telles.

Observa-se, pela Figura (7.14), que aplicando a transformação de Telles o erro relativo foi menor do que o obtido pela integração numérica convencional para uma mesma quantidade de pontos de integração.

É possível abordar esta técnica por duas óticas: uma primeira, seria manter os pontos de integração obtendo melhora dos resultados; e, uma segunda, seria reduzir os pontos de integração ganhando em tempo de processamento.

Portanto, a aplicação do método de Telles é recomendada tanto pela sua grande facilidade de implementação quanto pela melhoria observada nos resultados. 
Tabela 7.4: Tensões $\sigma_{12}$ do problema viga engastada sob carregamento uniforme (MPa)

\begin{tabular}{crrr}
\hline$\sigma_{12}\left(x_{1}, x_{2}\right)$ & Analítico & Gauss-Legendre & Telles \\
\hline$\sigma_{12}(1,+0.21875)$ & -0.703125 & -0.709449 & -0.705986 \\
$\sigma_{12}(1,+0.18750)$ & -1.312500 & -1.319268 & -1.315781 \\
$\sigma_{12}(1,+0.15625)$ & -1.828125 & -1.831878 & -1.830065 \\
$\sigma_{12}(1,+0.12500)$ & -2.250000 & -2.248350 & -2.249093 \\
$\sigma_{12}(1,+0.09375)$ & -2.578125 & -2.570261 & -2.573551 \\
$\sigma_{12}(1,+0.06250)$ & -2.812500 & -2.799136 & -2.804294 \\
$\sigma_{12}(1,+0.03125)$ & -2.953125 & -2.936128 & -2.942140 \\
$\sigma_{12}(1,+0.00000)$ & -3.000000 & -2.981903 & -2.988082 \\
$\sigma_{12}(1,-0.03125)$ & -2.953125 & -2.936608 & -2.942766 \\
$\sigma_{12}(1,-0.06250)$ & -2.812500 & -2.799877 & -2.804979 \\
$\sigma_{12}(1,-0.09375)$ & -2.578125 & -2.570841 & -2.574013 \\
$\sigma_{12}(1,-0.12500)$ & -2.250000 & -2.248197 & -2.249039 \\
$\sigma_{12}(1,-0.15625)$ & -1.828125 & -1.830408 & -1.829271 \\
$\sigma_{12}(1,-0.18750)$ & -1.312500 & -1.316230 & -1.314255 \\
$\sigma_{12}(1,-0.21875)$ & -0.703125 & -0.705700 & -0.704256 \\
\hline
\end{tabular}

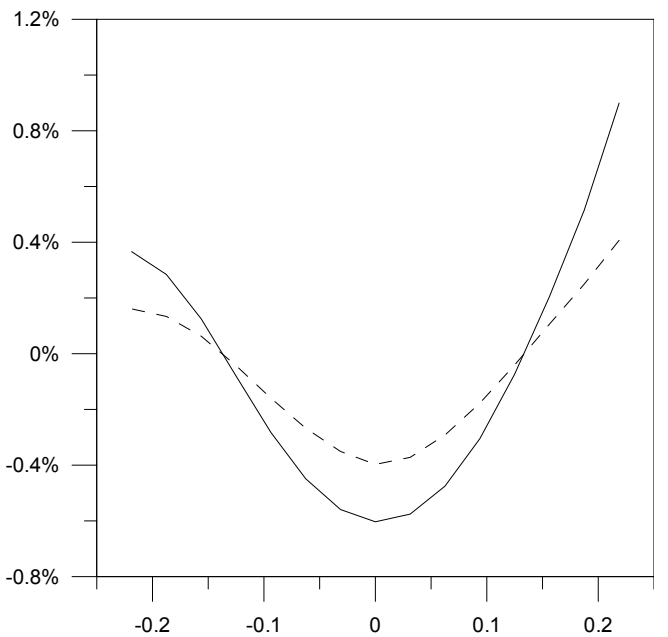

Figura 7.14: Erro relativo das tensões $\sigma_{12}$ para viga engastada sob carregamento uniforme com integração numérica de Gauss-Legendre (—) e Telles (-----).

\subsection{Furo Elíptico em Meio Infinito}

Considere o furo elíptico em um meio infinito constituído de mesmo material apresentado no exemplo (7.3) com tração uniforme na direção de $x_{1}$ de intensidade $p=1.0 \mathrm{MPa}$ (Figura 7.15).
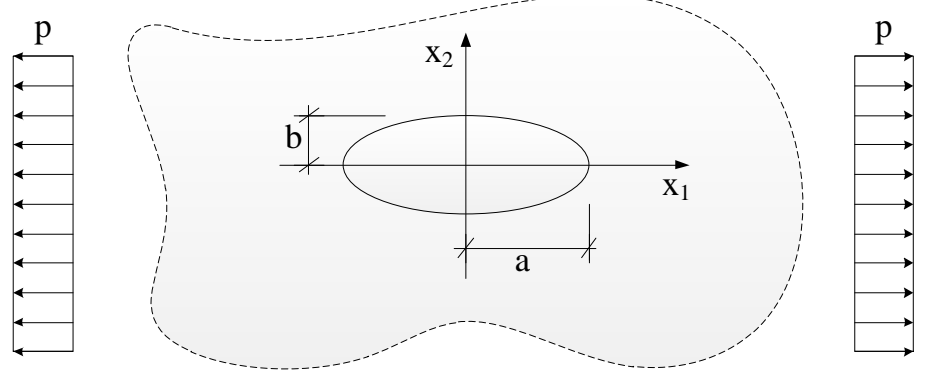

Figura 7.15: Furo eliptico em meio infinito. 
É relevante destacar a importância do trabalho desenvolvido por Savin (1961) sobre o estudo da distribuição de tensões em volta de furos. A equação para tensões, desenvolvida por ele, da solução analítica é

$$
\begin{aligned}
& \sigma_{11}=p+\operatorname{Re}\left[\frac{p b \mu_{1}^{2} i}{\left(\mu_{1}-\mu_{2}\right)\left(a+i \mu_{1} b\right)}\left(\frac{z_{1}}{\sqrt{z_{1}^{2}-\left(a^{2}+\mu_{1}^{2} b^{2}\right)}}-1\right)\right. \\
& \left.-\frac{p b \mu_{2}^{2} i}{\left(\mu_{1}-\mu_{2}\right)\left(a+i \mu_{2} b\right)}\left(\frac{z_{2}}{\sqrt{z_{2}^{2}-\left(a^{2}+\mu_{2}^{2} b^{2}\right)}}-1\right)\right] \\
& \sigma_{22}=\operatorname{Re}\left[\frac{p b i}{\left(\mu_{1}-\mu_{2}\right)\left(a+i \mu_{1} b\right)}\left(\frac{z_{1}}{\sqrt{z_{1}^{2}-\left(a^{2}+\mu_{1}^{2} b^{2}\right)}}-1\right)\right. \\
& \left.-\frac{p b i}{\left(\mu_{1}-\mu_{2}\right)\left(a+i \mu_{2} b\right)}\left(\frac{z_{2}}{\sqrt{z_{2}^{2}-\left(a^{2}+\mu_{2}^{2} b^{2}\right)}}-1\right)\right] \\
& \sigma_{12}=\operatorname{Re}\left[\frac{p b \mu_{1} i}{\left(\mu_{1}-\mu_{2}\right)\left(a+i \mu_{1} b\right)}\left(\frac{z_{1}}{\sqrt{z_{1}^{2}-\left(a^{2}+\mu_{1}^{2} b^{2}\right)}}-1\right)\right. \\
& \left.-\frac{p b \mu_{2} i}{\left(\mu_{1}-\mu_{2}\right)\left(a+i \mu_{2} b\right)}\left(\frac{z_{2}}{\sqrt{z_{2}^{2}-\left(a^{2}+\mu_{2}^{2} b^{2}\right)}}-1\right)\right]
\end{aligned}
$$

Considerando $a=b=0.1 \mathrm{~m}$, este problema foi discretizado conforme Figura (7.16) utilizando 10 elementos quadráticos para discretizar o furo, e 4 elementos quadráticos para discretizar o meio infinito que considera-se ter 10 vezes a dimensão do furo.

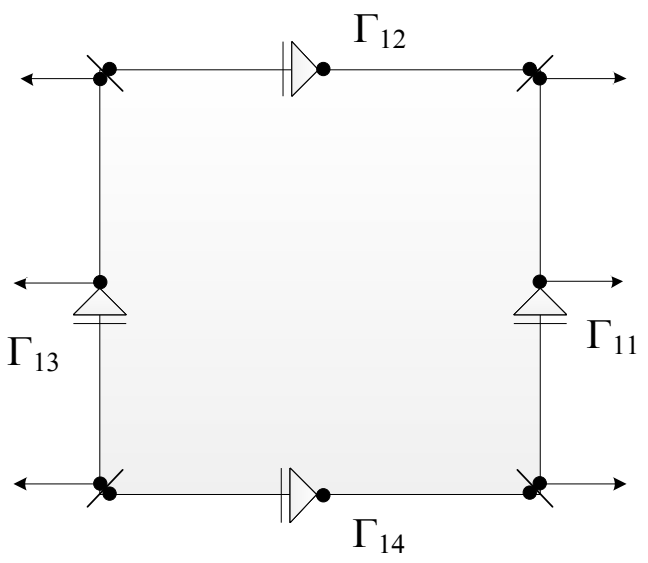

(a)

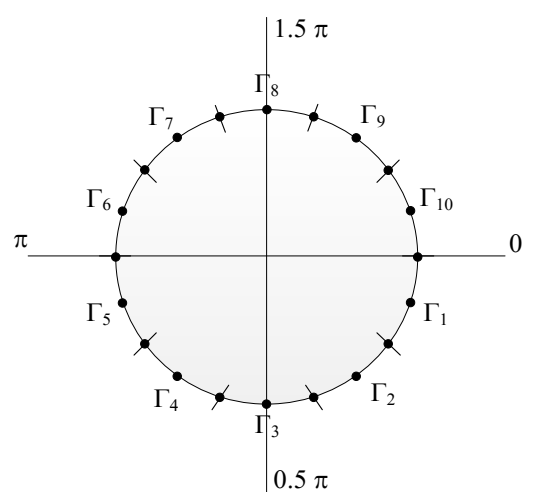

(b)

Figura 7.16: A figura mostra a discretização para: (a) o meio infinito; e, (b) o furo.

Para o caso particular de um furo circular, $a=b$, em meio infinito ortotrópico, o furo se torna uma elipse com semi-eixos

$$
\begin{aligned}
& a^{\prime}=a\left[1+\frac{p}{E_{11}}\left(1-i \mu_{1}-i \mu_{2}\right)\right] \\
& b^{\prime}=a\left(1-\frac{p}{\sqrt{E_{11} E_{22}}}\right)
\end{aligned}
$$


A configuração deformada do problema é mostrada na Figura (7.17) com os deslocamentos ampliados em 1000 vezes.

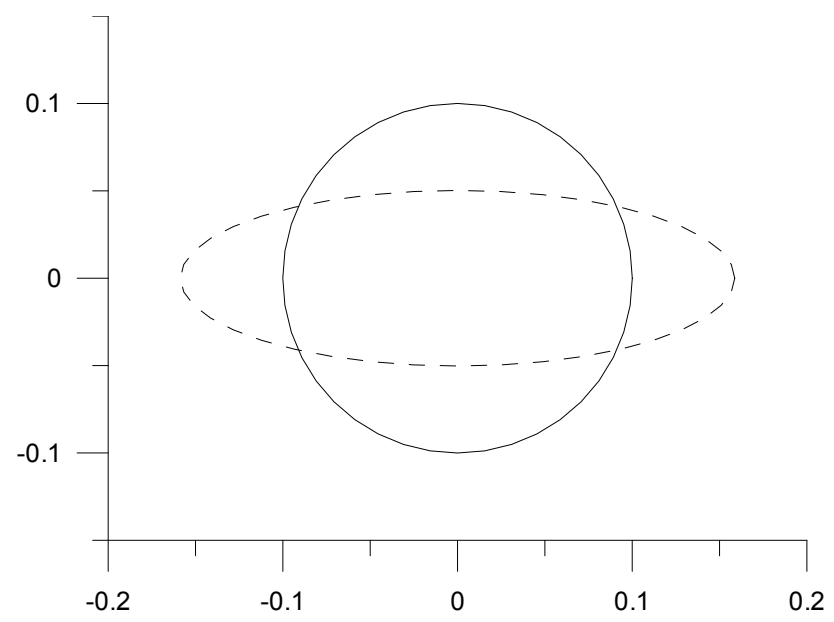

Figura 7.17: Configuração indeformada (—) e deformada (-----) do problema furo elíptico em meio infinito.

Neste caso, o erro relativo à solução analítica para os deslocamentos podem ser calculados (Figura 7.18).

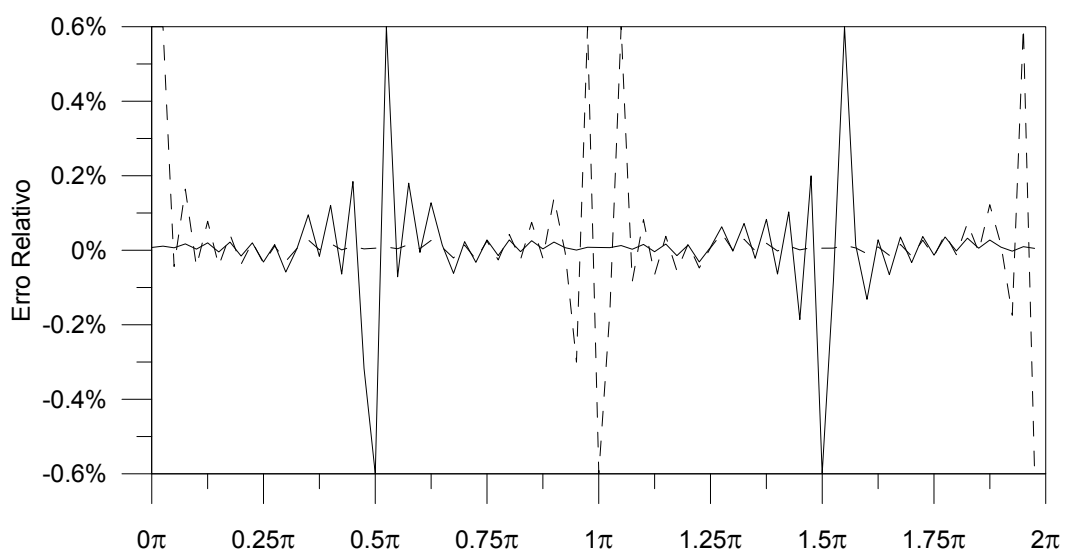

Figura 7.18: Erro relativo para os deslocamentos $u_{1}$ (—) e $u_{2}(-----)$ do problema furo elíptico em meio infinito.

A Figura (7.19) mostra as distribuições de tensões $\sigma_{11}$ e $\sigma_{22}$ ao redor do furo circular com seus respectivos erros relativos para as seções A-A' e B-B'.

Os resultados observados, tanto em deslocamento quanto em tensões, mostraram-se satisfatórios. 

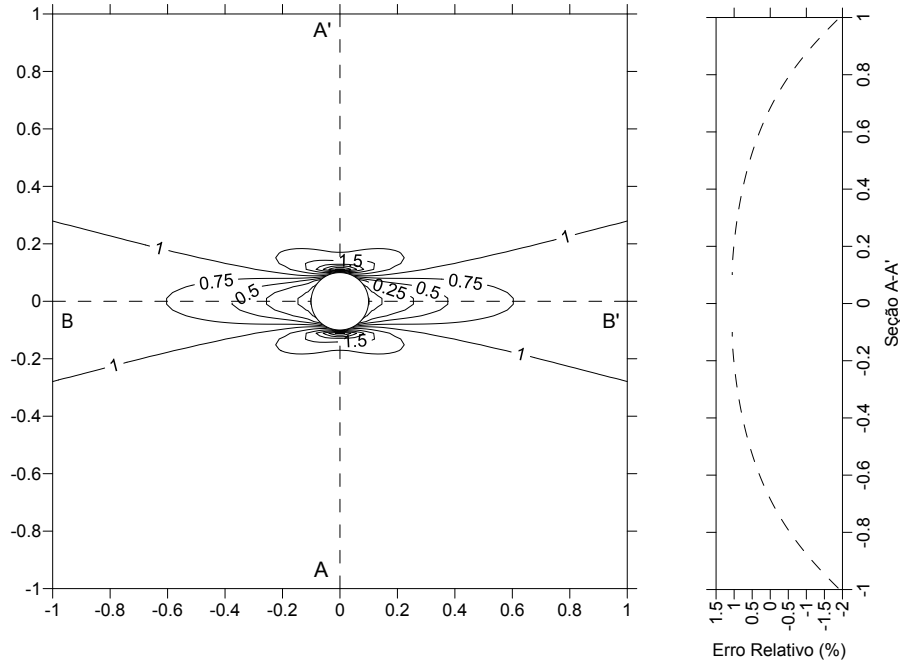

(a)

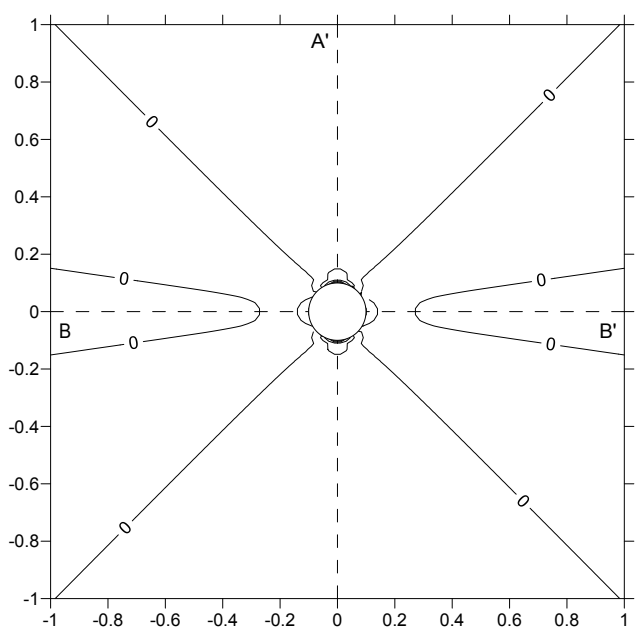

(b)
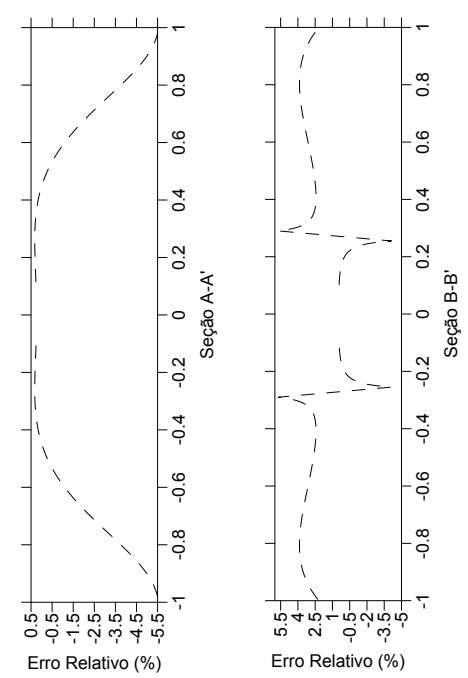

Figura 7.19: A figura mostra as distribuições de tensões em MPa para o problema furo elíptico em meio infinito: (a) $\sigma_{11}$; e, (b) $\sigma_{22}$, com seus respectivos erros relativos para as seções em $x_{1}=0$ e $x_{2}=0$

\subsection{Fratura em Meio Infinito}

Por fim, considere o problema do meio infinito com furo elíptico analisado no exemplo (7.5). Agora, porém, tomando o limite de $a \rightarrow 0$. Neste caso, o furo elíptico pode ser considerado uma fratura em meio infinito e as equações para tensões apresentadas anteriormente permanecem válidas.

O método dos elementos de contorno dual prova ser uma ferramenta valiosa na análise deste tipo de problema. A fratura pode ser discretizada, conforme a Figura (7.20), utilizando 10 elementos quadráticos e o meio infinito pode ser discretizado exatamente igual ao exemplo (7.5).

Ao se tomar o limite de $\Delta \rightarrow 0$ as equações geradas por um ponto fonte em $\Gamma_{1}$ geraria exatamente as mesmas equações que o ponto fonte em $\Gamma_{10}$, um ponto fonte em $\Gamma_{2}$ geraria as mesmas equações que um em $\Gamma_{9}$ e assim por diante. Como já discutido, este problema é contornado adotando-se, 


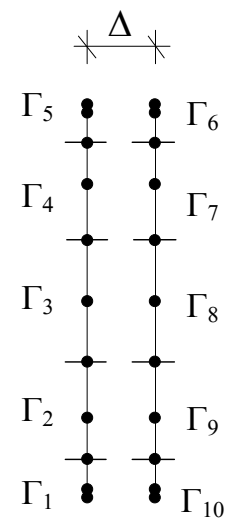

Figura 7.20: Discretização do problema fratura em meio infinito.

por exemplo, nos elementos do lado esquerdo da fratura pontos fontes com a formulação em força de superfície e para os elementos do lado direito da fratura pontos fontes com formulação em deslocamento.

A configuração deformada do problema é mostrada na Figura (7.21) com os deslocamentos ampliados em 1000 vezes.

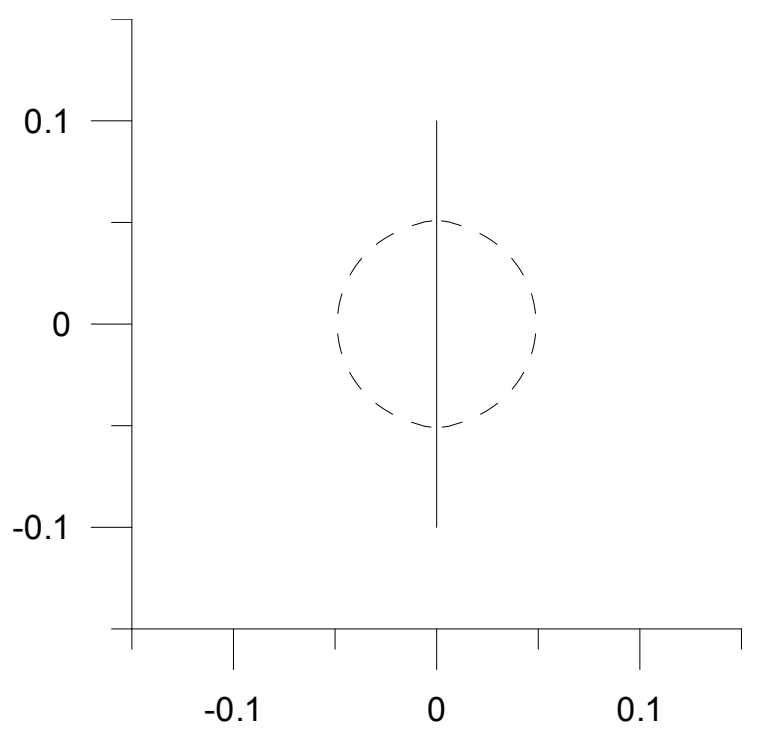

Figura 7.21: Configuração indeformada (—) e deformada (----) do problema fratura em meio infinito.

A Figura (7.22) mostra as distribuições de tensões $\sigma_{11}$ e $\sigma_{22}$ ao redor da fratura. 


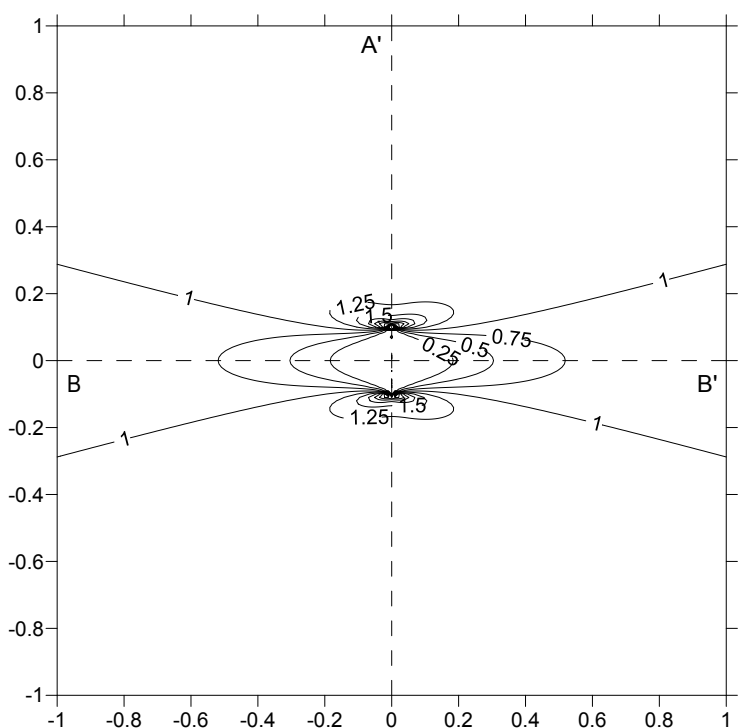

(a)

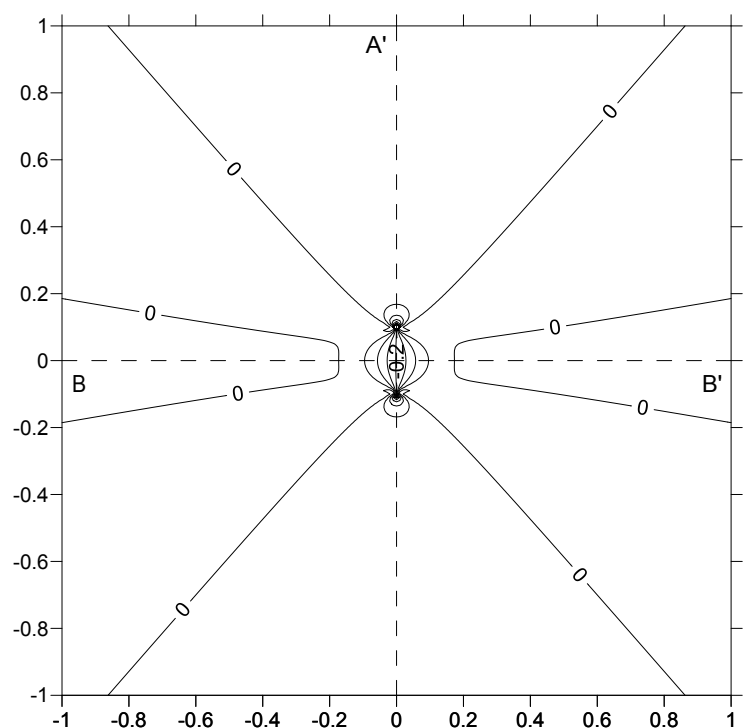

(b)

Figura 7.22: A figura mostra as distribuições de tensões em MPa para o problema fratura em meio infinito: (a) $\sigma_{11} ; e$, (b) $\sigma_{22}$.

As Figuras (7.23) e (7.25) mostram os valores das tensões $\sigma_{11}$ e $\sigma_{22}$ exata e calculada, para as seções A-A' e B-B' indicadas na Figura (7.22). Enquanto as Figura (7.24) e (7.26) mostram os valores dos erros absolutos e relativos das respectivas seções.

É interessante notar que os erros relativos máximos ocorrem nos pontos onde as tensões deveriam ter valor nulo e em pontos de concentração de tensões.

Para se obter uma melhora nos resultados nas proximidades da fratura é necessário refinar a discretização do problema, bem como aumentar o número de pontos de integração devido a variação brusca de tensões. Ainda assim, para a discretização grosseira utilizada nesta análise os resultados se mostraram satisfatórios. 


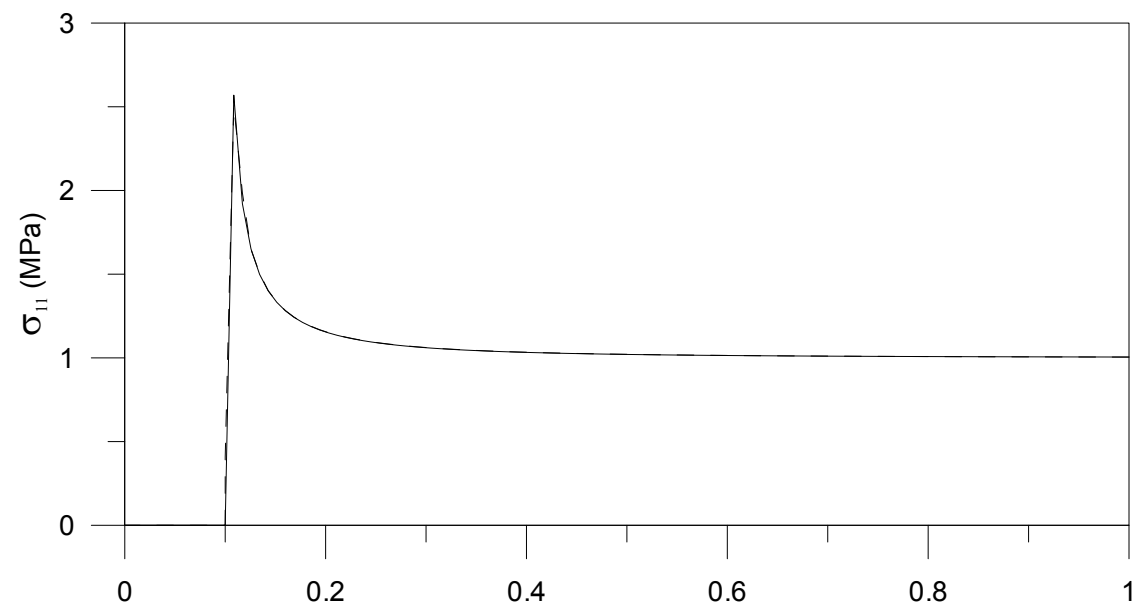

(a)

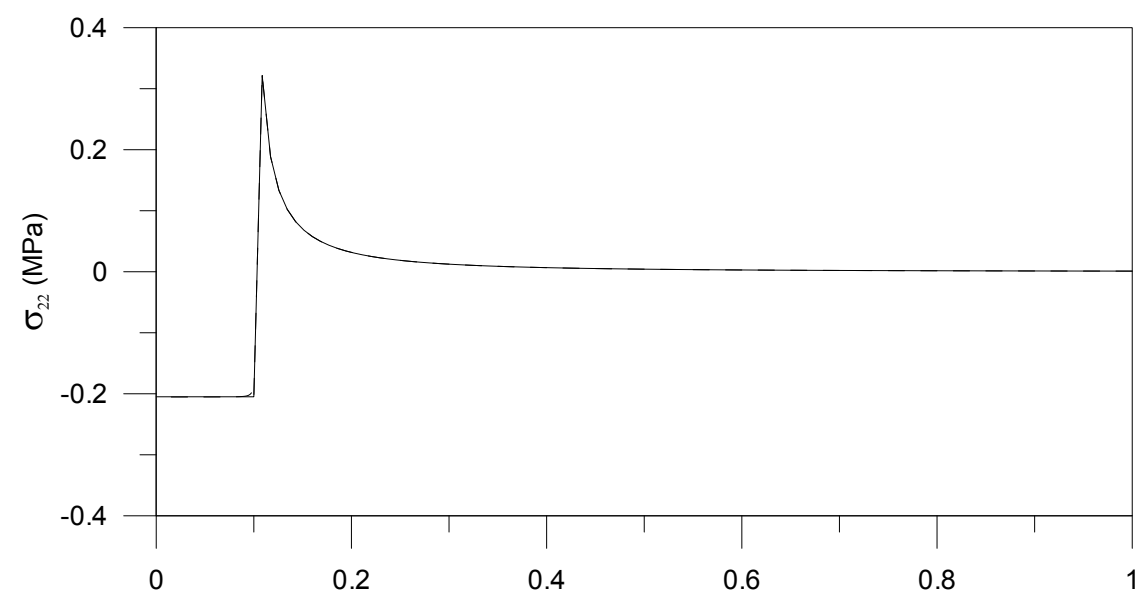

(b)

Figura 7.23: Tensões exatas (—) e aproximadas (-----) de $\sigma_{11}$ (a) e $\sigma_{22}$ (b) para a seção $A-A$ ' do problema fratura em meio infinito. 


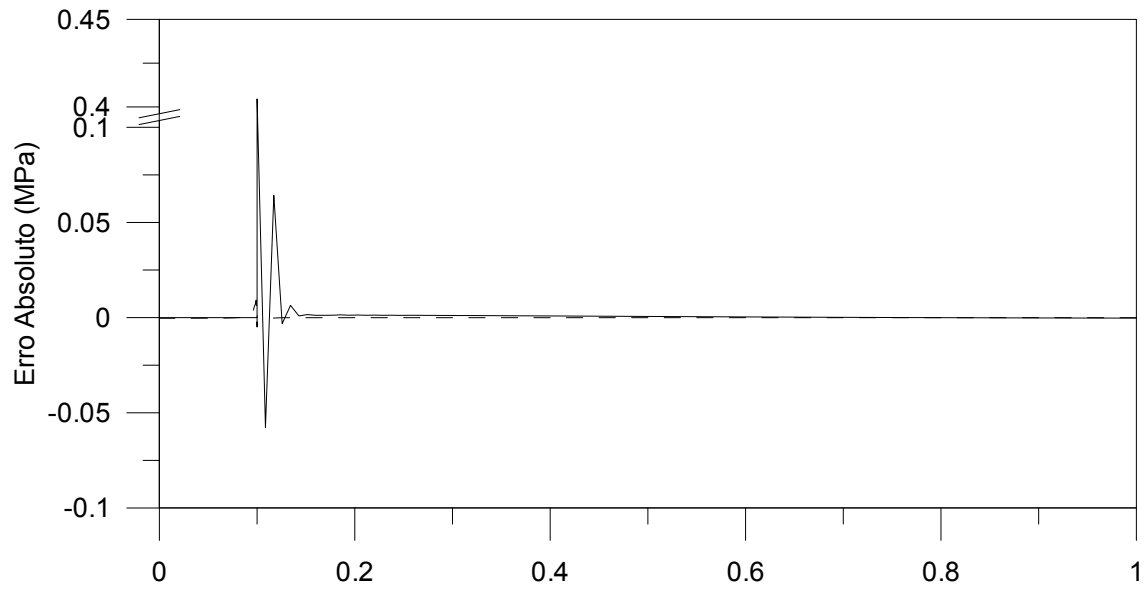

(a)

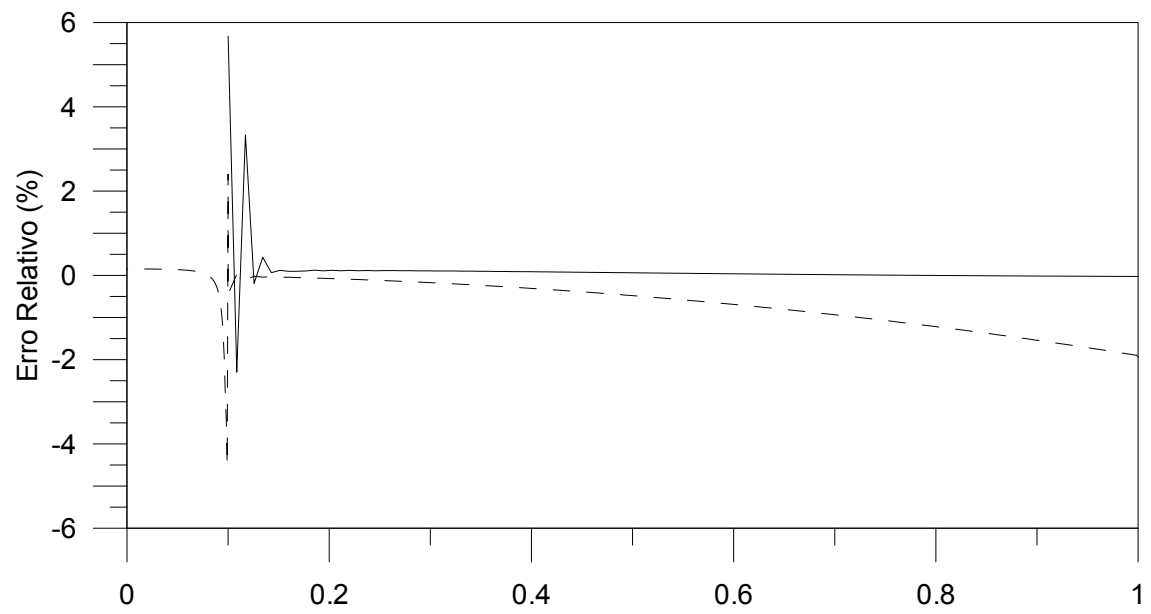

(b)

Figura 7.24: Erros (a) absolutos e, (b) relativos, das tensões $\sigma_{11}\left(-(-)\right.$ e $\sigma_{22}\left(--_{---}\right)$para a seção $A-A$ 'do problema fratura em meio infinito. 


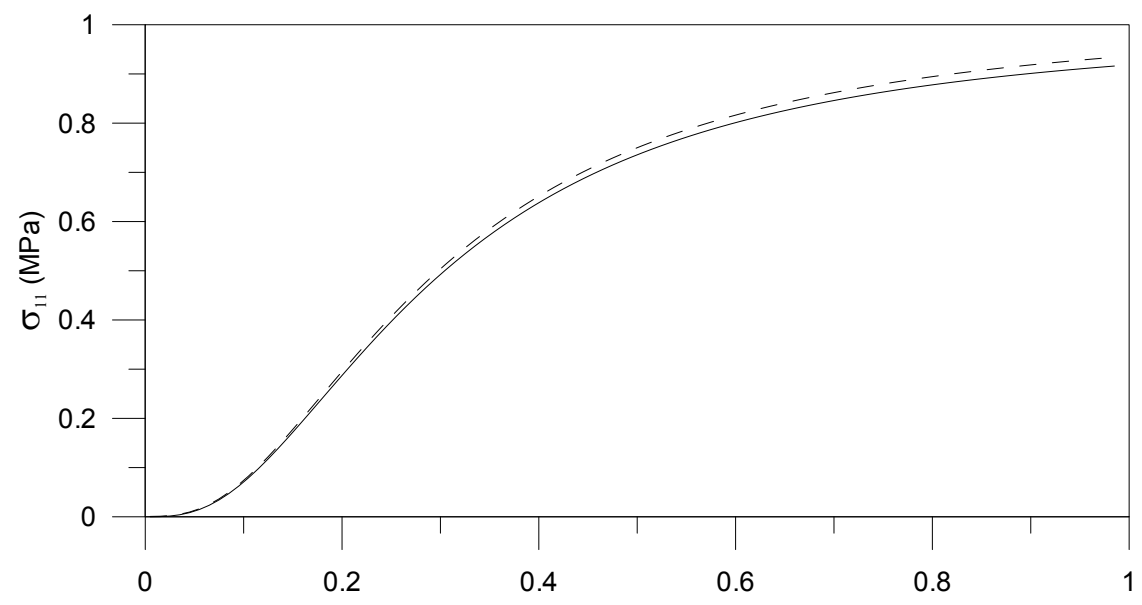

(a)

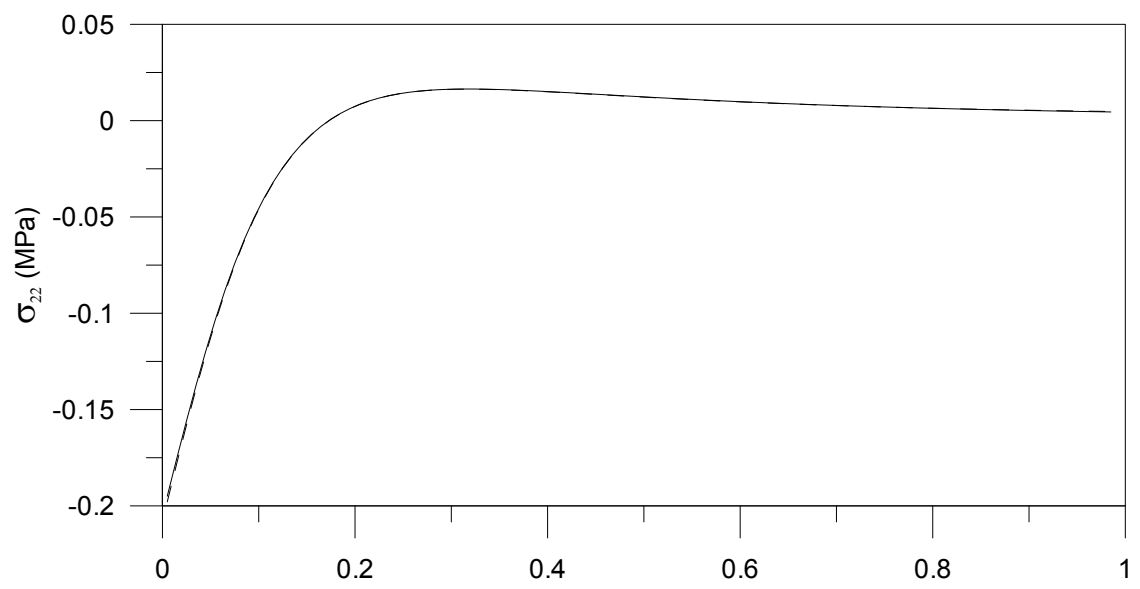

(b)

Figura 7.25: Tensões exatas (problema fratura em meio infinito. 


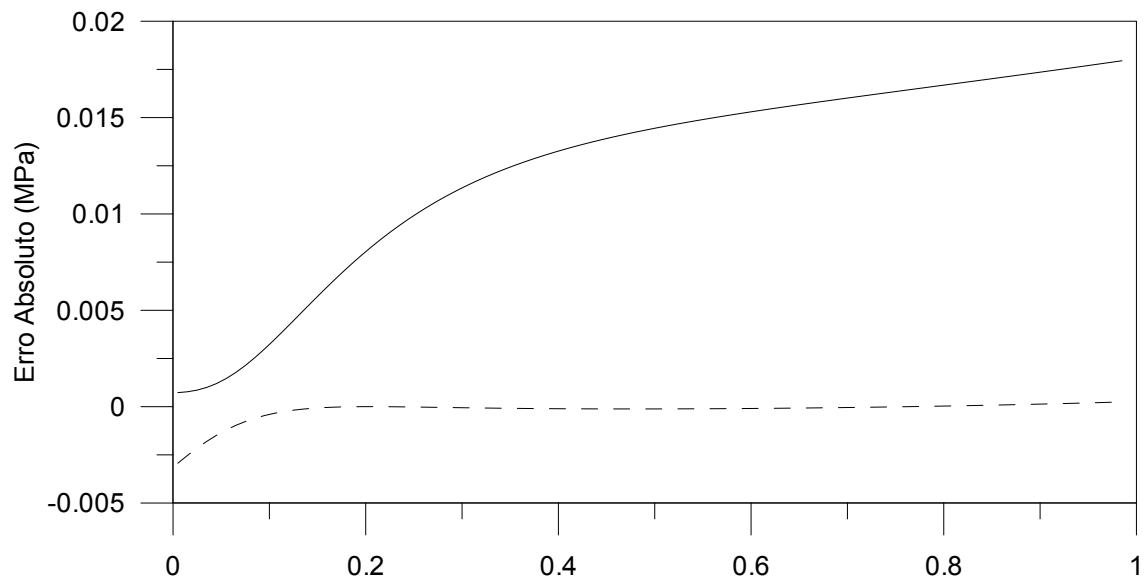

(a)

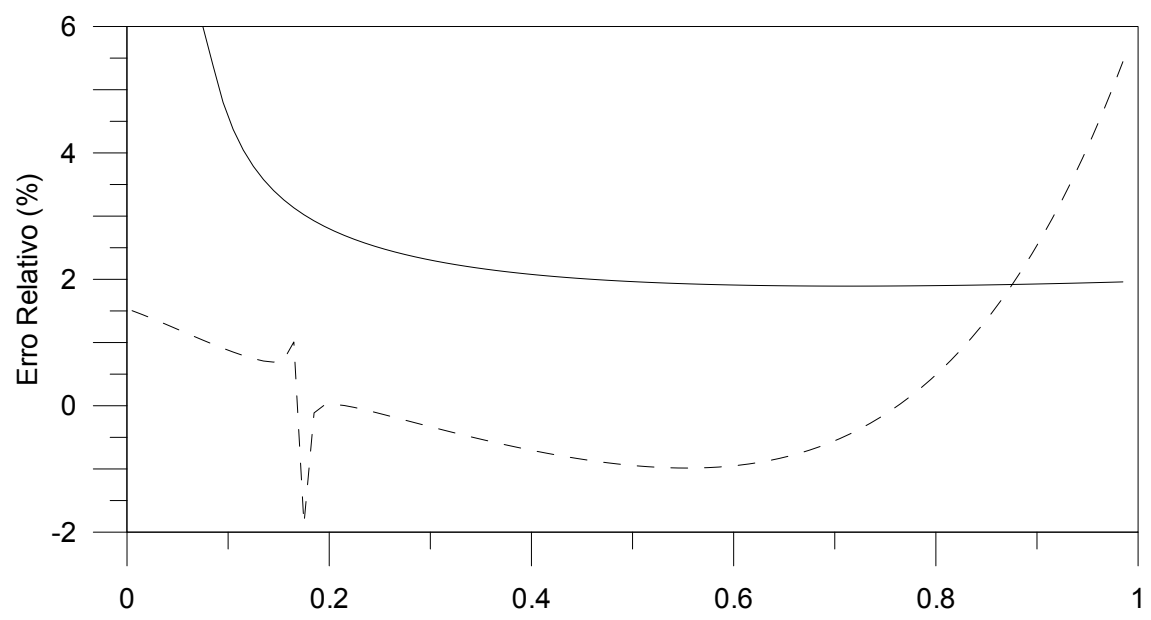

(b)

Figura 7.26: Erros (a) absolutos e, (b) relativos, das tensões $\sigma_{11}$ (— $)$ e $\sigma_{22}(-----)$ para a seção $B-B$ ' do problema fratura em meio infinito. 


\section{Capítulo 8}

\section{Conclusões}

Neste capítulo apresentam-se algumas considerações finais acerca do trabalho desenvolvido. E tendo em vista a continuidade de pesquisas na área encerra-se com sugestões para futuras pesquisas.

\subsection{Considerações Finais}

O Método dos Elementos de Contorno Dual utilizando a técnica de regularização das integrais impróprias através do método da subtração de singularidade e transformação de Telles (1987) para a integração numérica de integrais quase-singulares apresentou resultados satisfatórios em todos os exemplos analisados.

Os erros máximos observados coincidem com os pontos onde as grandezas avaliadas admitem valores absolutos mínimos e em pontos onde há concentração de tensões. Uma vez que a ordem de grandeza dos valores absolutos mínimos são, em geral, pequenos se comparados as valores absolutos máximos, deve-se dar atenção especial para os pontos de concentração de tensões.

Recomenda-se a transformação de Telles para avaliação de integrais quase-singulares pela melhora na precisão dos resultados e principalmente pela sua facilidade de implementação.

O emprego de elementos descontínuos como descrito por Brebbia e Dominguez (1992) é discutido e demonstra-se que a técnica de alterar as funções de forma dos elementos, nada mais é do que uma maneira de lidar com a contribuição do termo livre em cada nó do elemento.

Tomou-se o cuidado de garantir que o algoritmo desenvolvido seguindo os paradigmas da programação orientada a objetos e processamento em paralelo estivesse bem documentado permitindo sua utilização por outros pesquisadores. 


\subsection{Sugestões para Pesquisas Futuras}

Como sugestão para pesquisas futuras acredita-se ser relevante destacar alguns itens:

- Método dos Elementos de Contorno Dual Anisotrópico Tridimensional. Muitos problemas reais de engenharia são tridimensionais. A formulação tridimensional do MEC teria aplicações práticas.

- Quadraturas especiais para avaliação de integrais impróprias. Um grande desvantagem do MEC ainda é sua performance. Quadraturas especiais para integração de integrais singulares e quase-singulares poderiam, além de melhorar os resultados, otimizar a performance (Noronha, 1998).

- Processamento massivamente paralelo. A produção de threads como apresentado neste trabalho consome muito recurso somente para que o sistema possa gerenciá-los. Apesar desta técnica apresentar ganhos de performance expressivos, ela ainda não é a melhor alternativa. Atualmente estão sendo desenvolvidos placas gráficas com centenas de processadores que permitem a criação e processamento de milhares de threads simultâneas sem o contratempo de gastar recursos do sistema para gerenciá-las. Essa solução é a evolução natural dos atuais algoritmos multi-threads (Kirk e Hwu, 2010; Sanders e Kandrot, 2010).

- Projeto de código livre. A criação de um projeto de código livre colaborativo evitaria muito do retrabalho que a maioria dos pesquisadores que se iniciam na área tem, além de gerar um projeto que abrangeria cada vez mais problemas da engenharia (Wieleba e Sikora, 2009). 


\section{Apêndice A}

\section{Delta de Dirac}

Considere a função $g(x)$ da Figura (A.1) definida para todo $x$

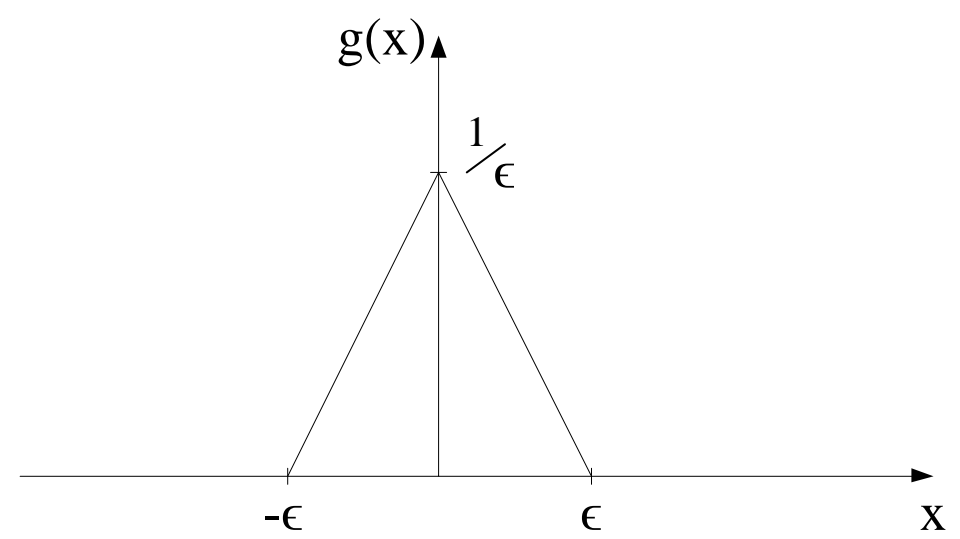

Figura A.1: Delta de Dirac.

A expressão desta função é

$$
g(x)=\left\{\begin{array}{lll}
0 & \text { se } \quad x \leq-\epsilon, \\
\frac{1}{\epsilon^{2}}(x+\epsilon) & \text { se } \quad-\epsilon \leq x \leq 0, \\
\frac{1}{\epsilon^{2}}(\epsilon-x) & \text { se } \quad 0 \leq x \leq \epsilon, \\
0 & \text { se } \quad x \geq \epsilon,
\end{array}\right.
$$

Essa função é integrável e o seu resultado é independente de $\epsilon$

$$
\int_{-\infty}^{+\infty} g(x) d x=\frac{2}{\epsilon^{2}} \int_{0}^{\epsilon}(\epsilon-x) d x=\left.\frac{2}{\epsilon^{2}}\left[x \epsilon-\frac{x^{2}}{2}\right]\right|_{0} ^{\epsilon}=1
$$


No limite em que $\epsilon \rightarrow 0$ a função $g(x)$ se torna o delta de Dirac

$$
\lim _{\epsilon \rightarrow 0} g(x)=\delta\left(x-x_{0}\right)
$$

Com as propriedades:

1. $\delta\left(x-x_{0}\right)=0 \quad$ se $\quad x \neq x_{0}$

2. $\delta\left(x-x_{0}\right)=+\infty \quad$ se $\quad x=x_{0}$

3. $\int_{-\infty}^{+\infty} \delta\left(x-x_{0}\right) d x=1$;

4. $\int_{-\infty}^{+\infty} f(x) \delta\left(x-x_{0}\right) d x=f\left(x_{0}\right)$.

A propriedade (1) e (2) são imediatas ao se considerar o limite da definição do delta de Dirac da equação (A.1). Estas duas propriedades são importantes na mecânica das estruturas pois são a definição de uma carga concentrada de valor unitário (Strichartz, 1994).

A propriedade (3) pode ser deduzida de forma análoga ao feito na equação (A.2). E a propriedade (4) pode ser demonstrada.

Desde que o delta de Dirac é zero para todo $x \neq x_{0}$, o intervalo de integração pode ser avaliado em um intervalo infinitesimal, $\epsilon$, em volta de $x_{0}$

$$
\int_{-\infty}^{+\infty} f(x) \delta\left(x-x_{0}\right) d x=\int_{x_{0}-\epsilon}^{x_{0}+\epsilon} f(x) \delta\left(x-x_{0}\right) d x
$$

Podemos considerar a função $f(x)$ constante no intervalo de integração e, portanto, ser retirada da integral.

$$
\int_{x_{0}-\epsilon}^{x_{0}+\epsilon} f(x) \delta\left(x-x_{0}\right) d x=f\left(x_{0}\right) \int_{x_{0}-\epsilon}^{x_{0}+\epsilon} \delta\left(x-x_{0}\right) d x
$$

Da propriedade (3) temos que a integral do lado direito é igual a 1, demonstrando a propriedade (4). Esta propriedade, conhecida como propriedade de seleção, é muito importante pois permite lidar com a integral de domínio que surge no desenvolvimento da formulação das equações integrais de contorno. 


\section{Apêndice B}

\section{Subtração de Singularidade para}

\section{Elemento Linear}

Considere o elemento linear da Figura (B.1) com nós 1 e 2 de coordenadas $\left(x_{1}^{1}, x_{2}^{1}\right)$ e $\left(x_{1}^{2}, x_{2}^{2}\right)$, respectivamente. Para este elemento pode-se escrever as funções de forma $\phi^{1}(\xi)$ e $\phi^{2}(\xi)$, como mostrado.
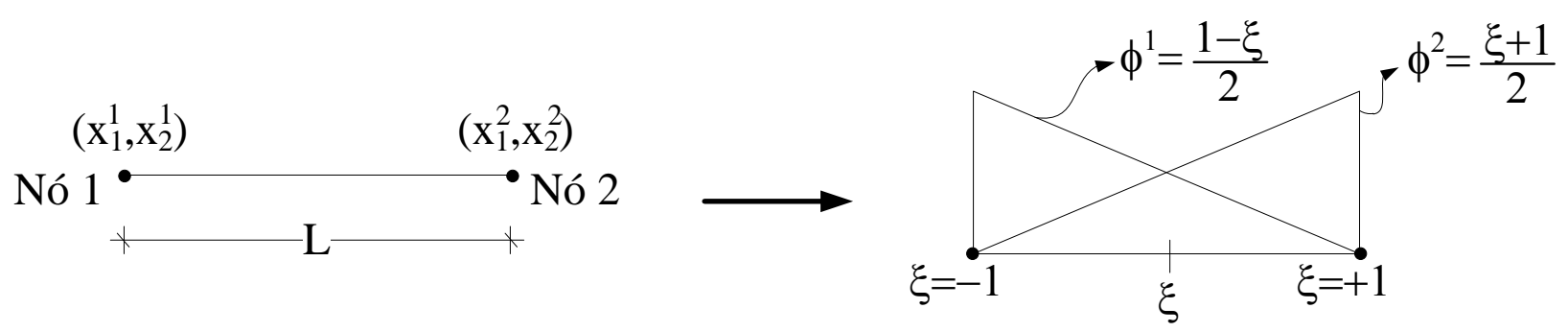

Figura B.1: Parametrização elemento linear.

É facilmente demonstrado que o Jacobiano da parametrização e as componentes do versor normal ao elemento são dados por

$$
\begin{gathered}
J=L / 2 \\
n_{1}=\frac{x_{2}^{1}-x_{2}^{2}}{L} \\
n_{2}=\frac{x_{1}^{2}-x_{1}^{1}}{L}
\end{gathered}
$$

Desta forma, pode-se proceder com a aplicação do método da subtração de singularidade para o caso particular de elementos lineares. Analisando-se as integrais para cada um dos nós, em separado, o processo torna-se extremamente simples.

Considere a equação geral para regularização da integral com singularidade do tipo $\ln |r|$ abaixo 


$$
\begin{aligned}
f_{-1}^{1} \phi^{l}(\xi) t_{i}^{l} U_{k i}^{*}\left(\xi^{\prime}, \xi\right) J(\xi) d \xi= & t_{i}^{l} \int_{-1}^{1} U_{k i}^{*}\left(\xi^{\prime}, \xi\right)\left[\phi^{l}(\xi) J(\xi)-\phi^{l}\left(\xi^{\prime}\right) J\left(\xi^{\prime}\right)\right] d \xi \\
& +\phi^{l}\left(\xi^{\prime}\right) t_{i}^{l} J\left(\xi^{\prime}\right) f_{-1}^{1} U_{k i}^{*}\left(\xi^{\prime}, \xi\right) d \xi
\end{aligned}
$$

Substituindo-se as equações da função de forma, o jacobiano, vetor normal e da equação da solução fundamental na equação acima pode-se proceder com sua integração.

Considerando-se inicialmente o nó 1, para a primeira integral do lado direito, tem-se

$$
\begin{aligned}
& t_{i}^{1} \int_{-1}^{1} U_{k i}^{*}\left(\xi^{\prime}, \xi\right)\left[\phi^{1}(\xi) J(\xi)-\phi^{1}\left(\xi^{\prime}\right) J\left(\xi^{\prime}\right)\right] d \xi= \\
& t_{i}^{1} \frac{L}{2}\left\{\int_{-1}^{1} 2 \operatorname{Re}\left[q_{i 1} A_{k 1} \ln \left(\frac{L}{2}\left|\xi-\xi^{\prime}\right|\left(\frac{x_{1}^{2}-x_{1}^{1}}{L}+\mu_{1} \frac{x_{2}^{2}-x_{2}^{1}}{L}\right)\right)\right]\left[\frac{1-\xi}{2}-\frac{1-\xi^{\prime}}{2}\right] d \xi\right. \\
& \left.\quad+\int_{-1}^{1} 2 \operatorname{Re}\left[q_{i 2} A_{k 2} \ln \left(\frac{L}{2}\left|\xi-\xi^{\prime}\right|\left(\frac{x_{1}^{2}-x_{1}^{1}}{L}+\mu_{2} \frac{x_{2}^{2}-x_{2}^{1}}{L}\right)\right)\right]\left[\frac{1-\xi}{2}-\frac{1-\xi^{\prime}}{2}\right] d \xi\right\}
\end{aligned}
$$

Integrando analiticamente, tem-se

$$
\begin{aligned}
& t_{i}^{1} \int_{-1}^{1} U_{k i}^{*}\left(\xi^{\prime}, \xi\right)\left[\phi^{l}(\xi) J(\xi)-\phi^{l}\left(\xi^{\prime}\right) J\left(\xi^{\prime}\right)\right] d \xi= \\
& -t_{i}^{1} \frac{L}{8}\left\{\left.\operatorname{Re}\left[q_{i 1} A_{k 1}\left(\xi-\xi^{\prime}\right)^{2}\left[2 \ln \left(\left|\xi-\xi^{\prime}\right|\left(\frac{x_{1}^{2}-x_{1}^{1}}{2}+\mu_{1} \frac{x_{2}^{2}-x_{2}^{1}}{2}\right)\right)-1\right]\right]\right|_{-1} ^{+1}\right. \\
& \left.\quad+\left.\operatorname{Re}\left[q_{i 2} A_{k 2}\left(\xi-\xi^{\prime}\right)^{2}\left[2 \ln \left(\left|\xi-\xi^{\prime}\right|\left(\frac{x_{1}^{2}-x_{1}^{1}}{2}+\mu_{2} \frac{x_{2}^{2}-x_{2}^{1}}{2}\right)\right)-1\right]\right]\right|_{-1} ^{+1}\right\}
\end{aligned}
$$

Após algumas simplificações algébricas, tem-se

$$
\begin{aligned}
& t_{i}^{1} \int_{-1}^{1} U_{k i}^{*}\left(\xi^{\prime}, \xi\right)\left[\phi^{1}(\xi) J(\xi)-\phi^{1}\left(\xi^{\prime}\right) J\left(\xi^{\prime}\right)\right] d \xi= \\
& -t_{i}^{1} \frac{L}{4}\left\{\operatorname { R e } \left[q _ { i 1 } A _ { k 1 } \left[\left(1+\xi^{\prime 2}\right) \ln \left(\frac{\left|1-\xi^{\prime}\right|}{\left|1+\xi^{\prime}\right|}\right)+2 \xi^{\prime}\right.\right.\right. \\
& \left.\left.\quad-4 \xi^{\prime} \ln \left(\left(1-\xi^{\prime 2}\right)\left(\frac{x_{1}^{2}-x_{1}^{1}}{2}+\mu_{1} \frac{x_{2}^{2}-x_{2}^{1}}{2}\right)^{2}\right)\right]\right] \\
& +\operatorname{Re}\left[q _ { i 2 } A _ { k 2 } \left[\left(1+\xi^{\prime 2}\right) \ln \left(\frac{\left|1-\xi^{\prime}\right|}{\left|1+\xi^{\prime}\right|}\right)+2 \xi^{\prime}\right.\right. \\
& \left.\left.\left.-4 \xi^{\prime} \ln \left(\left(1-\xi^{\prime 2}\right)\left(\frac{x_{1}^{2}-x_{1}^{1}}{2}+\mu_{2} \frac{x_{2}^{2}-x_{2}^{1}}{2}\right)^{2}\right)\right]\right]\right\}
\end{aligned}
$$

Para a segunda integral do lado direito, pode-se aplicar a equação (5.18) resultando em

$$
\phi^{1}\left(\xi^{\prime}\right) t_{i}^{1} J\left(\xi^{\prime}\right) f_{-1}^{1} U_{k i}^{*}\left(\xi^{\prime}, \xi\right) d \xi=t_{i}^{l} \frac{\left(1-\xi^{\prime}\right) L}{2} \operatorname{Re}\left[q_{i 1} A_{k 1}\left(V P C_{1}\right)+q_{i 2} A_{k 2}\left(V P C_{2}\right)\right]
$$


Em que

$$
\begin{aligned}
V P C_{1}= & \left(1+\xi^{\prime}\right) \ln \left(\left|1+\xi^{\prime}\right|\left(\frac{x_{1}^{2}-x_{1}^{1}}{2}+\mu_{1} \frac{x_{2}^{2}-x_{2}^{1}}{2}\right)\right) \\
& +\left(1-\xi^{\prime}\right) \ln \left(\left|1-\xi^{\prime}\right|\left(\frac{x_{1}^{2}-x_{1}^{1}}{2}+\mu_{1} \frac{x_{2}^{2}-x_{2}^{1}}{2}\right)\right)-\left[\left(1+\xi^{\prime}\right)+\left(1-\xi^{\prime}\right)\right] \\
V P C_{2}= & \left(1+\xi^{\prime}\right) \ln \left(\left|1+\xi^{\prime}\right|\left(\frac{x_{1}^{2}-x_{1}^{1}}{2}+\mu_{2} \frac{x_{2}^{2}-x_{2}^{1}}{2}\right)\right) \\
& +\left(1-\xi^{\prime}\right) \ln \left(\left|1-\xi^{\prime}\right|\left(\frac{x_{1}^{2}-x_{1}^{1}}{2}+\mu_{2} \frac{x_{2}^{2}-x_{2}^{1}}{2}\right)\right)-\left[\left(1+\xi^{\prime}\right)+\left(1-\xi^{\prime}\right)\right]
\end{aligned}
$$

Agora, considere a equação geral para regularização da integral com singularidade do tipo $|r|^{-1}$ abaixo

$$
\begin{aligned}
f_{-1}^{1} \phi^{l}(\xi) & u_{i}^{l} T_{k i}^{*}\left(\xi^{\prime}, \xi\right) J(\xi) d \xi \\
= & u_{i}^{l} \int_{-1}^{1} T_{k i}^{*}\left(\xi^{\prime}, \xi\right)\left[\phi^{l}(\xi) J(\xi)-\phi^{l}\left(\xi^{\prime}\right) J\left(\xi^{\prime}\right)\right] d \xi \\
& +\phi^{l}\left(\xi^{\prime}\right) u_{i}^{l} J\left(\xi^{\prime}\right) \int_{-1}^{1} T_{k i}^{*}\left(\xi^{\prime}, \xi\right) d \xi
\end{aligned}
$$

Novamente, considerando-se as expressões do Jacobiano, funções de forma e vetor normal para o nó 1 e substituindo-as na primeira integral do lado direito da equação (B.7), tem-se

$$
\begin{aligned}
& u_{i}^{1} \int_{-1}^{1} T_{k i}^{*}\left(\xi^{\prime}, \xi\right)\left[\phi^{1}(\xi) J(\xi)-\phi^{1}\left(\xi^{\prime}\right) J\left(\xi^{\prime}\right)\right] d \xi \\
& \quad=-u_{i}^{1} \operatorname{Re}\left[g_{i 1} A_{k 1}+g_{i 2} A_{k 2}\right]\left(\frac{\xi^{\prime}+1}{\left|\xi^{\prime}+1\right|}+\frac{\xi^{\prime}-1}{\left|1-\xi^{\prime}\right|}\right)
\end{aligned}
$$

Enquanto para a segunda integral do lado direito da equação (B.7) tem-se

$$
\phi^{1}\left(\xi^{\prime}\right) u_{i}^{1} J\left(\xi^{\prime}\right) f_{-1}^{1} T_{k i}^{*}\left(\xi^{\prime}, \xi\right) d \xi=u_{i}^{1} \operatorname{Re}\left[V P C\left(g_{i 1} A_{k 1}+g_{i 2} A_{k 2}\right)\right]\left(\xi^{\prime}-1\right)
$$

Em que

$$
V P C=\ln \left(1-\xi^{\prime}\right)-\ln \left(1+\xi^{\prime}\right)
$$

Para se obter as equações referentes ao nó 2 , basta proceder de forma análoga ao demonstrado anteriormente. Porém substituindo $\phi^{1}\left(\xi^{\prime}\right)$ por $\phi^{2}\left(\xi^{\prime}\right)$.

Observa-se que mesmo para um elemento simples, como o elemento linear, já torna-se complexo avaliar todas as integrais analiticamente.

Ao contrário da formulação isotrópica, a formulação anisotrópica envolve expressões mais complexas que tornam a integração analítica de todas as integrais impraticável. 
Acredita-se que através da ilustração apresentada neste apêndice tenha-se esclarecido a vantagem da estratégia de solução apresentada no Capitulo 5. Avaliando-se os termos singulares analiticamente através do valor principal de Cauchy e parte finita de Hadamard, e as integrais regulares, que seriam impraticáveis de se integrar analiticamente, através de uma quadratura numérica. Essa estratégia, além da simplicidade, permite a generalização da ordem de aproximação dos elementos utilizados. 


\section{Apêndice C}

\section{Tensões Sobre o Contorno}

Os métodos para a obtenção das tensões no contorno podem ser divididos em dois grupos:

1. Solução das integrais de tensão sobre o contorno;

2. Utilização da solução do problema em deslocamentos e forças de superfície e aplicação dos conceitos da teoria da elasticidade.

O primeiro método só pode ser aplicado sobre superfícies suaves. Assim, os nós de extremidade devem ser deslocados para o interior dos elementos através da alteração das funções de forma. Além dessa particularidade, o método tem o inconveniente de ser computacionalmente caro.

O segundo método tem aplicação direta e geral. Sendo por isso adotado neste trabalho. Diversos trabalhos como Zhao (1995), Chen (2000) e Miranda-Valenzuela et al. (2003) tratam do assunto para o caso particular de material isotrópico. Aqui será apresentado o segundo método para o caso geral de anisotropia.

Considere o elemento da Figura (C.1) para o qual são conhecidos todos os valores de deslocamentos e forças de superfície referentes ao sistema de coordenadas global $x_{1}$ e $x_{2}$.

As deformações $\varepsilon_{11}$ e $\varepsilon_{22}$ para qualquer ponto sobre o contorno podem ser calculadas em função da coordenada paramétrica do elemento por

$$
\begin{aligned}
& \varepsilon_{11}(\xi)=\frac{x_{1, \xi}(\xi)}{J(\xi)}=\frac{\phi_{l, \xi}(\xi) x_{1}^{l}}{J(\xi)} \\
& \varepsilon_{22}(\xi)=\frac{x_{2, \xi}(\xi)}{J(\xi)}=\frac{\phi_{l, \xi}(\xi) x_{2}^{l}}{J(\xi)}
\end{aligned}
$$

Este método se baseia na propriedade de invariância do tensor de tensões. Portanto, podemos transformar estas deformações e forças de superfície para o sistema de coordenadas local $x_{1}^{\prime}$ e $x_{2}^{\prime}$ do elemento (Figura C.2) pelas seguintes rotações 


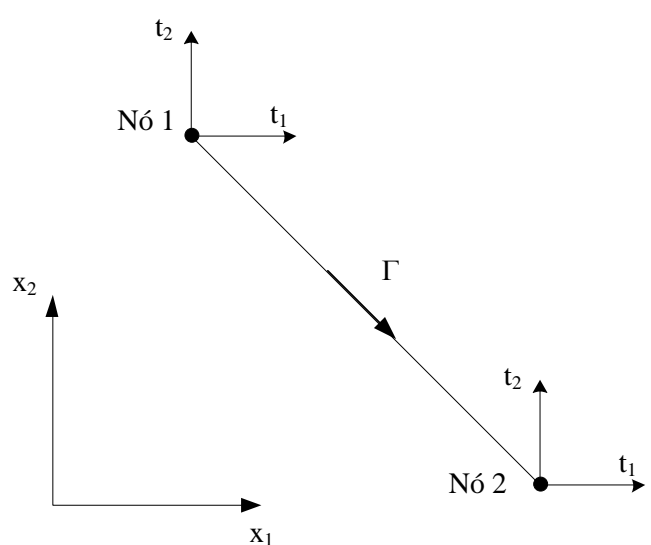

Figura C.1: Elemento com grandezas referentes ao sistema de coordenadas global.

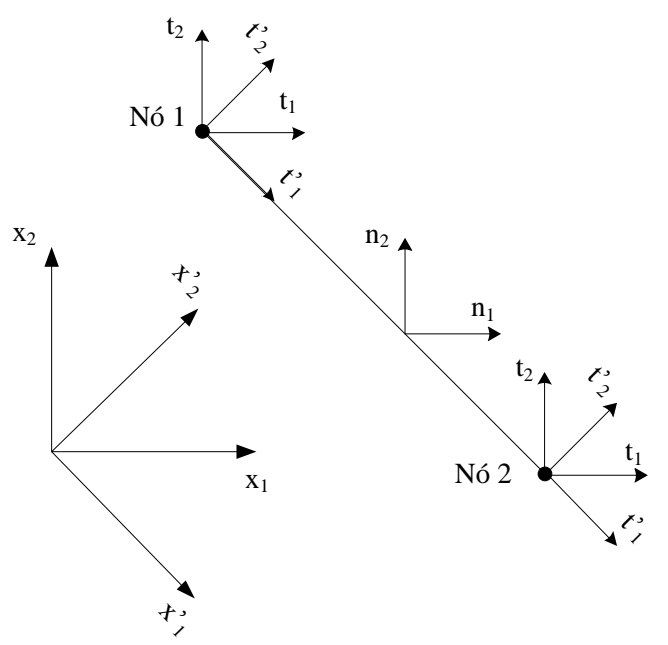

Figura C.2: Elemento com grandezas referentes ao sistema de coordenadas local.

$$
\begin{aligned}
& \left\{\begin{array}{l}
u_{11}^{\prime}(\xi) \\
u_{22}^{\prime}(\xi)
\end{array}\right\}=\left[\begin{array}{cc}
n_{1}(\xi) & n_{2}(\xi) \\
-n_{2}(\xi) & n_{1}(\xi)
\end{array}\right]\left\{\begin{array}{l}
u_{11}(\xi) \\
u_{22}(\xi)
\end{array}\right\} \\
& \left\{\begin{array}{l}
t_{1}^{\prime}(\xi) \\
t_{2}^{\prime}(\xi)
\end{array}\right\}=\left[\begin{array}{cc}
n_{1}(\xi) & n_{2}(\xi) \\
-n_{2}(\xi) & n_{1}(\xi)
\end{array}\right]\left\{\begin{array}{l}
t_{1}(\xi) \\
t_{2}(\xi)
\end{array}\right\} \\
{\left[\begin{array}{ccc}
c_{11}^{\prime} & c_{12}^{\prime} & c_{16}^{\prime} \\
c_{12}^{\prime} & c_{22}^{\prime} & c_{26}^{\prime} \\
c_{16}^{\prime} & c_{26}^{\prime} & c_{66}^{\prime}
\end{array}\right]=} & {\left[\begin{array}{ccc}
n_{1}(\xi) & n_{2}(\xi) & 0 \\
-n_{2}(\xi) & n_{1}(\xi) & 0 \\
0 & 0 & 1
\end{array}\right]\left[\begin{array}{lll}
c_{11} & c_{12} & c_{16} \\
c_{12} & c_{22} & c_{26} \\
c_{16} & c_{26} & c_{66}
\end{array}\right]\left[\begin{array}{ccc}
n_{1}(\xi) & n_{2}(\xi) & 0 \\
-n_{2}(\xi) & n_{1}(\xi) & 0 \\
0 & 0 & 1
\end{array}\right]^{T} }
\end{aligned}
$$

Observe que para o caso anisotrópico devemos rotacionar a matriz de coeficientes elásticos também. Se recordarmos a equação (3.32) de força de superfície iremos perceber que $t_{1}^{\prime}=\sigma_{11}^{\prime} \mathrm{e}$ $t_{2}^{\prime}=\sigma_{12}^{\prime}$. Aplicando-se a equação de deformações (3.10b) aos deslocamentos $u_{22}^{\prime}(\xi)$ é possível obter 
as deformações $\varepsilon_{22}^{\prime}(\xi)$ e aplicando a lei de Hooke seremos capazes de obter $\sigma_{22}^{\prime}$

$$
\varepsilon_{22}^{\prime}=\sigma_{11}^{\prime} c_{12}^{\prime}+\sigma_{22}^{\prime} c_{22}^{\prime}+\sigma_{12}^{\prime} c_{26}^{\prime}
$$

Onde podemos evidenciar $\sigma_{22}^{\prime}$ da forma

$$
\sigma_{22}^{\prime}=\frac{1}{c_{22}^{\prime}}\left(\varepsilon_{22}^{\prime}-\sigma_{11}^{\prime} c_{12}^{\prime}-\sigma_{12}^{\prime} c_{26}^{\prime}\right)
$$

E finalmente podemos obter o tensor de tensões rotacionando o sistema de coordenadas local de volta para o sistema de coordenadas global

$$
\left[\begin{array}{ll}
\sigma_{11} & \sigma_{12} \\
\sigma_{12} & \sigma_{22}
\end{array}\right]=\left[\begin{array}{cc}
n_{1}(\xi) & n_{2}(\xi) \\
-n_{2}(\xi) & n_{1}(\xi)
\end{array}\right]^{T}\left[\begin{array}{cc}
\sigma_{11}^{\prime} & \sigma_{12}^{\prime} \\
\sigma_{12}^{\prime} & \sigma_{22}^{\prime}
\end{array}\right]\left[\begin{array}{cc}
n_{1}(\xi) & n_{2}(\xi) \\
-n_{2}(\xi) & n_{1}(\xi)
\end{array}\right]
$$

Resultando no tensor de tensões sobre o contorno do elemento.

É importante observar que este método é válido para elementos de qualquer ordem com qualquer tipo de anisotropia e pode facilmente ser ampliado para problemas tridimensionais. 


\section{Apêndice D}

\section{Erro Absoluto e Relativo}

- Erro Absoluto. O erro entre a solução exata u e o valor aproximado ú é dado por

$$
\text { Erro }_{a b s}=|\tilde{u}-u|
$$

- Erro Relativo. Seja $\tilde{u}$ uma aproximação de $x \neq 0$, então o erro

$$
\text { Errorel }_{r}=\frac{|\tilde{u}-u|}{|u|}
$$

é chamado de erro relativo de $x$. 
APÊNDICE D 


\section{Apêndice E}

\section{Dados do Tempo de Processamento}

Tabela E.1: Tempo de processamento para formulação em deslocamento (ms)

\begin{tabular}{|c|c|c|c|c|c|c|}
\hline \multirow{2}{*}{$\begin{array}{l}\mathrm{N}^{\circ} \text { Pontos } \\
\text { de Gauss }\end{array}$} & \multicolumn{3}{|c|}{ SingleThread } & \multicolumn{3}{|c|}{ MultiThread } \\
\hline & 12 Nós & 20 Nós & 28 Nós & 12 Nós & 20 Nós & 28 Nós \\
\hline 100 & 1321 & 2667 & 4680 & 909 & 1348 & 2036 \\
\hline 200 & 1888 & 3938 & 7909 & - & 1759 & 3067 \\
\hline 400 & 2721 & 6975 & 14750 & - & 2567 & 5180 \\
\hline 600 & 3707 & 10122 & 22444 & - & 4199 & 6949 \\
\hline 800 & 4679 & 13891 & 30023 & - & 4740 & 8390 \\
\hline 1000 & 5999 & 18176 & 38401 & 2172 & 5808 & 10045 \\
\hline 2000 & 12083 & 44153 & 87246 & 3902 & 10557 & 18750 \\
\hline 4000 & 32718 & 123938 & - & 8032 & 25155 & 42879 \\
\hline 6000 & 62980 & 245958 & - & 14086 & 46204 & 76132 \\
\hline 8000 & 102957 & - & - & 20747 & - & - \\
\hline 10000 & 152763 & - & - & 30525 & - & - \\
\hline
\end{tabular}

Tabela E.2: Tempo de processamento para formulação em força de superfície (ms)

\begin{tabular}{lrrrrrrr}
\hline \multirow{2}{*}{$\begin{array}{l}\text { No Pontos } \\
\text { de Gauss }\end{array}$} & \multicolumn{3}{c}{ SingleThread } & & \multicolumn{3}{c}{ MultiThread } \\
\cline { 2 - 5 } \cline { 6 - 8 } & 12 Nós & 20 Nós & 28 Nós & & 12 Nós & 20 Nós & 28 Nós \\
\hline 100 & 1268 & 2742 & 5090 & & 944 & 1326 & 2143 \\
200 & - & 4140 & 8339 & & - & 1826 & 3209 \\
400 & - & 7385 & 14952 & & - & 2950 & 5310 \\
600 & - & 10785 & 22471 & & - & 4002 & 7367 \\
800 & - & 14446 & 30244 & & - & 5093 & 8950 \\
1000 & 6444 & 18395 & 38528 & & 2286 & 6268 & 10897 \\
2000 & 13189 & 43329 & 87251 & & 4184 & 11263 & 19479 \\
4000 & 33098 & 122353 & - & 8529 & 25646 & 43931 \\
6000 & 63770 & - & - & 14367 & - & 77292 \\
8000 & 104319 & - & - & 22118 & - & - \\
10000 & 155173 & - & - & 32128 & - & - \\
\hline
\end{tabular}




\section{Referências Bibliográficas}

Anselone(2009) P. M. Anselone. Singularity subtraction in the numerical solution of integral equations. The Journal of the Australian Mathematical Society. Series B. Applied Mathematics, 22(04):408. ISSN 0334-2700. Citado na pág. 38

Brebbia e Dominguez(1992) C. A. Brebbia e J. Dominguez. Boundary Elements: An Introductory Course. Computational Mechanics, 2 edição. ISBN 1562520873. Citado na pág. 1, 37, 77

Chen(2000) Y.Z Chen. An accurate technique for evaluating stress at boundary points in boundary element method. Engineering Analysis with Boundary Elements, 24(4):357-360. ISSN 0955-7997. Citado na pág. 85

Cheng e Cheng(2005) Alexander H.-D. Cheng e Daisy T. Cheng. Heritage and early history of the boundary element method. Engineering Analysis with Boundary Elements, 29(3):268-302. ISSN 0955-7997. Citado na pág. 6

Cho et al.(1992) Sang Bong Cho, Kab Rae Lee e Yong Shick Choy. A further study of twodimensional boundary element crack analysis in anisotropic or orthotropic materials. Engineering Fracture Mechanics, 43(4):589-601. ISSN 0013-7944. Citado na pág. 6

Chou e Pagano(1992) Pei Chi Chou e Nicholas J. Pagano. Elasticity: Tensor, Dyadic, and Engineering Approaches. Dover Publications. ISBN 0486669580. Citado na pág. 5, 17

Cruse e Swedlow(1971) Thomas A. Cruse e J. L. Swedlow. Interactive program for analysis and design problems in advanced composites technology. Air Force Materials Laboratory, Air Force Systems Command. Citado na pág. 6

Davis et al.(2007) Philip J. Davis, Philip Rabinowitz e Mathematics. Methods of Numerical Integration: Second Edition. Dover Publications, 2 edição. ISBN 0486453391. Citado na pág. 39

Deitel e Deitel(2011) Paul Deitel e Harvey Deitel. Java How to Program (early objects) (9th Edition). Prentice Hall, 9 edição. ISBN 0132575663. Citado na pág. 7

Delves e Mohamed(1988) L. M. Delves e J. L. Mohamed. Computational Methods for Integral Equations. CUP Archive. ISBN 9780521357968. Citado na pág. 38

Denda e Marante(2004) M. Denda e M.E. Marante. Mixed mode BEM analysis of multiple curvilinear cracks in the general anisotropic solids by the crack tip singular element. International Journal of Solids and Structures, 41(5-6):1473-1489. ISSN 0020-7683. Citado na pág. 6

Eshelby et al.(1953) J.D. Eshelby, W.T. Read e W. Shockley. Anisotropic elasticity with applications to dislocation theory. Acta Metallurgica, 1(3):251-259. ISSN 0001-6160. Citado na pág. 5

Ferreira(2008) Reginaldo Lopes Ferreira. Pré-Processador para Modelos Reticulados e Planos do Método dos Elementos Finitos. Dissertação de mestrado, Universidade Federal de Minas Gerais, Belo Horizonte. Citado na pág. 51 
Finlayson e Scriven(1966) B. A. Finlayson e L. E. Scriven. The method of weighted residuals - a review. Applied Mechanics Reviews, 19(9):735-748. Citado na pág. 6, 27

Goetz et al.(2006) Brian Goetz, Tim Peierls, Joshua Bloch, Joseph Bowbeer, David Holmes e Doug Lea. Java Concurrency in Practice. Addison-Wesley Professional, 1 edição. ISBN 0321349601. Citado na pág. 7,55

Hsiao e Wendland(2010) George C. Hsiao e Wolfgang L. Wendland. Boundary Integral Equations. Springer, softcover reprint of hardcover 1st ed. 2008 edição. ISBN 3642057330. Citado na pág. 31

Hwu(2010) Chyanbin Hwu. Anisotropic Elastic Plates. Springer, 2010 edição. ISBN 1441959149. Citado na pág. 5

Kane(1993) James H. Kane. Boundary Element Analysis in Engineering Continuum Mechanics. Prentice Hall. ISBN 0130869279. Citado na pág. 24

Khayat e Wilton(2005) M. A Khayat e D. R Wilton. Numerical evaluation of singular and nearsingular potential integrals. IEEE Transactions on Antennas and Propagation, 53(10):3180-3190. ISSN 0018-926X. Citado na pág. 38

Kim-Chuan e Mukherjee(1994) Toh Kim-Chuan e Subrata Mukherjee. Hypersingular and finite part integrals in the boundary element method. International Journal of Solids and Structures, 31(17):2299-2312. ISSN 0020-7683. Citado na pág. 6

Kirk e Hwu(2010) David B. Kirk e Wen-mei W. Hwu. Programming Massively Parallel Processors: A Hands-on Approach. Morgan Kaufmann, 1 edição. ISBN 0123814723. Citado na pág. 78

Kolosov(1935) G. V. Kolosov. Application of Complex Diagrams and the Theory of Functions of a Complex Variable to the Theory of Elasticity. ONTI, Moscow. Citado na pág. 5

Kzam(2009) Aref Kalilo Lima Kzam. Formulação dual em mecânica da fratura utilizando elementos de contorno curvos de ordem qualquer. Dissertação de mestrado, USP, São Carlos. Citado na pág. 34,38

Lekhnitskii(1968) S. Lekhnitskii. Anisotropic Plates. Routledge, reprint edição. ISBN 0677206704. Citado na pág. 5, 22, 58, 59, 61,64

Lekhnitskii(1981) Sergei Georgievich Lekhnitskii. Theory of Elasticity of an Anisotropic Body. Mir Publishers. Citado na pág. 5, 24

Love(1944) A. E. H. Love. A Treatise on the Mathematical Theory of Elasticity. Dover Publications, 4 edição. ISBN 0486601749. Citado na pág. 5

Martin e Rizzo(1996) P. A Martin e F. J Rizzo. Hypersingular integrals:: how smooth must the density be? International Journal for Numerical Methods in Engineering, 39(4):687-704. ISSN 1097-0207. Citado na pág. 6

Miranda-Valenzuela et al.(2003) J.C. Miranda-Valenzuela, K.H. Muci-Küchler e S. SorianoSoriano. Efficient computation of boundary stresses and error indicators in two-dimensional thermoelasticity. Engineering Analysis with Boundary Elements, 27(2):159-173. ISSN 0955-7997. Citado na pág. 85

Mukherjee(2000) Subrata Mukherjee. CPV and HFP integrals and their applications in the boundary element method. International Journal of Solids and Structures, 37(45):6623-6634. ISSN 0020-7683. Citado na pág. 6 
Muskhelishvili(1977) N.I. Muskhelishvili. Some Basic Problems of the Mathematical Theory of Elasticity. Springer, 1 edição. ISBN 9001607012. Citado na pág. 5

Noronha(1998) Marcos Aurelio Marques Noronha. Técnicas avançadas de integração numérica e programação orientada a objetos aplicadas a métodos de elementos de contorno. Tese de doutorado, Pontifícia Universidade Católica, Rio de Janeiro. Citado na pág. 78

Nourine et al.(2010) L Nourine, A Sahli, M Riyad Abdelkader e O Rahmani. Boundary element method analysis of cracked anisotropic bodies. The Journal of Strain Analysis for Engineering Design, 45(1):45-56. ISSN 0309-3247, 2041-3130. Citado na pág. 6

Partridge et al.(1992) P. W. Partridge, C. A. Brebbia e L. C. Wrobel. The Dual Reciprocity Boundary Element Method (International Series on Computational Engineering). Computational Mechanics. ISBN 0945824823. Citado na pág. 6

Prenter(1975) P.M. Prenter. Splines and Variational Methods. John Wiley \& Sons Inc, first edition edição. ISBN 0471696609. Citado na pág. 35

Press et al.(2007) William H. Press, Saul A. Teukolsky, William T. Vetterling e Brian P. Flannery. Numerical Recipes 3rd Edition: The Art of Scientific Computing. Cambridge University Press, 3 edição. ISBN 0521880688. Citado na pág. 55

Rand e Rovenski(2004) Omri Rand e Vladimir Rovenski. Analytical Methods in Anisotropic Elasticity: with Symbolic Computational Tools. Birkhäuser Boston, 1 edição. Citado na pág. 5

Rizzo e Shippy(1970) F. J Rizzo e D. J Shippy. A method for stress determination in plane anisotropic elastic bodies. Journal of Composite Materials, 4(1):36-61. ISSN 0021-9983, 1530793X. Citado na pág. 6

Runge(1901) Carl Runge. Über empirische funktionen und die interpolation zwischen äquidistanten ordinaten. Zeitschrift für Mathematik und Physik, 46:224-243. Citado na pág. 36

Sadd(2009) Martin H. Sadd. Elasticity, Second Edition: Theory, Applications, and Numerics. Academic Press, 2 edição. ISBN 0123744466. Citado na pág. 5

Sanders e Kandrot(2010) Jason Sanders e Edward Kandrot. CUDA by Example: An Introduction to General-Purpose GPU Programming. Addison-Wesley Professional, 1 edição. ISBN 0131387685. Citado na pág. 78

Savin(1961) Gurii Nikolaevich Savin. Stress concentration around holes. Pergamon Press. Citado na pág. 7,67

Scarborough(1930) James Blaine Scarborough. Numerical mathematical analysis. Johns Hopkins Press. Citado na pág. 43

Schclar(1994) N. A. Schclar. Anisotropic Analysis Using Boundary Elements. Computational Mechanics. ISBN 1562522574. Citado na pág. 1, 6

Shilov(1977) Georgi E. Shilov. Linear Algebra. Dover Publications. ISBN 048663518X. Citado na pág. 55

Sládek e Sladek(1998) Vladimír Sládek e J. Sladek. Singular integrals in boundary element methods. Computational Mechanics Publications. ISBN 9781853125331. Citado na pág. 7, 38, 41

Smiley(2002) John Smiley. Learn To Program with Java. John Smiley Publishing. Citado na pág. 7

Snyder e Cruse(1975) M. D. Snyder e T. A. Cruse. Boundary-integral equation analysis of cracked anisotropic plates. International Journal of Fracture, 11(2):315-328. ISSN 0376-9429. Citado na pág. 6 
Sollero e Aliabadi(1993) P. Sollero e M. H. Aliabadi. Fracture mechanics analysis of anisotropic plates by the boundary element method. International Journal of Fracture, 64(4):269-284. ISSN 0376-9429, 1573-2673. Citado na pág. 6, 24

Sollero e Aliabadi(1995) P. Sollero e M.H. Aliabadi. Anisotropic analysis of cracks in composite laminates using the dual boundary element method. Composite Structures, 31(3):229-233. ISSN 0263-8223. Citado na pág. 6

Strichartz(1994) Robert Strichartz, editor. A Guide to Distribution Theory and Fourier Transforms. CRC-Press, 1 edição. ISBN 0849382734. Citado na pág. 80

Stroh(1958) A. N. Stroh. Dislocations and cracks in anisotropic elasticity. Philosophical Magazine, 3(30):625-646. ISSN 0031-8086. Citado na pág. 5

Stroh(1962) AN Stroh. Steady state problems in anisotropic elasticity. Journal of Mathematics and Physics, 41(2):77-103. Citado na pág. 5

Tan e Gao(1992) C.L. Tan e Y.L. Gao. Boundary element analysis of plane anisotropic bodies with stress concentrations and cracks. Composite Structures, 20(1):17-28. ISSN 0263-8223. Citado na pág. 6

Telles(1987) J. C. F Telles. A self-adaptive co-ordinate transformation for efficient numerical evaluation of general boundary element integrals. International Journal for Numerical Methods in Engineering, 24(5):959-973. ISSN 1097-0207. Citado na pág. 7, 44, 77

Telles e Oliveira(1994) J.C.F. Telles e R.F. Oliveira. Third degree polynomial transformation for boundary element integrals: Further improvements. Engineering Analysis with Boundary Elements, 13(2):135-141. ISSN 0955-7997. Citado na pág. 44, 64

Timoshenko(1970) S. Timoshenko. Theory of Elasticity. McGraw-Hill Publishing Company, 3rd edição. ISBN 0070858055. Citado na pág. 5, 9

Ting(1996) Thomas C. T. Ting. Anisotropic Elasticity: Theory and Applications. Oxford University Press, USA. ISBN 0195074475. Citado na pág. 5, 9

Vanalli(2004) Leandro Vanalli. O MEC e o MEF aplicados à análise de problemas viscoplásticos em meios anisotrópicos e compostos. Tese de doutorado, USP, São Carlos. Citado na pág. 25

Wieleba e Sikora(2009) Paweł Wieleba e Jan Sikora. Open source BEM library. Adv. Eng. Softw., 40(8):564-569. ISSN 0965-9978. Citado na pág. 78

Wrobel e Aliabadi(2002) L. C. Wrobel e M. H. Aliabadi. The Boundary Element Method, The Boundary Element Method. Wiley, 1 edição. ISBN 0470841397. Citado na pág. 33, 38

Zhao(1995) Zhiye Zhao. On the calculation of boundary stresses in boundary elements. Engineering Analysis with Boundary Elements, 16(4):317-322. ISSN 0955-7997. Citado na pág. 85 